Article

\title{
Dynamic Performance Enhancement of a Renewable Energy System for Grid Connection and Stand-Alone Operation with Battery Storage
}

\author{
Mahmoud A. Mossa ${ }^{1,2, *(D)}$, Olfa Gam ${ }^{3}$ and Nicola Bianchi ${ }^{2}$ \\ 1 Electrical Engineering Department, Faculty of Engineering, Minia University, Minia 61111, Egypt \\ 2 Department of Industrial Engineering, University of Padova, Via Gradenigo 6/a, 35131 Padova, Italy; \\ nicola.bianchi@unipd.it \\ 3 Département École de Genie, Université Québéc en Abitibi Témiscamingue, \\ Rouyn-Noranda, QC J9X 5E4, Canada; gamo01@uqat.ca \\ * Correspondence: mahmoud_a_mossa@mu.edu.eg
}

Citation: Mossa, M.A.; Gam, O.; Bianchi, N. Dynamic Performance Enhancement of a Renewable Energy System for Grid Connection and Stand-Alone Operation with Battery Storage. Energies 2022, 15, 1002. https://doi.org/10.3390/en15031002 Academic Editor: Surender Reddy Salkuti

Received: 14 January 2022

Accepted: 25 January 2022

Published: 29 January 2022

Publisher's Note: MDPI stays neutral with regard to jurisdictional claims in published maps and institutional affiliations.

Copyright: (C) 2022 by the authors. Licensee MDPI, Basel, Switzerland. This article is an open access article distributed under the terms and conditions of the Creative Commons Attribution (CC BY) license (https:// creativecommons.org/licenses/by/ $4.0 /)$.

\begin{abstract}
This paper introduces a new formulated control scheme for enhancing the dynamic performance of a wind driven surface permanent magnet synchronous generator. The designed control scheme is based on predictive control theory, in which the shortcomings of previous predictive controllers are avoided. To visualize the effectiveness of the proposed control scheme, the performance of the generator was dynamically evaluated under two different operating regimes: grid connection and standalone operation in which a battery storage system was used to enhance the power delivery to the isolated loads. In addition, a detailed performance comparison between the proposed controller and traditional predictive controllers was carried out. The traditional control topologies used for comparison were the model predictive direct power control, model predictive direct torque control, and model predictive current control. A detailed description of each control scheme is introduced illustrating how it is configured to manage the generator operation. Furthermore, to achieve the optimal exploitation of the wind energy and limit the power in case of exceeding the nominal wind speed, maximum power point tracking and blade pitch angle controls were adopted. A detailed performance comparison effectively outlined the features of each controller, confirming the superiority of the proposed control scheme over other predictive controllers. This fact is illustrated through its simple structure, low ripples, low computation burdens and low current harmonics obtained with the proposed control scheme.
\end{abstract}

Keywords: PMSG; predictive control; wind power; MPPT; battery storage; ripples; computation burden; standalone operation

\section{Introduction}

Currently, searching for alternative renewable energy sources to compensate for the depletion of usual energy sources has become a vital requirement [1-3]. Among the different forms of renewable energy systems, wind generation systems are considered among the most significant units $[4,5]$. This fact motivated us to investigate more about the most effective way to exploit and extract naturally stored energy using various control theories [6]. Concerning wind energy, the most significant part of the system to be managed is the generation unit, which is responsible for handling the electric power either to the utility grid or to isolated loads. The generation unit is an electric machine driven by a shaft coupling mechanical system rotated by the wind power $[7,8]$. The coupling mechanical system should be managed using a specific control scheme to prevent damage to the generator/turbine shafts. Important are blade pitch angle $(\beta)$ control and the maximum power point tracking (MPPT) algorithm [9,10]. Furthermore, the suitable selection of wind turbine systems to fulfill the increasing load demands in rural area has become a vital 
requirement. The researchers in [11] proposed a detailed design for a horizontal axis wind turbine system according to the available wind speed statistics to ensure optimal wind power exploitation. In [12], a compromise between the capacity factor and annual power production was adopted to optimally exploit wind energy. Other researchers have been concerned with searching for suitable approaches to design a compact wind turbine nacelle to reduce maintenance costs [13].

Different machine types are used in wind generation systems, starting with a selfexcited induction generator suitable for parallel operation, but the need for an external reactive power source for excitation is the greatest challenge [14,15]. Another promising machine is the doubly fed induction generator (DFIG), which has the ability to operate at fixed and variable speeds with reduced scale power converters that reduce costs [16,17]. The DFIG also has the ability to provide reactive power to the utility grid. The DFIG has the advantage of fault-tolerant operation. However, the fault tolerant operation cannot be realized easily without affecting system complexity, in addition to regular maintenance of the slip rings and windings. Synchronous generators have started to play an important role due to their high efficiency, ease of maintenance and rugged structure $[18,19]$. For these reasons, the current study is concerned with analyzing SPMSG performance for different operating regimes and using several control approaches.

Whatever the used generator type, the implemented control algorithm for the generation unit is the most important point to be considered in achieving different requirements, such as low ripples, fast dynamics and proper steady-state operation [20]. Searching for a unique control algorithm that can achieve all or at most of these requirements is the main target of control designers. Investigations started with vector control theory and field orientation control (FOC) [21,22]. FOC achieved promising steady-state dynamics in addition to low current total harmonic distortion (THD), but suffered from high complexity and the requirement for a modulation mechanism (i.e., PWM or SVPWM), in addition to a significant response delay [23]. The direct torque control (DTC) appeared as an alternative to the FOC, with the merits of simple structure, faster response and no requirement for using a modulation stage [24,25]. The DTC achieved its targets effectively, but noticeable ripples and variable switching frequency were its most significant shortcomings. A direct power control (DPC) is a transposition, or mirror, of the DTC technique, in which two hysteresis active and reactive power controllers are used in addition to a look-up table [26-28]. The main difference is the used control loops; for example, in the DPC, there is no need for estimating the torque or flux using machine model parameters, as power can be directly measured using stator voltages and currents, which is an advantage of the DPC over the DTC in terms of robustness.

Recently, advanced control techniques for the SPMSG have replaced former techniques, such as sliding mode control [29], backstepping control [30], fuzzy control [31] and model predictive control (MPC) [32,33]. Among these algorithms, MPC has caught the attention of control designers. MPC comes with different configurations, such as hysteresis-based, trajectory-based, continuous control set, and finite control set (FCS) MPC [34,35]. Among these categories, the FCS MPC shows the most promising behavior, as it utilizes the switching states and not PWM. In addition, it identifies voltage vectors from a definite set of eight vectors $[35,36]$.

For these reasons, the FCS principle is used with different predictive controllers for the SPMSG. For example, the model predictive direct power control (MP DPC) used in [37], utilized the same principle of a classic look-up table-based DPC, except for replacing the hysteresis controllers and look up tables with a single cost function combining the normalized absolute errors of active and reactive powers. The FCS predictive control principle was adopted when considering the torque and flux control as stated in [38], in which the cost function combined the normalized absolute errors of torque and flux, which finally constituted the MP DTC algorithm. The performance of SPMSG was improved after considering the MP DPC and MP DTC in comparison with the classic DPC and DTC, respectively. This has been noticed through the ripple reduction. However, the computation 
burdens of both predictive controllers (MP DPC and MP DTC) are noticeable. In addition, both controllers require the use of a weighting value $\left(w_{f}\right)$ in the cost function, which has to be precisely selected to balance the importance/weight of each control variable with respect to the others. Attempts have been made to develop online tuning to obtain optimal $w_{f}[39,40]$, which have helped significantly in enhancing the steady state performance; however, the computation burden is negatively affected.

To avoid the risk of wrong $w_{f}$ selection, an orientation towards a weighting-free MPC has aroused great interest. This has been achieved through selecting terms of cost function of the same type; for example, the FCS principle has been used to formulate the model predictive current control (MP CC) technique as stated in [41]. The MP CC has showed its superiority over the FOC in terms of faster dynamic response and reduced complexity rate, in addition to not using a weighting value in comparison with the MP DTC and MP DPC. However, the computation burden is still challenging.

Furthermore, the three predictive controllers: MP DPC, MP DTC and MP CC are based on using one voltage vector per sampling interval [42], and this is not a precise action as absolute error deviation within the sampling interval may occur, resulting in increased ripples. Some attempts have been made use more than one voltage vector in the same interval $[43,44]$. In [45,46], one active and zero voltage vectors were utilized within the one interval: An improved performance was achieved especially at low operating frequencies, but the variable switching frequency and torque ripples were still present. Multi-vector MPC techniques are considered in $[47,48]$, in which several vectors are applied within one switching interval, resulting in reduced current/torque ripples. However, the main drawback of multi-vector MPCs is that the duration time of one or two of the selected vectors result in negative values, causing the removal of such vectors. In [49,50], an MPC scheme which considered four vectors per one interval was presented to achieve lower ripples and fix switching frequency, in addition to solving the issue of negative duration times. However, the computation burdens remain the most challenging task in these schemes. The deadbeat principle has also been incorporated with the MPC as proposed by $[51,52]$ in an attempt to limit the ripples at different operating frequencies; however, the controller was highly sensitive to parameter mismatch, as the deadbeat principle usually utilized the machine model. To avoid the issue of parameter sensitivity, [53] considered a model-free predictive control principle which utilized sampled current differences. However, this technique mainly depended on the precision of signal measurement, which is not guaranteed.

In order to avoid the dependency of the cost function on the machine model, and keeping the computation burdens within the acceptable rates, the current paper proposes a form of cost function, which consists of two similar terms enabling the elimination of the weighting factor and, at the same time, the controlled cost function terms are not estimated variables such as those used in MP DPC, MP DTC and MP CC controllers. This enhances robustness and limits computation time. The formulated cost function is used by what is titled predictive voltage control, as the terms of the function are the normalized absolute errors of the $d-q$ components of the stator voltage of the SPMSG. The error terms of the cost function are obtained using the reference and actual voltages. The actual voltages are obtained with the help of the FCS principle using switching states without incorporating the PWM tool, meanwhile the reference voltages are obtained through by designing torque and flux regulators. Thus, the derivation of reference voltages is not dependent on the model parameters as in the deadbeat strategy, which enhances control robustness.

To investigate generator dynamics using the designed PVC and validate its effectiveness compared to other predictive algorithms, the performance is tested using the designed PVC and three other predictive controllers: MP DPC, MP DTC and MP CC. The wind driven generation system is tested for two operating conditions: grid connected and stand-alone operations. As the purpose of this study is to investigate the dynamics of the SPMSG generator, in the grid connection case the four designed controllers are mainly used to control the machine side converter while the grid side converter is controlled solely 
using the MP CC scheme. Alternatively, for the stand-alone operation, the generation system feeds a DC average load, and is connected in parallel to a battery storage system. A model of the battery and its storage system management are described in detail. Two different wind speed profiles are used with the two operating conditions to investigate the effectiveness of MPPT and pitch angle control strategies.

Contributions of the paper can be summarized as follows,

- The paper proposes a new predictive voltage control scheme (PVC) to enhance the performance of a wind-driven surface permanent magnet synchronous generator under grid connection and stand-alone operating conditions.

- The paper introduces a systematic design for the overall wind generation system starting with the wind turbine and its power management system, then the generation unit, followed by the power converters and its control, and finally with the grid model, the battery storage system and isolated load.

- To confirm the validity of the proposed predictive controller, a wind driven generator performance is also evaluated using different classical control algorithms and a detailed comparison is carried out.

- $\quad$ The proposed control algorithm proved its validity in enhancing generator dynamics by achieving low computational burdens, low ripples, a simple structure and low current harmonics compared to classic techniques.

- The proposed control algorithm can be used to manage the operation of other types of wind-based generators considering the theory of operation and structure of each type.

The paper is organized as follows. In Section 2, the modeling of SPMSG and its wind turbine power management system is introduced. Section 2 also presents a model of the battery and its energy storage management system. In Section 3, the designs of the used control algorithms are introduced in a systematic manner. In Section 4, the test results are presented for each control algorithm and a comparison is carried out. In Section 5, the conclusions and research outputs are summarized.

\section{Wind Energy Conversion System}

\subsection{Wind Turbine Model}

The aerodynamic model of the wind turbine is illustrated in Figure 1, which provides a detailed view of the turbine and its power management system. As shown, the system involves the MPPT and blade pitch angle control. The MPPT is concerned with extracting the maximum available power from the wind for operating speeds lower than nominal. This can be achieved by assigning the optimal tip speed ratio [10,20]. Meanwhile, the pitch angle control is concerned with limiting power in case the wind speed exceeds its rated value. This is achieved by observing the wind speed and assigning a relevant pitch angle for each speed value utilizing the $V_{w}-\beta$ curve data and pitch servo system. The ratio $\mu$ can be evaluated by

$$
\mu=\frac{r \omega_{\mathrm{t}}}{V_{w}}
$$

where $\omega_{t}$ is the turbine speed and $r$ is the blade radius.

Knowing $\mu$ and $\beta$, the power coefficient $C_{P}$, which is used to calculate the turbine power [20] can be evaluated by

$$
C_{P}=[0.5-0.00167(\beta-2)] \sin \left[\frac{\pi(\mu+0.1)}{10-0.3(\beta-2)}\right]-0.00184(\mu-3)(\beta-2)
$$

The turbine and wind powers can be calculated respectively by

$$
P_{t}=C_{P} P_{w}, \text { and } P_{w}=\frac{1}{2} \rho S V_{w}^{3}
$$

where $S$ is the air covered area, and $\rho$ is the air density. 
Then, from (1), (2) and (3), the turbine torque is evaluated by

$$
T_{t}=\frac{P_{t}}{\omega_{\mathrm{t}}}=\frac{C_{P} \cdot \frac{1}{2} \rho S V_{w}^{3}}{\omega_{\mathrm{t}}}
$$

A gearbox ratio $K$ is utilized to achieve the balance between the low-speed shaft (turbine side) and high-speed shaft (machine side). Consequently, the generator torque and speed are calculated as follows

$$
\begin{gathered}
T_{g}=\frac{T_{t}}{K} \\
\omega_{g}=K \omega_{t}
\end{gathered}
$$

In addition, the dynamics of the mechanical shaft can be represented using the following expression:

$$
T_{t}-K T_{g}-F K \omega_{\mathrm{t}}=\left(\frac{J_{t}}{K}+K J_{g}\right) \frac{d \omega_{\mathrm{t}}}{d t}
$$

As stated earlier, to adopt the MPPT operation, the turbine must operate at optimal $\left(\mu_{\text {opt }}\right)$, which results in maximizing the power coefficient $C_{P, \text { max }}$ and turbine power $P_{t, \max }$ according to (2) and (3).

Using these hypotheses, the turbine and generator reference speeds are obtained by

$$
\begin{gathered}
\omega_{t}^{*}=\frac{\mu_{o p t} V_{w}}{R} \\
\omega_{g}^{*}=K \omega_{t}^{*}
\end{gathered}
$$

where ${ }^{*}$ refers to the reference value. Pitch angle control is activated when wind speed goes above the nominal speed $\left(V_{w, n o m}\right)$. The pitch servo system shown in Figure 1 enables the correct selection of $\beta$ according to the wind speed.

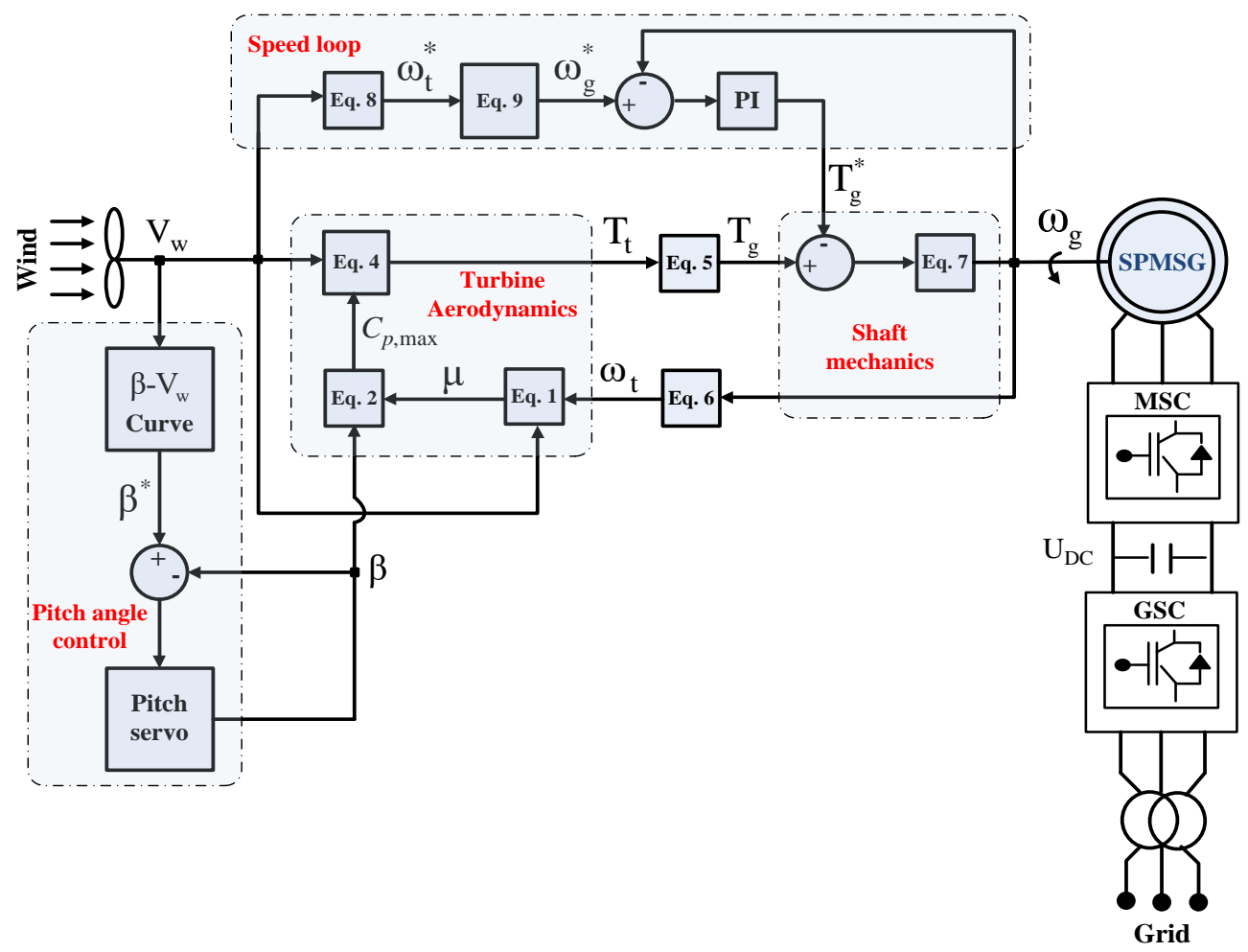

Figure 1. Wind energy conversion system. 
An illustration of the operating regions of the wind turbine is shown in Figure 2, which provides a detailed view of the regions at which the MPPT and pitch angle control are active. It is worth noting that in region 4, due to an excessive increase in wind speed, the system will not be able to effect pitch control, and thus the system is shut down.

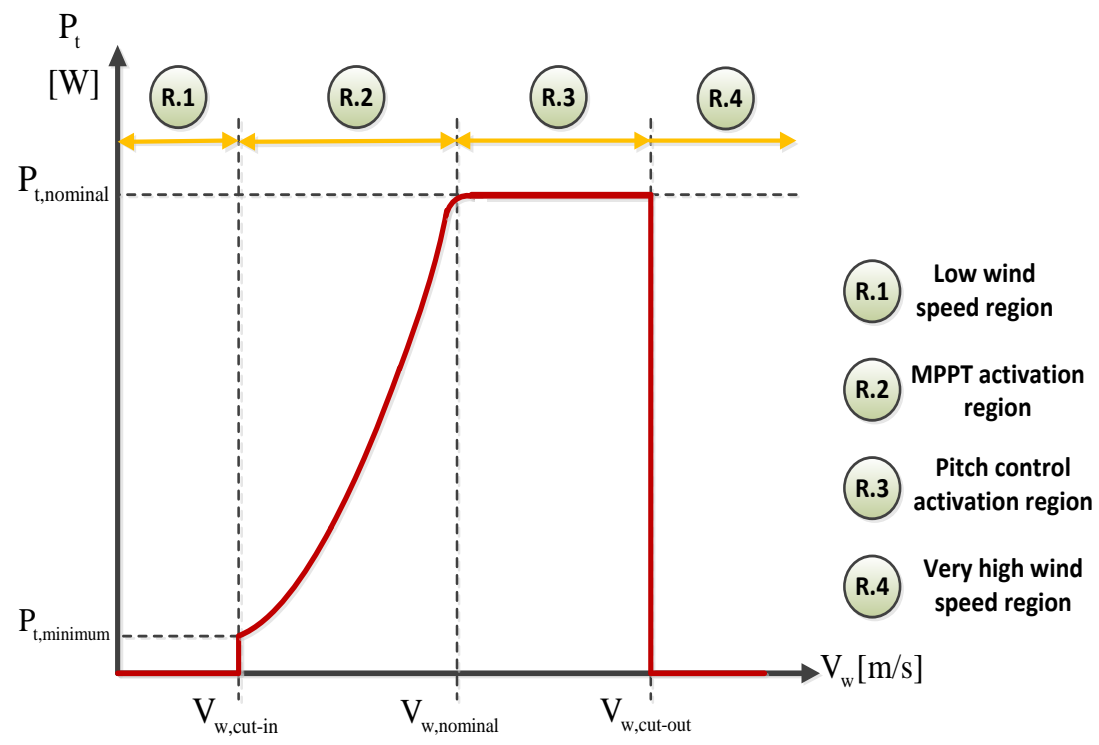

Figure 2. Operating regions of wind turbine.

\subsection{Mathematical Model of Synchronous Generator}

The electric dynamics of SPMSG can be described in a discrete form at instant $\mathrm{KT}_{\mathrm{S}}$ by the following expressions [21-23]:

$$
\begin{gathered}
\frac{d i_{d s, k}}{d t}=\frac{1}{L_{s}}\left(u_{d s, k}-R i_{d s, k}+\omega_{s, k} L_{s} i_{q s, k}\right) \\
\frac{d i_{q s, k}}{d t}=\frac{1}{L_{s}}\left(u_{q s, k}-R i_{q s, k}-\omega_{s, k} L_{s} i_{d s, k}-\omega_{s, k} \psi_{f, k}\right)
\end{gathered}
$$

The mechanical dynamic can be expressed by

$$
\frac{d \omega_{g, k}}{d t}=\frac{1}{J}\left(T_{t, k}-T_{g, k}-T_{f, k}\right)
$$

where $J$ refers to the combined inertia of turbine and generator.

The developed generator torque can be expressed by

$$
T_{g, k}=1.5 p \psi_{f, k} i_{q s, k}
$$

The parameters of the wind turbine and SPMSG are given in Table A1, in Appendix A.

\subsection{Modeling of the Converters, DC Bus and Filter for Grid Connection Purpose}

In the first operating regime of the SPMSG, it is connected to the utility grid and, therefore, an output filter must be utilized to pass generated power to the grid. The filter is at the output of the grid side converter (GSC) which is controlled to regulate the DC link voltage and achieve a unity power factor operation, which provides the filtered quantities to the grid. Figure 3 shows an illustration of this connection.

Considering that the grid voltage $\bar{u}_{g, k}$ is oriented to the $q$-axis of the rotating frame, then

$$
u_{q g, k}=\left|\bar{u}_{g, k}\right|, \text { and } u_{d g, k}=0.0
$$




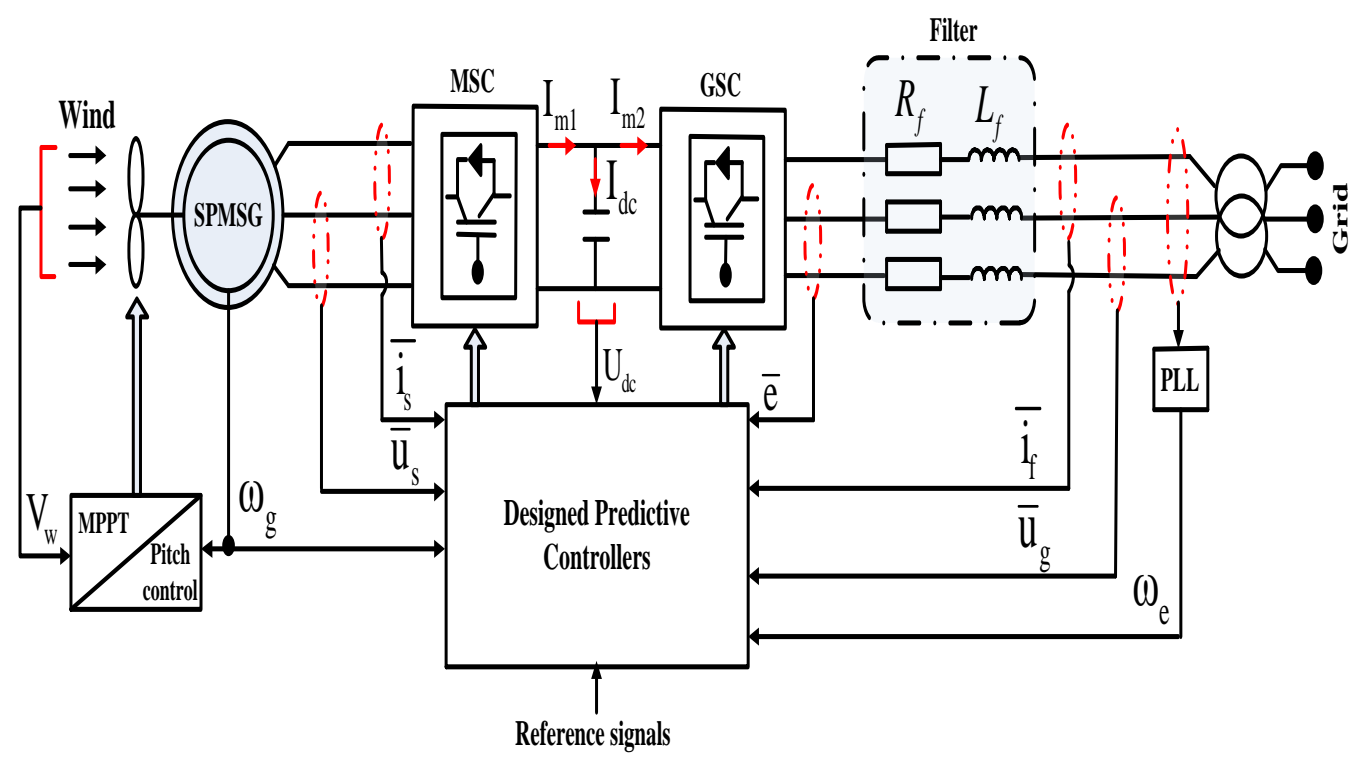

Figure 3. Schematic diagram of wind driven grid connected SPMSG.

Then, the voltage balance across the filter is expressed by

$$
\begin{gathered}
\frac{d i_{d f, k}}{d t}=\frac{1}{L_{f}}\left(e_{d, k}-R_{f} i_{d f, k}+\omega_{e, k} L_{f} i_{q f, k}\right) \\
\frac{d i_{q f, k}}{d t}=\frac{1}{L_{f}}\left(e_{q, k}-R_{f} i_{q f, k}-\omega_{e, k} L_{f} i_{d f, k}-u_{q g, k}\right)
\end{gathered}
$$

where $e_{d}$ and $e_{q}$ are the GSC $d-q$ voltages, $\omega_{e}$ is the angular frequency of the grid, which is identified using a phase-locked loop system [54].

Compared with the dynamics of the wind system, the power converters (MSC and GSC) have a faster switching frequency. Therefore, it is sufficient to calculate only the low frequency of the converter model quantities to analyze the dynamics of the entire generation system [55-57]. Thus, an equivalent continuous model of the converter is utilized to configure the current and voltage balancing conditions. Based on this, the average modulated voltages of the MSC can be evaluated in terms of the DC link voltage as following:

$$
\left[\begin{array}{l}
u_{d s, k} \\
u_{q s, k}
\end{array}\right]=\frac{u_{d c, k}}{2}\left[\begin{array}{l}
u_{d s, k}^{c} \\
u_{q s, k}^{c}
\end{array}\right]
$$

where $u_{d s}^{c}$ and $u_{q s}^{c}$ are the MSC control signals.

Then, the average modulated current from the generator $I_{m 1}$, shown in Figure 3 , can be calculated from the generator currents as presented in $[55,56]$ by

$$
I_{m 1, k}=\frac{1}{2}\left(u_{d s, k}^{c} i_{d s, k}+u_{q s, k}^{c} i_{q s, k}\right)
$$

In the same manner, the current $I_{m 2}$, which represents the average modulated current at the GSC side, can be calculated as following:

$$
I_{m 2, k}=\frac{1}{2}\left(e_{d, k}^{c} i_{d f, k}+e_{q, k}^{c} i_{q f, k}\right)
$$

where $e_{d}^{c}$ and $e_{q}^{c}$ are the GSC control signals. 
Similar to (17), the average modulated voltages of the GSC can be calculated by

$$
\left[\begin{array}{l}
e_{d, k} \\
e_{q, k}
\end{array}\right]=\frac{U_{d c, k}}{2}\left[\begin{array}{l}
e_{d, k}^{c} \\
e_{q, k}^{c}
\end{array}\right]
$$

From (18) and (19), the DC bus dynamics can be also represented by

$$
\mathrm{C} \frac{d U_{d c, k}}{d t}=I_{d c, k}=I_{m 1, k}-I_{m 2, k}
$$

It is worth mentioning that the control system designs for the MSC and GSC converters are described later in Section 3.

\subsection{Modeling of Battery Storage System for Standalone Operation Purpose}

As the wind-driven SPMSG is also used for stand-alone operation, feeding an isolated average DC load, a battery model is constructed to handle the excess power and provides the required load power in case of wind energy shortage. Furthermore, the unpredictable and intermittent nature of the wind requires the utilization of batteries as storage systems. Lead acid batteries (LAB) have proven their effectiveness and shown promising features when used in autonomous power supply (APS) systems $[58,59]$. Therefore, the model of the LAB is constructed and used by the standalone generation system. Figure 4 illustrates the equivalent circuit model of a LAB.

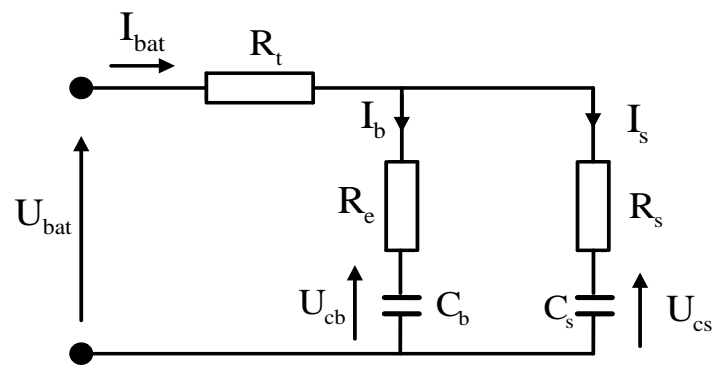

Figure 4. Model of lead-acid battery.

The voltage balance in the battery equivalent circuit of Figure 4 can be expressed by

$$
U_{b a t, k}=I_{b a t, k} R_{t}+I_{b, k} R_{e}+U_{c b, k}=I_{b a t, k} R_{t}+I_{s, k} R_{s}+U_{c s, k}
$$

The state variable representation of the battery-voltages can be expressed as in [58] by

$$
\left[\begin{array}{c}
\frac{d U_{c b, k}}{d t} \\
\frac{d u_{c s, k}}{d u^{\prime t}} \\
\frac{d U_{b a t, k}}{d t}
\end{array}\right]=\left[\begin{array}{lll}
A_{11} & A_{12} & A_{13} \\
A_{21} & A_{22} & A_{23} \\
A_{31} & A_{32} & A_{33}
\end{array}\right] \cdot\left[\begin{array}{c}
U_{c b, k} \\
U_{c s, k} \\
U_{b a t, k}
\end{array}\right]+\left[\begin{array}{c}
\frac{R_{s}}{C_{b}\left(R_{e}+R_{s}\right)} \\
\frac{\left.R_{b}\right)}{C_{s}\left(R_{e}+R_{s}\right)} \\
B
\end{array}\right] \cdot I_{b a t, k}
$$

where $A_{11}=\frac{-1}{C_{b}\left(R_{e}+R_{s}\right)}, A_{12}=\frac{1}{C_{b}\left(R_{e}+R_{s}\right)}, A_{13}=0$.

$A_{21}=\frac{1}{C_{s}\left(R_{e}+R_{s}\right)}, A_{22}=\frac{-1}{C_{s}\left(R_{e}+R_{s}\right)}, A_{23}=0$.

$A_{31}=\frac{-R_{s}}{C_{b}\left(R_{e}+R_{s}\right)^{2}}+\frac{R_{e}}{C_{s}\left(R_{e}+R_{s}\right)^{2}}-\frac{R_{s}^{2}}{C_{b} R_{e}\left(R_{e}+R_{s}\right)^{2}}+\frac{R_{s}}{C_{s}\left(R_{e}+R_{s}\right)^{2}}, A_{32}=0$,

$A_{33}=\frac{R_{s}}{C_{b} R_{e}\left(R_{e}+R_{s}\right)}-\frac{1}{C_{s}\left(R_{e}+R_{s}\right)}$.

$B=\frac{R_{e}^{2}}{C_{b}\left(R_{e}+R_{s}\right)^{2}}-\frac{R_{s} R_{t}}{C_{b}\left(R_{e}+R_{s}\right)}+\frac{R_{s} R_{e}}{C_{s}\left(R_{e}+R_{s}\right)^{2}}+\frac{R_{t}}{C_{s}\left(R_{e}+R_{s}\right)}$.

The storage system used in the present study is a $240 \mathrm{~V}$ battery with efficiency $\eta_{b a t}$ of $85 \%$, and depth of discharge (DOD) limit of $60 \%$. The nominal capacity of the battery is $50 \mathrm{Ah}$.

An overall schematic diagram for the standalone operation of SPMSG is illustrated in Figure 5. As can be seen, only the MSC converter is present to manage the operation 
of the wind driven SPMSG, while a bidirectional DC/DC converter is utilized to manage the charging and discharging processes of the battery. This is in addition to the connected variable DC load, which is used to illustrate the power handling process between the SPMSG and the battery.

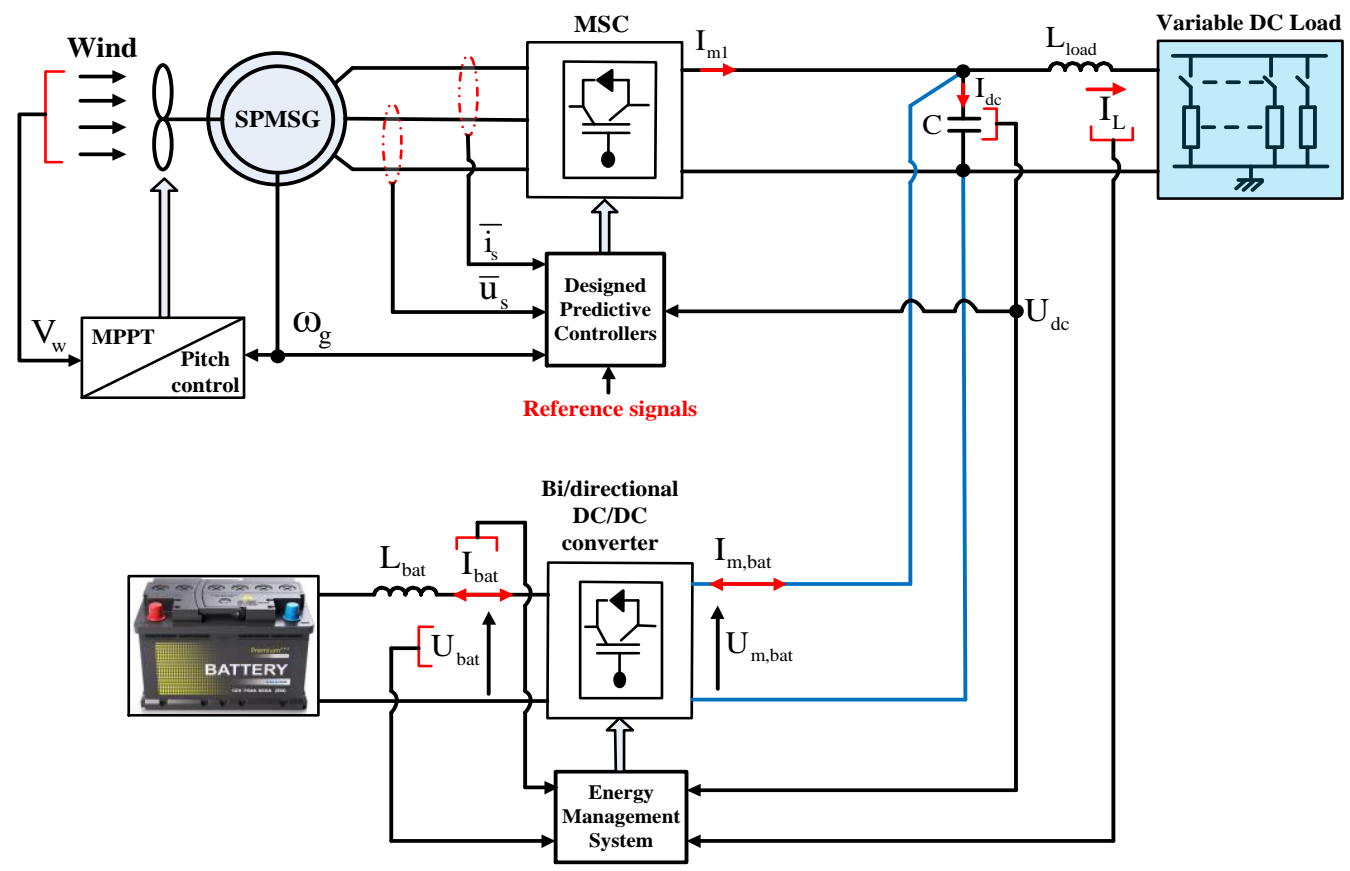

Figure 5. Standalone operation of SPMSG with battery storage system and variable DC load.

To represent the DC bus dynamics under stand-alone operation, the current flow through capacitor $C$ is constructed using the modulated current $I_{m 1}$ calculated by (18), the modulated battery current $I_{m, \text { bat }}$ and the load current $I_{L}$ as following:

$$
C \frac{d U_{d c, k}}{d t}=I_{d c, k}=I_{m 1, k}+I_{m, b a t, k}-I_{L, k}
$$

The power flow between the MSC, DC link, Load and bi-directional converter is shown in Figure 6. The specified powers are defined as follows:

$$
\begin{gathered}
P_{g, k}=I_{m 1, k} U_{d c, k} \\
P_{d c, k}=I_{d c, k} U_{d c, k} \\
P_{L, k}=I_{L, k} U_{d c, k} \\
P_{m, b a t, k}=I_{m, b a t, k} U_{m, b a t, k}
\end{gathered}
$$

where $I_{L}$ is the load current, $U_{m, b a t}$ and $I_{m, b a t}$ are the modulated battery voltage and current, respectively, $P_{g}$ is the MSC output power, $P_{d c}$ is the DC link power, $P_{L}$ is the load power, and $P_{m, b a t, k}$ is the bidirectional power to/from the bidirectional converter.

An equivalent continuous model of the converter is adequate for the study [56]. Thus, the modulated voltage $U_{m b a t}$ and the modulated current $I_{m b a t}$ of the converter can be obtained as followings:

$$
U_{m, b a t}=m_{b a t} U_{d c} \text {, and } I_{m, b a t}=m_{b a t} I_{b a t}
$$

where $m_{b a t}$ is the modulation signal. An illustration for obtaining the modulated signals is shown in Figure 7.

As seen in Figure 6, the bi-directional power $\left(P_{m, b a t}\right)$ flow of the battery is calculated in terms of the modulated battery current and modulated battery voltage, and illustrates how these two quantities are derived by making a power balance between the different units. A 
detailed scheme in Figure 7 is shown. In this scheme, the procedure starts with calculating the powers $P_{g}, P_{d c}$ and $P_{L}$. The collective net power of the three quantities should balance the battery power. Using the net power and battery voltage, the reference battery current $I_{b a t}^{*}$ is calculated, and then is compared with the calculated battery current $I_{b a t}$ passing through the inductor $L_{b a t}$ to obtain the modulated battery voltage $U_{m, b a t}$. Finally, the modulated battery current $I_{m, b a t}$ is obtained from the battery current $I_{b a t}$ after multiplying it by the ratio $\left(U_{m, b a t} / U_{d c}\right)$. By ensuring power exchange balance, the load power can be effectively covered, as will be illustrated through the test results.

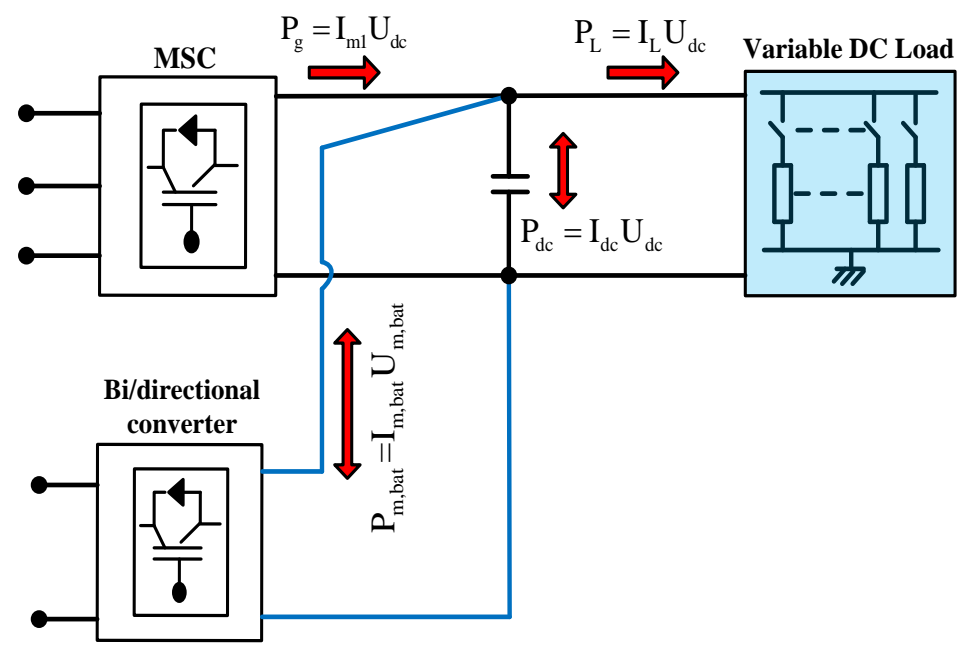

Figure 6. Power flow between different system components.

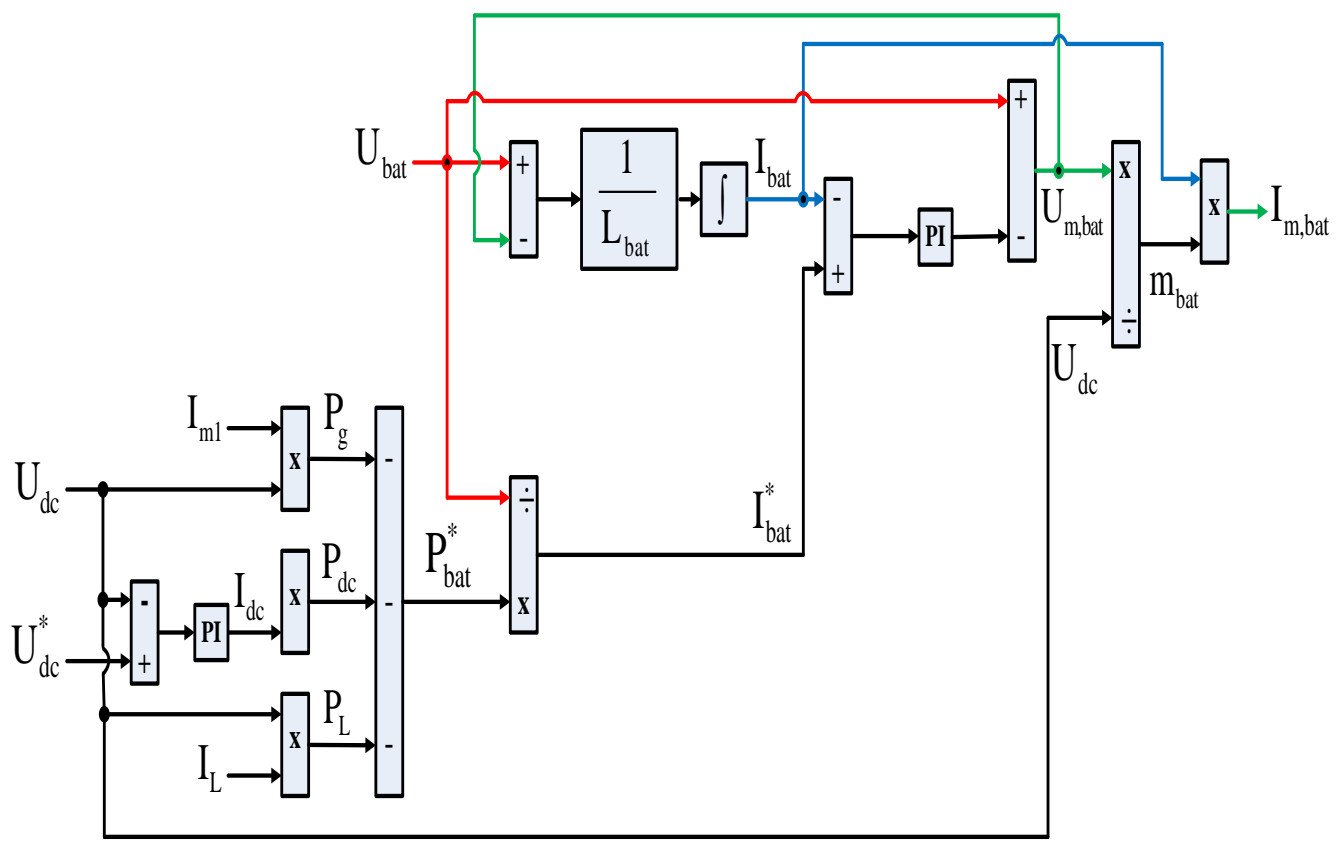

Figure 7. Power balance detailed view between battery and other system units.

\section{Control System Designs}

This section presents the design of the control systems e used by the wind energy conversion system for grid connection and stand-alone operation. Four control algorithms are used to manage the operation of the MSC, which are MP DPC, MP DTC, MP CC and a formulated PVC scheme. For the grid connection regime, only the MP CC controls the GSC converter. 


\subsection{Design of Model Predictive Current Control for Grid Side Converter}

MP CC control topology is utilized to regulate the operation of GSC. Control is achieved by a cost function form, which combines the absolute errors between the reference and predicted values of $d-q$ filtered grid currents $\left(i_{d f, k+1}, i_{q f, k+1}\right)$. Thus, the cost function [41] can be represented at instant $T_{s}(k+1)$ by

$$
\Delta_{k+1}^{i}=\left|i_{d f, k+1}^{*}-\widetilde{i}_{d f, k+1}\right|^{i}+\left|i_{q f, k+1}^{*}-\widetilde{i}_{q f, k+1}\right|^{i}
$$

where ${ }^{i}$ refers to the voltage index, and $\widetilde{i}_{d f, k+1}$ and $\widetilde{i}_{q f, k+1}$ are the predicted values of filtered grid currents, which can be obtained using (15) and (16) as follows:

$$
\widetilde{i}_{d f, k+1}=i_{d f, k}+\left(\frac{d i_{d f, k}}{d t}\right) T_{s,} \text { and } \widetilde{i}_{q f, k+1}=i_{q f, k}+\left(\frac{d i_{q f, k}}{d t}\right) T_{s}
$$

Under the orientation of grid voltage along the $q$-axis of the rotating frame, the reference current $i_{q f, k+1}^{*}$ can be obtained by regulating the difference between the reference and actual value of the DC link voltage, while the reference current $i_{d f, k+1}^{*}$ can be obtained in terms of the reference reactive power $Q_{g, k+1}^{*}$, which is set to zero to achieve unity pf operation. An illustration for the control scheme of GSC using the MP CC principle is shown in Figure 8.

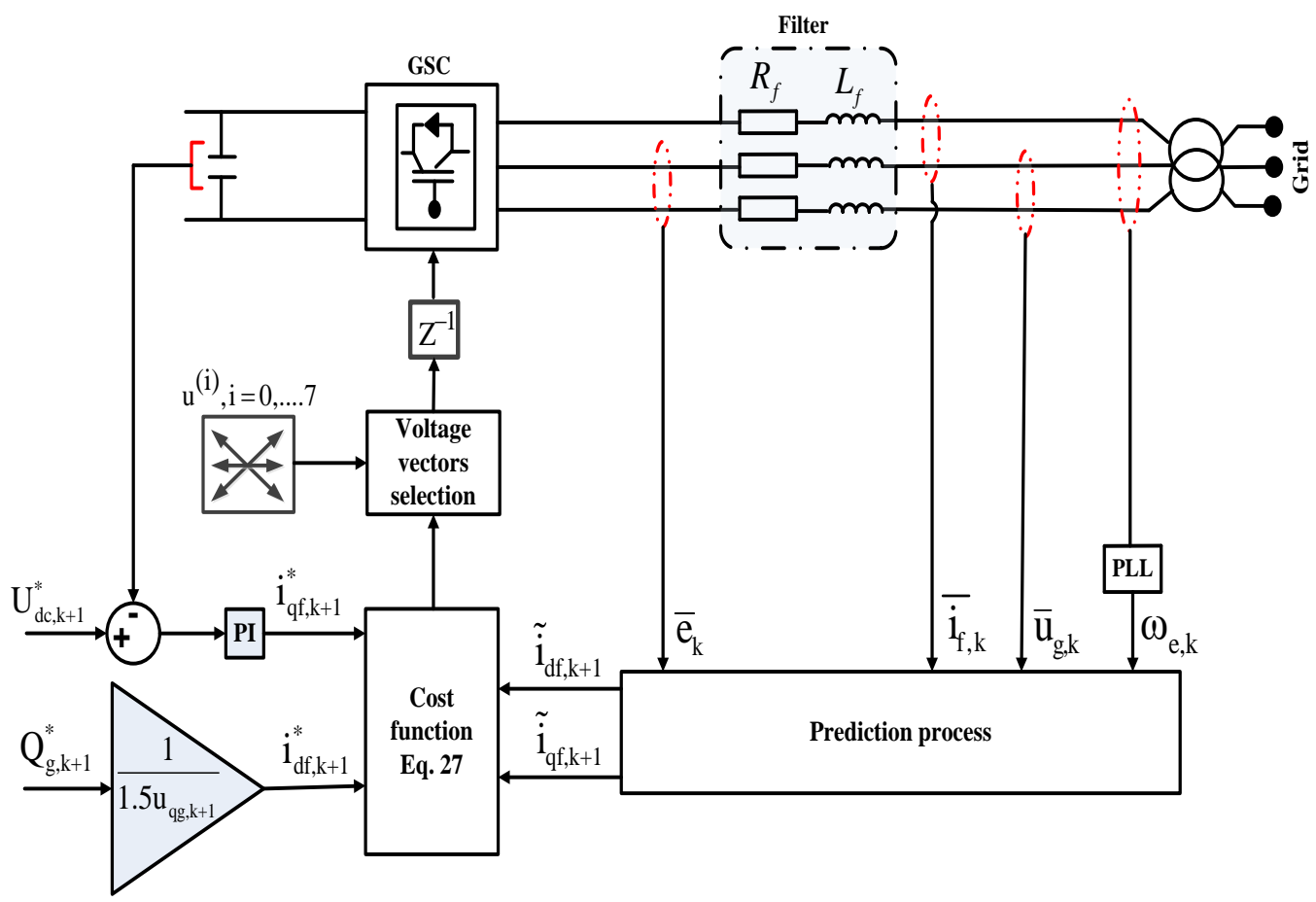

Figure 8. Model of the predictive current control scheme for the grid side converter.

\subsection{Control of Machine Side Converter for Grid Connected and Standalone Operations}

\subsubsection{Design of Model Predictive Direct Power Control Scheme}

The MP DPC scheme is concerned with regulating the operation of MSC via controlling the active and reactive powers of the SPMSG directly without involving current loops, as in MP CC, or torque and flux loops as in MP DTC. The main part of the MP DPC is the cost function, which consists of the absolute errors between the reference and predicted values of active and reactive powers, in addition to using a weighting value $w_{f}=\frac{P_{\text {nominal }}}{Q_{\text {nominal }}}$, 
which is used to achieve a weighting balance between the controlled powers. Thus, the cost function of the MP DPC [37] can be expressed as follows:

$$
C_{k+1}^{i}=\left|P_{g, k+1}^{*}-\widetilde{P}_{g, k+1}\right|^{i}+w_{f}\left|Q_{g, k+1}^{*}-\widetilde{Q}_{g, k+1}\right|^{i}
$$

The reference reactive power $Q_{g, k+1}^{*}$ is set to zero, and the reference active power $\left(P_{g, k+1}^{*}=T_{g, k+1}^{*} * \omega_{g, k+1}^{*}\right)$ is obtained through the multiplication of the reference generator torque $T_{g, k+1}^{*}$ and reference generator speed $\omega_{g, k+1}^{*}$; both are obtained from the wind turbine power management system as illustrated in Figure 1. On the other hand, the predicted values $\widetilde{P}_{g, k+1}$ and $\widetilde{Q}_{g, k+1}$ are calculated as follows:

$$
\begin{aligned}
\widetilde{P}_{g, k+1} & =1.5\left(u_{d s, k+1} \widetilde{i}_{d s, k+1}+u_{q s, k+1} \widetilde{i}_{q s, k+1}\right) \\
\widetilde{Q}_{g, k+1} & =1.5\left(u_{q s, k+1} \widetilde{i}_{d s, k+1}-u_{d s, k+1} \widetilde{i}_{q s, k+1}\right)
\end{aligned}
$$

where $\widetilde{i}_{d s, k+1}$ and $\widetilde{i}_{q s, k+1}$ are the predicted stator current $d-q$ components of SPMSG which can be obtained using (10) and (11) as follows:

$$
\widetilde{i}_{d s, k+1}=i_{d s, k}+\left(\frac{d i_{d s, k}}{d t}\right) T_{s, \text { and }} \widetilde{i}_{q s, k+1}=i_{q s, k}+\left(\frac{d i_{q s, k}}{d t}\right) T_{s}
$$

Meanwhile, the stator voltage components $u_{d s, k+1}$ and $u_{q s, k+1}$ are obtained as follows:

$$
u_{d s, k+1}=u_{d s, k}+\left(\frac{u_{d s, k-} u_{d s, k-1}}{\Delta T}\right) T_{s}, \text { and } u_{q s, k+1}=u_{q s, k}+\left(\frac{u_{q s, k-} u_{q s, k-1}}{\Delta T}\right) T_{s}
$$

The schematic diagram of the MP DPC for the MSC is illustrated in Figure 9.

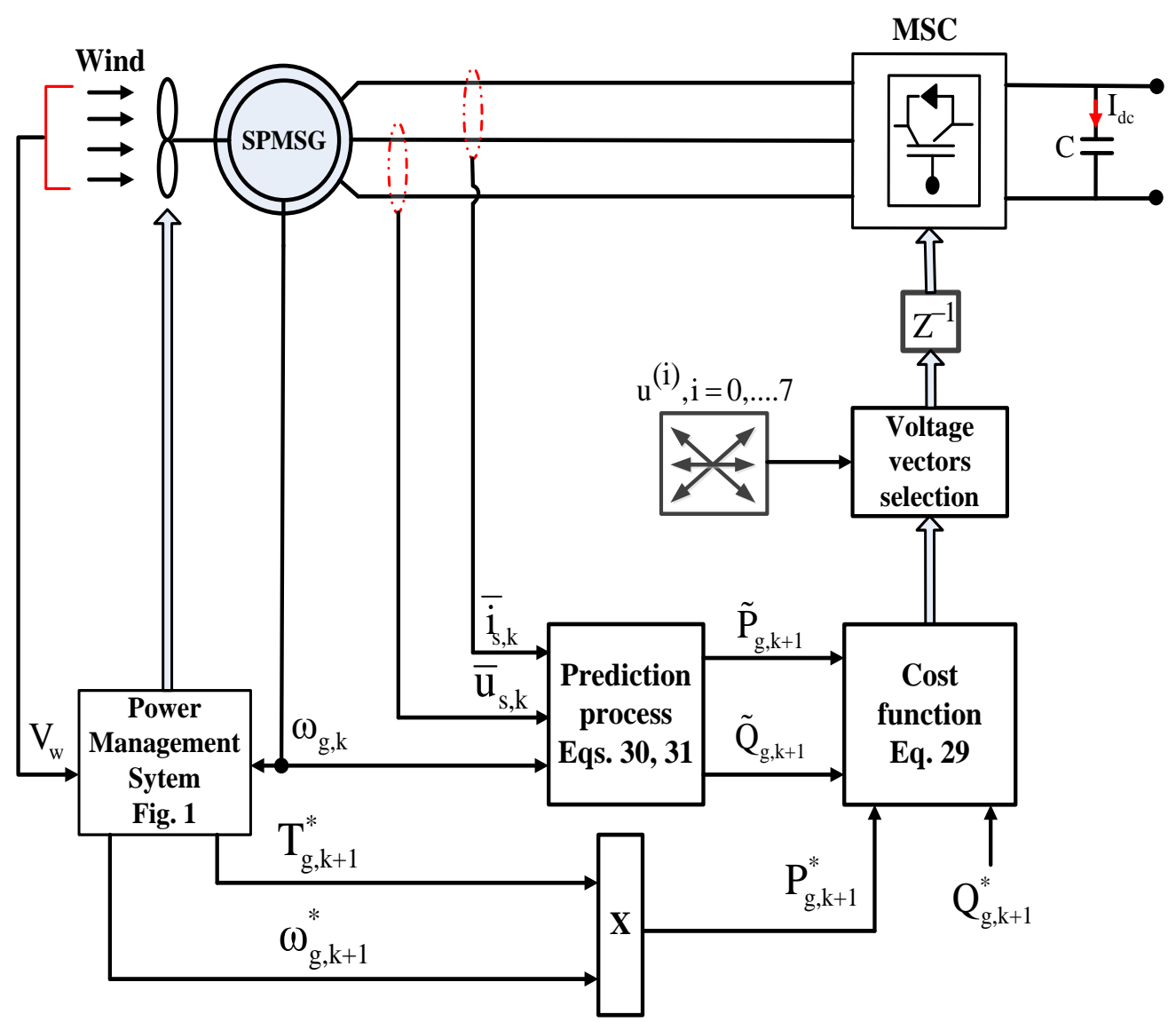

Figure 9. Model of the predictive direct power control scheme for the machine side converter. 


\subsubsection{Design of the Model Predictive Direct Torque Control Scheme}

The MP DTC is concerned with regulating the torque and flux of the SPMSG. To formulate the control system, a cost function that combines the absolute errors of the torque and flux must be used. This cost function replaces the function of hysteresis controllers and look-up tables in classic DTC technique. Consequently, the cost function of the MP DTC [38] can be expressed by

$$
\partial_{k+1}^{i}=\left|T_{g, k+1}^{*}-\widetilde{T}_{g, k+1}\right|^{i}+w_{f}^{\prime}\left|\psi_{g, k+1}^{*}-\widetilde{\psi}_{g, k+1}\right|^{i}
$$

where $T_{g, k+1}^{*}$ and $\psi_{g, k+1}^{*}$ are the reference torque and flux for the SPMSG. $w_{f}^{\prime}=\frac{T_{\text {nominal }}}{\psi_{\text {nominal }}}$ is the weighting factor. $\widetilde{T}_{g, k+1}$ and $\widetilde{\psi}_{g, k+1}$ are the predicted values of the torque and flux.

The reference torque signal $T_{g, k+1}^{*}$ is obtained from the wind turbine power management system shown in Figure 1, while the reference flux $\psi_{g, k+1}^{*}$ is obtained using the reference current $d-q$ components as follows:

$$
\psi_{g, k+1}^{*}=\sqrt{\left(L_{s} i_{d s, k+1}^{*}+\psi_{f, k+1}\right)^{2}+\left(L_{s} i_{q s, k+1}^{*}\right)^{2}}
$$

The reference current $i_{d s, k+1}^{*}$ is set to zero, while the reference $i_{q s, k+1}^{*}$ is obtained by

$$
i_{q s, k+1}^{*}=\frac{T_{g, k+1}^{*}}{1.5 p \psi_{f, k+1}}
$$

The predicted torque and flux values to be used in (34) are obtained by

$$
\begin{gathered}
\widetilde{T}_{g, k+1}=1.5 p \psi_{f, k+1} \widetilde{i}_{q s, k+1} \\
\widetilde{\psi}_{g, k+1}=\sqrt{\left(L_{s} \widetilde{i}_{d s, k+1}+\psi_{f, k+1}\right)^{2}+\left(L_{s} \widetilde{i}_{q s, k+1}\right)^{2}}
\end{gathered}
$$

The predicted currents $\widetilde{i}_{d s, k+1}$ and $\widetilde{i}_{q s, k+1}$ are calculated using (32).

Thus, the MP DTC evaluates the value of (34) using the eight possible voltage vectors and selects the first voltage vector that minimizes it and applies it to the machine terminals. The MP DTC scheme for the MSC is illustrated in Figure 10.

\subsubsection{Design of Model Predictive Current Control Scheme}

The MP CC scheme is dedicated to regulating the $d-q$ stator current components $\left(i_{d s, k}\right.$, $i_{q s, k}$ ) of the SPMSG. This is accomplished by utilizing a weighting-free cost function, which incorporates the absolute errors of the $d$ - $q$ current components. Thus, the MP CC utilizes the inner current control loops, and, for this reason, it is considered as a transposition of the FOC principle but with removing the PI regulators. The cost function of the MP CC [41] can be expressed by

$$
\cap_{k+1}^{i}=\left|i_{d s, k+1}^{*}-\widetilde{i}_{d s, k+1}\right|^{i}+\left|i_{q s, k+1}^{*}-\widetilde{i}_{q s, k+1}\right|^{i}
$$

In (39), the reference current $i_{d s, k+1}^{*}$ is set to zero, while the reference current $i_{q s, k+1}^{*}$ is obtained using (36). In addition, the predicted currents $\widetilde{i}_{d s, k+1}$ and $\widetilde{i}_{q s, k+1}$ are evaluated using (32). It is worth stating that the MP CC uses a weighting-free cost function, which contributes to some extent in avoiding the ripples issue found in MP DPC and MP DTC. However, as the current prediction process depends on the machine model, the MP CC is still a time-consuming approach, in addition to the dependency on the model parameters, which makes the cost function not generally robust. A schematic diagram of the MP CC for the MSC is illustrated in Figure 11. 


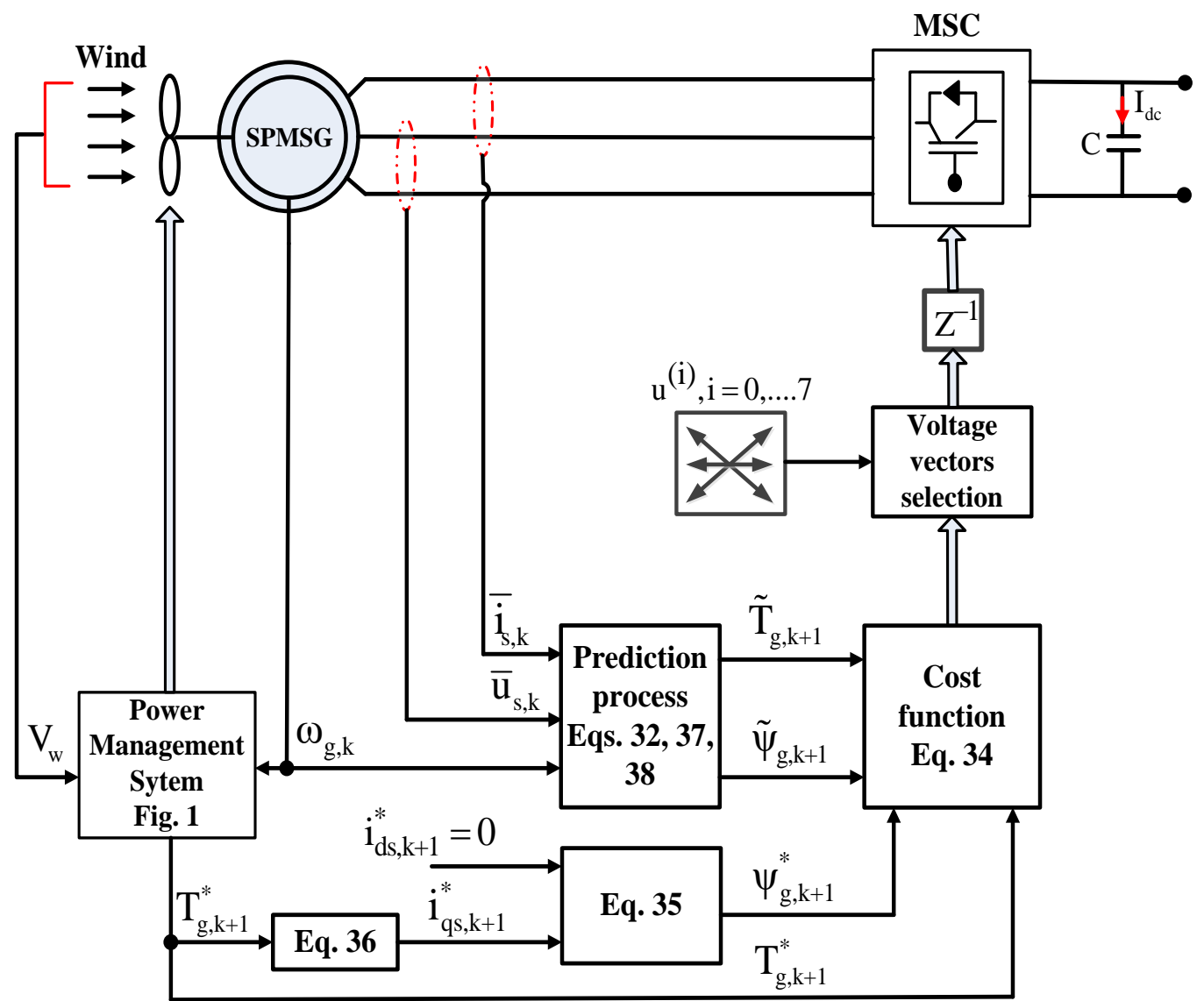

Figure 10. Model of the predictive direct torque control scheme for the machine side converter.

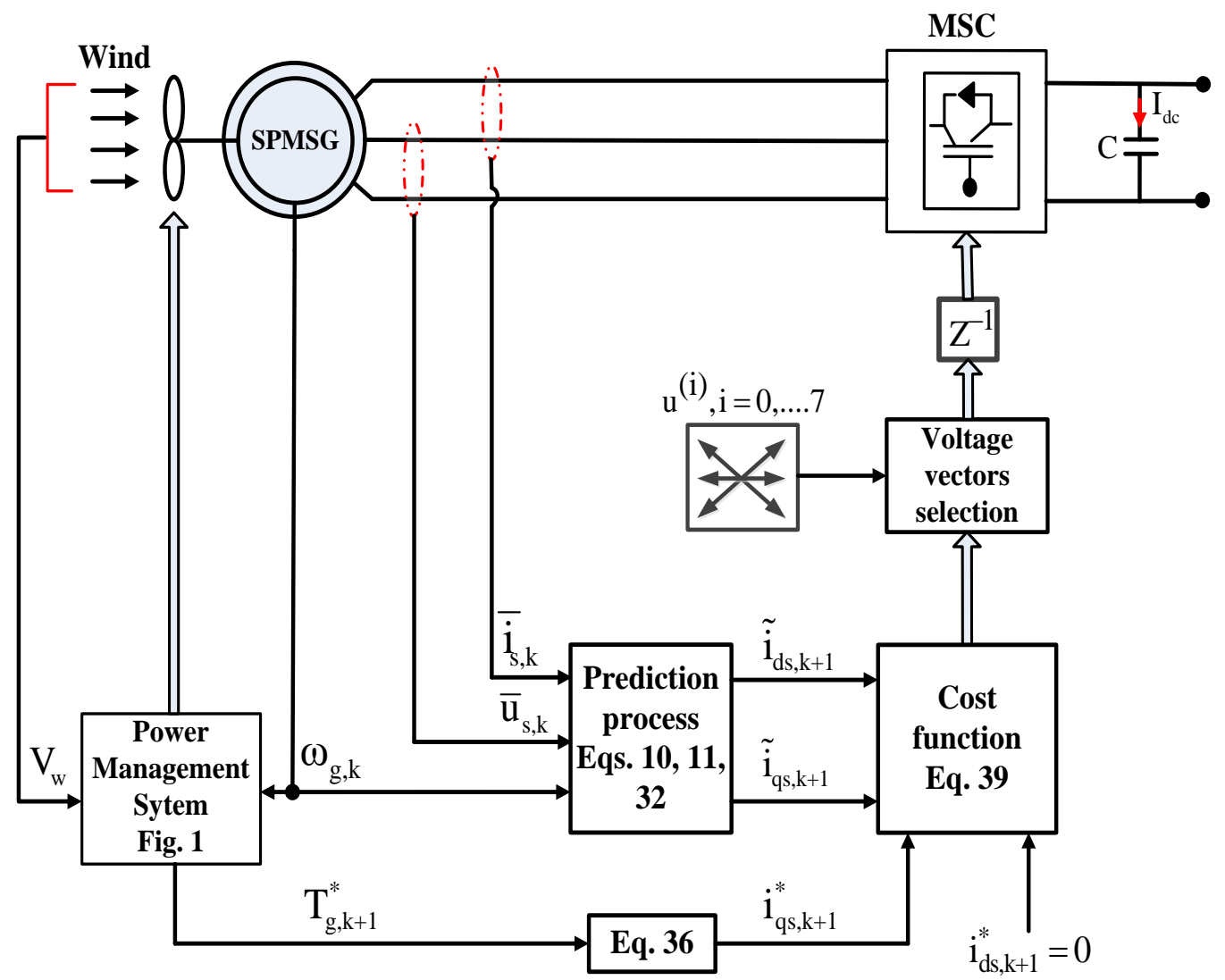

Figure 11. Model of the predictive current control for the machine side converter. 


\subsubsection{Proposed Predictive Voltage Control Scheme}

As an attempt to avoid the shortcomings of the model-dependent predictive control schemes described above, an effective predictive voltage control (PVC) scheme was formulated. The main idea is based using a robust cost function, which has no parameterdependent terms. To fulfill this requirement, the $d-q$ stator voltage components of the SPMSG are selected as the cost function variables. Thus, the PVC operation is managed using the following cost function represented at instant $(k+1) T_{s}$.

$$
\forall_{k+1}^{i}=\left|u_{d s, k+1}^{*}-u_{d s, k+1}\right|^{i}+\left|u_{q s, k+1}^{*}-u_{q s, k+1}\right|^{i}
$$

As seen in (40), all terms are of the same type; therefore, there is no need to use a weighting value. In addition, the voltage components are not evaluated in terms of the model parameters, which ensures high robustness.

The technique by which the PVC generates its references is described in Figure 12, which presents possible control behaviors. In Figure 12, it is assumed that the reference voltage $\bar{u}_{s}^{*}$ is present in sector 5 , and thus function (40) starts to check the vector that ensures minimal error. Three bisectors are formulated inside sector 5 , which are obtained by intersecting the inter-median lines of the sector itself (S1, S2 and S3). By checking, there are three possible vectors that can assume this role, being $u_{5}(001), u_{6}(101)$ and $u_{0}(000)$ /or $u_{7}(111)$, but the most appropriate vector is $u_{6}(101)$ as this causes the lowest deviation $\left(\bar{u}_{e 6}\right)$. Consequently, by tracking the location of the reference vector and using (40), the designed PVC is able to reach the control targets with minimal computation burden compared with the functional forms of (29), (34) and (39).

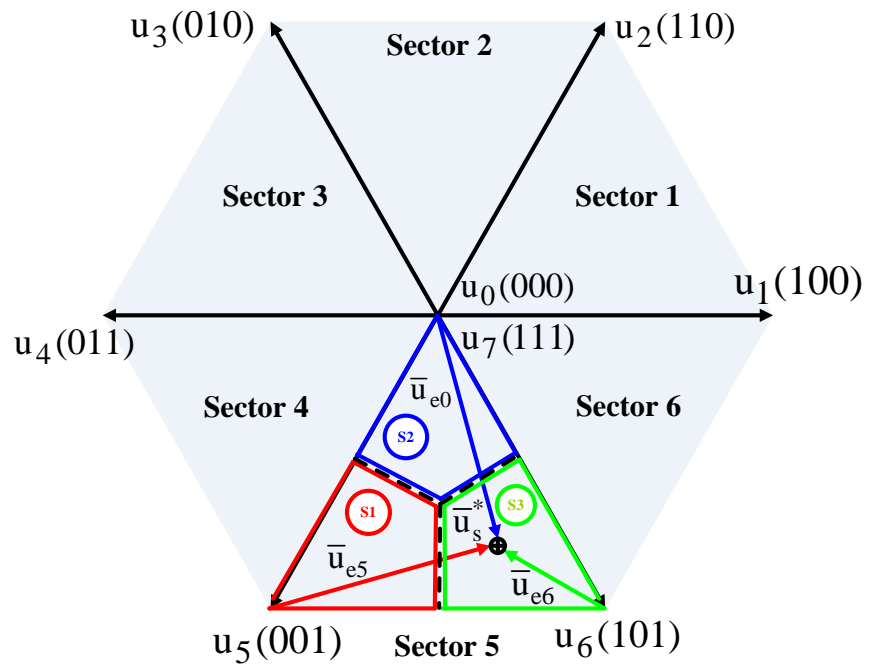

Figure 12. Optimal voltage selection mechanism using predictive voltage control.

The actual $d-q$ voltage components $u_{d s, k+1}$ and $u_{q s, k+1}$ in (40) are obtained using the FCS principle, which enables the evaluation of the voltage vectors in terms of the switching states without using a PWM topology. On the other hand, the derivation of reference voltage components $u_{d s, k+1}^{*}$ and $u_{q s, k+1}^{*}$ represents a central point of (40), as the references can be obtained using different methods as discussed earlier in the introduction section. One of these ways is to use the deadbeat principle to calculate the references; however, this technique suffers from dependency on the model parameters, which negatively affects the robustness of the cost function. Another method is to use traditional PI regulators to generate the reference voltages, but this technique requires the addition of compensating terms which are parameter-dependent and can be affected by system uncertainties. For these reasons, in the current study, the reference $d-q$ voltages are generated using two designed stator flux and torque regulators, which can provide the reference voltages directly without adding compensating terms. 
Design of Flux and Torque Regulators

The $q$-axis component of the stator flux is perpendicular to the stator-flux vector while the $d$-axis component is aligned to the flux vector. This results in

$$
\psi_{d g, k+1}=\left|\bar{\psi}_{g, k+1}\right|, \text { and } \psi_{q g, k+1}=0.0
$$

Then, by substituting from (41) into the stator voltage equations of SPMSG:

$$
\begin{gathered}
u_{d s, k+1}=R i_{d s, k+1}+\frac{d\left|\bar{\psi}_{g, k+1}\right|}{d t} \\
u_{q s, k+1}=R i_{q s, k+1}+\omega_{s, k+1}\left|\bar{\psi}_{g, k+1}\right|
\end{gathered}
$$

From (42), if the resistance voltage drop is ignored, the stator flux can be regulated directly using the $d$-axis voltage component $u_{d s, k+1}$.

From Figure 13, which illustrates the relationship between the stator flux $\bar{\psi}_{g, k+1}$ and permanent magnet rotor flux $\bar{\psi}_{f, k+1}$ vectors, the angular frequency of the stator flux $\left(\omega_{s, k+1}\right)$ can be calculated by

$$
\omega_{s, k+1}=\omega_{g, k+1}+\frac{d \delta_{k+1}}{d t}
$$

where $\delta_{k+1}$ is the torque angle, and $\omega_{g, k+1}$ is the angular frequency of the SPMSG rotor.

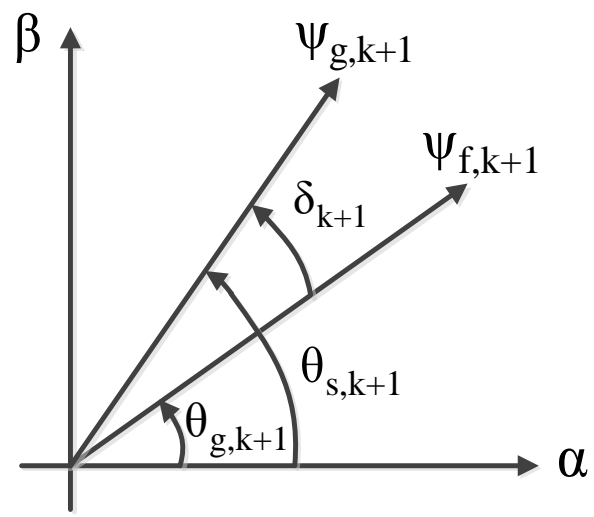

Figure 13. Space vector representation of stator and permanent magnet fluxes.

The $q$-axis current $i_{q s, k+1}$ in (43) can be evaluated in terms of the torque by

$$
i_{q s, k+1}=\frac{T_{g, k+1}}{1.5 p\left|\bar{\psi}_{g, k+1}\right|}
$$

Then, by substituting from (44) and (45) into (43):

$$
u_{q s, k+1}=R \frac{T_{g, k+1}}{1.5 p\left|\bar{\psi}_{g, k+1}\right|}+\left(\omega_{g, k+1}+\frac{d \delta_{k+1}}{d t}\right)\left|\bar{\psi}_{g, k+1}\right|
$$

From (46), the torque can be regulated using the $q$-axis voltage component $u_{q s, k+1}$.

Consequently, $d-q$ reference voltages needed by (40) can be obtained using a torque and flux regulators with outputs expressed by

$$
\begin{aligned}
& u_{d s, k+1}^{*}=\left(K_{P \psi}+\frac{K_{I \psi}}{s}\right)\left(\psi_{g, k+1}^{*}-\widetilde{\psi}_{g, k+1}\right) \\
& u_{q s, k+1}^{*}=\left(K_{P T}+\frac{K_{I T}}{s}\right)\left(T_{g, k+1}^{*}-\widetilde{T}_{g, k+1}\right)
\end{aligned}
$$


where $K_{P \psi}, K_{I \psi}, K_{P T}$ and $K_{I T}$ are the coefficients of flux and torque regulators, respectively.

Figure 14 represents the closed-loop flux model, which is obtained by applying the Laplace transformation on (42).

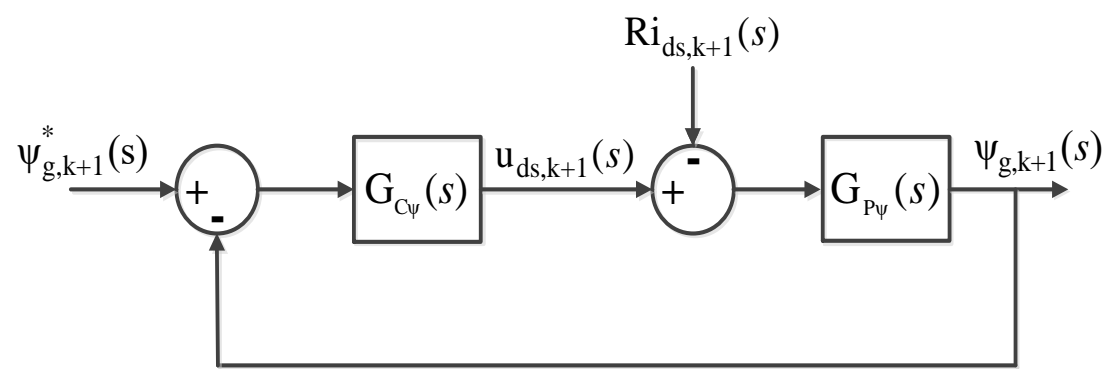

Figure 14. Closed loop flux control model.

In Figure 14, the control object transfer function $G_{P \psi}(s)$ and the flux regulator transfer function $G_{C \psi}(s)$ are represented by

$$
\begin{gathered}
G_{P \psi}(s)=\frac{1}{s} \\
G_{C \psi}(s)=\frac{K_{P \psi} s+K_{I \psi}}{s}
\end{gathered}
$$

By neglecting the resistance voltage drop, the transfer function of stator flux closed loop can be expressed by

$$
G_{\psi}(s)=\frac{G_{P \psi}(s) G_{C \psi}(s)}{1+G_{P \psi}(s) G_{C \psi}(s)}=\frac{K_{P \psi} s+K_{I \psi}}{s^{2}+K_{P \psi} s+K_{I \psi}}
$$

The transfer function (51) represents the dynamics of a second order system with an auxiliary equation defined by

$$
s^{2}+K_{P \psi} s+K_{I \psi}=0.0
$$

On the other hand, second order system dynamics [17] can be represented by

$$
s^{2}+2 \omega_{n} \xi s+\omega_{n}^{2}=0.0
$$

where $\omega_{n}$ and $\xi$ are the natural system frequency and damping coefficient, respectively.

By comparing, (52) and (53), the coefficients of flux regulators are obtained by

$$
K_{P \psi}=2 \omega_{n} \xi, \text { and } K_{I \psi}=\omega_{n}^{2}
$$

In the same manner, the torque regulator gains can be determined by analyzing (46). From Figure 13, the torque can be expressed by

$$
T_{g, k+1}=\frac{1.5 p}{L_{s}}\left|\psi_{f, k+1}\right|\left|\bar{\psi}_{g, k+1}\right| \sin \delta_{k+1}=K_{T} \sin \delta_{k+1}
$$

By differentiating (55), and adding the result to (46):

$$
u_{q s, k+1}=\frac{R T_{g, k+1}}{1.5 p\left|\bar{\psi}_{g, k+1}\right|}+\left(\omega_{g, k+1}+\frac{\frac{d T_{g, k+1}}{d t}}{Y_{T}}\right)\left|\bar{\psi}_{g, k+1}\right|
$$

where $Y_{T}=K_{T} \cos \delta_{k+1}$. 
Taking the Laplace transform of (56):

$$
u_{q s, k+1}(s)=\left(\frac{R}{1.5 p\left|\bar{\psi}_{g, k+1}\right|(s)}+\frac{\left|\bar{\psi}_{g, k+1}\right|(s)}{Y_{T}(s)} s\right) T_{g, k+1}(s)+\omega_{g, k+1}(s)\left|\bar{\psi}_{g, k+1}\right|(s)
$$

Using (57), the closed-loop torque control can be constructed as shown in Figure 15, where $G_{P T}(s)$ is the Laplace transform of the control object and $G_{C T}(s)$ is the Laplace transform of the torque regulator. Both transformations are expressed by

$$
G_{P T}(s)=\frac{1.5 p\left|\bar{\psi}_{g, k+1}\right|(s) * Y_{T}(s)}{R Y_{T}(s)+\left(1.5 p\left|\bar{\psi}_{g, k+1}\right|^{2}(s)\right) s}
$$

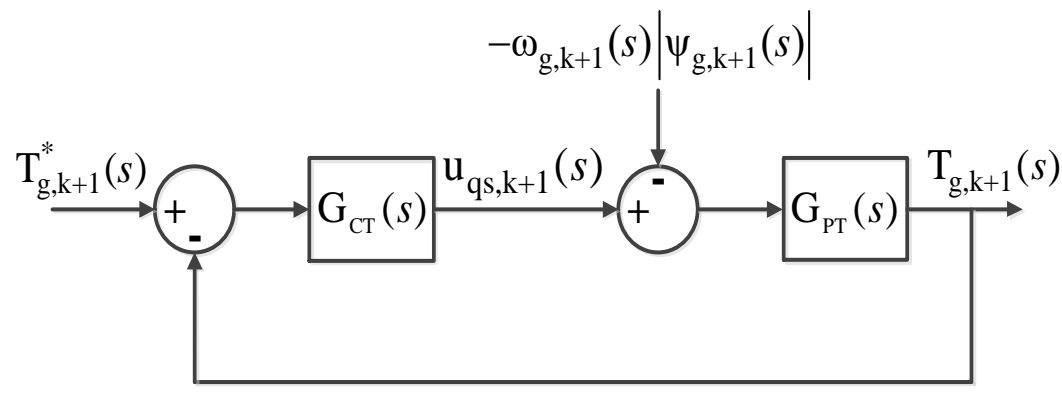

Figure 15. Closed loop torque control model.

$$
G_{C T}(s)=\frac{K_{P T} s+K_{I T}}{s}
$$

From Figure 15, the transfer function that outlines the dynamics of torque control loop can be expressed by

$$
G_{T}(s)=\frac{G_{P T}(s) G_{C T}(s)}{1+G_{P T}(s) G_{C T}(s)}=\frac{K_{P T} s+K_{I T}}{s^{2}+K_{P T} s+K_{I T}}=\frac{\left(1.5 p\left|\bar{\psi}_{g, k+1}\right|(s) * Y_{T}(s) K_{P T}\right) S+1.5 p\left|\bar{\psi}_{g, k+1}\right|(s) * Y_{T}(s) K_{I T}}{\left(1.5 p\left|\bar{\psi}_{g, k+1}\right|^{2}(s)\right) s^{2}+\left(R Y_{T}(s)+1.5 p\left|\bar{\psi}_{g, k+1}\right|(s) * Y_{T}(s) K_{P T}\right) s+1.5 p\left|\bar{\psi}_{g, k+1}\right|(s) * Y_{T}(s) K_{I T}}
$$

By comparing the terms of the characteristic equation in (60) with the characteristic equation in (53), the coefficients of the torque regulator can be calculated as following

$$
K_{P T}=\frac{3 p\left|\bar{\psi}_{g, k+1}\right|^{2} \omega_{n} \xi-R Y_{T}}{1.5 p\left|\bar{\psi}_{g, k+1}\right| Y_{T}}, \text { and } K_{I T}=\frac{\omega_{n}^{2}\left|\bar{\psi}_{g, k+1}\right|}{Y_{T}}
$$

After evaluating the coefficients of flux and torque regulators, the reference voltages $u_{d s, k+1}^{*}$ and $u_{q s, k+1}^{*}$ can be obtained and used in (40).

The schematic diagram of the proposed PVC for the MSC is illustrated in Figure 16.

The sequence of implementation for the proposed PVC scheme is given in Figure 17, which shows the detailed procedure of selecting the optimal voltage vectors using cost function (40). 


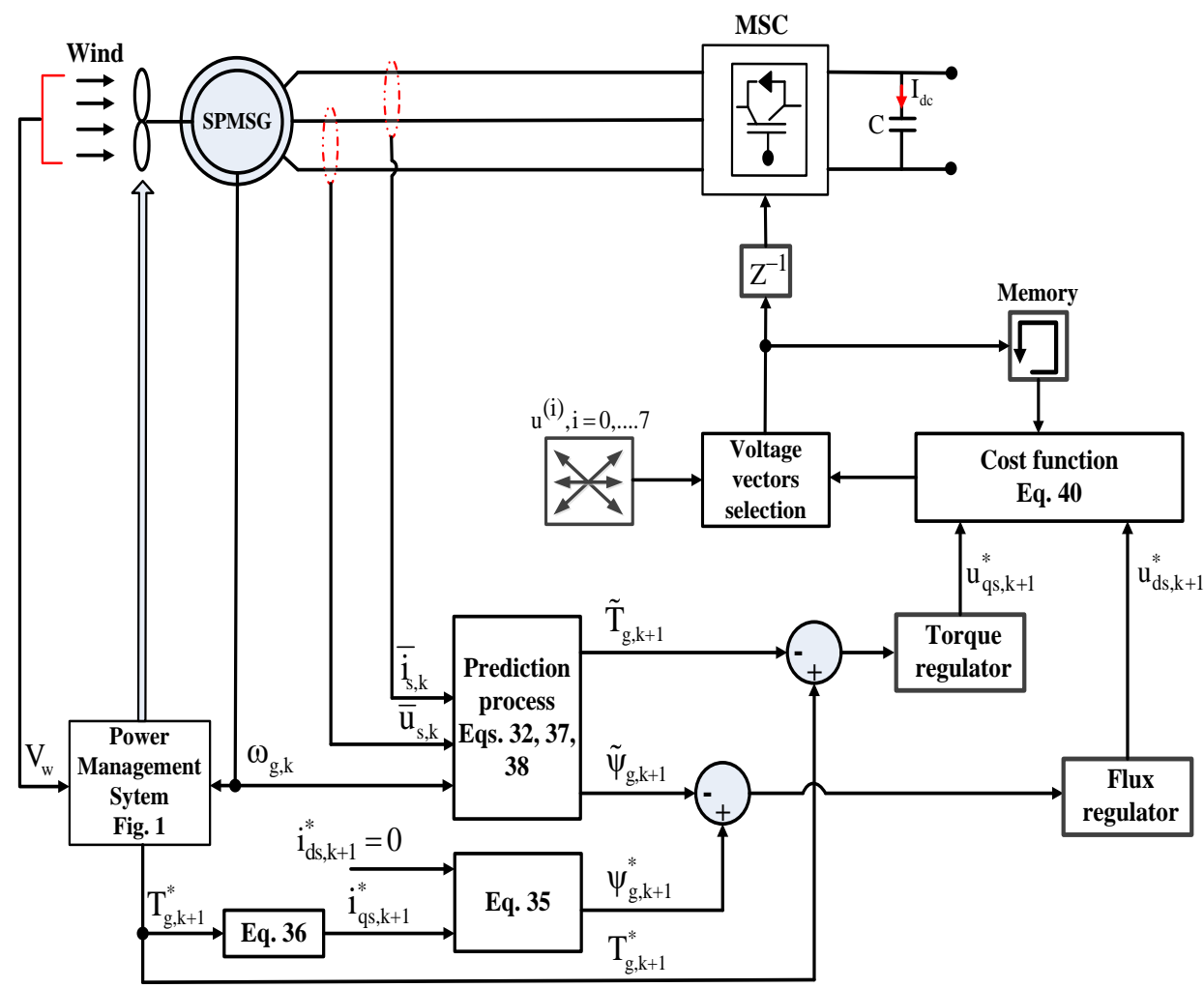

Figure 16. Proposed predictive voltage control scheme for the machine side converter.

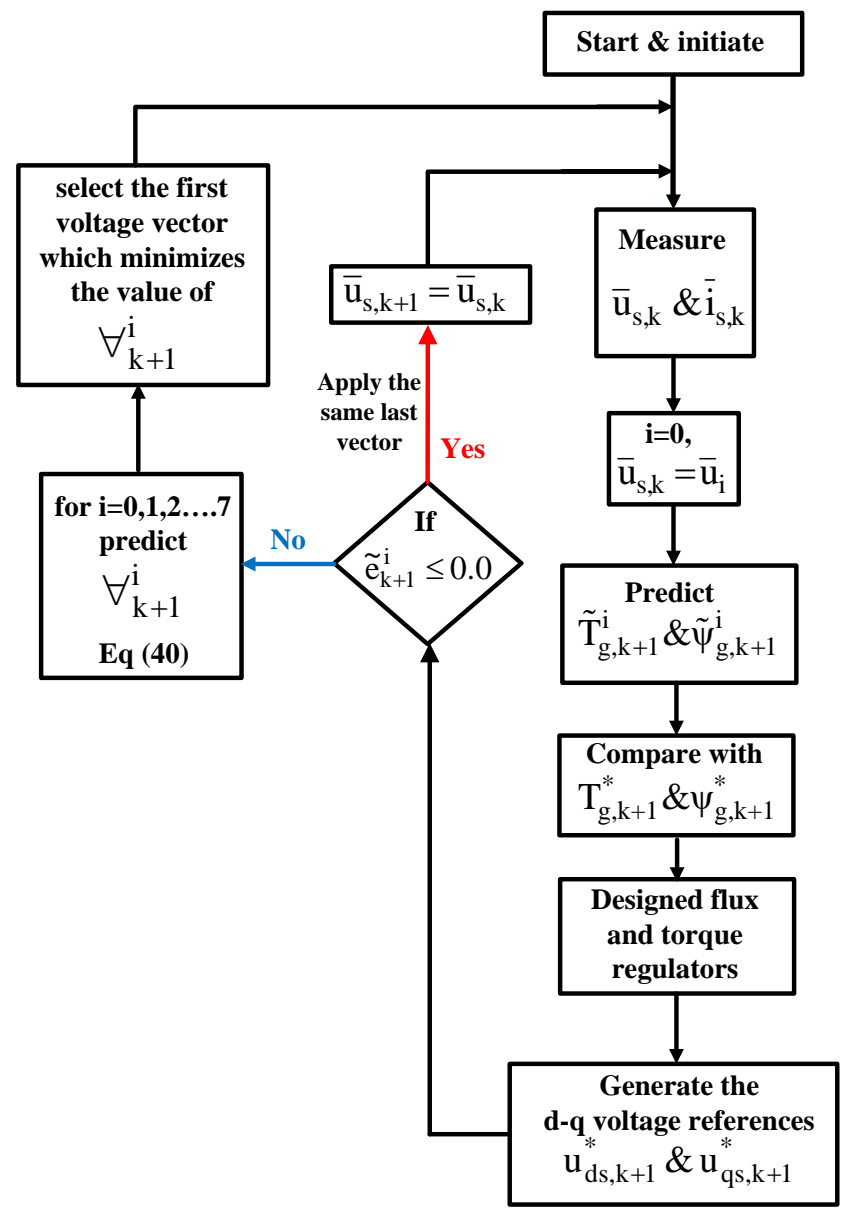

Figure 17. Sequence of predictive voltage control application. 


\section{Test Results}

\subsection{Grid Connected Operating Regime}

The first test was performed for the grid connection regime. The SPMSG was driven by the wind turbine system described in Figure 1. The machine side converter was controlled using the four described predictive controllers (MP DPC, MP DTC, MP CC and designed PVC); meanwhile the grid side converter was controlled only by the MP CC.

The wind speed profile is shown in Figure 18, with a nominal speed of $10 \mathrm{~m} / \mathrm{s}$. Figure 19 shows the generator speed under the four control approaches. From this figure, the generator speed tracks appropriately the wind speed variation, giving the designed PVC a priority in achieving a better smooth variation compared with the other techniques. Figure 20 illustrates the turbine power coefficient variation for the four techniques. From this figure, it is confirmed that the designed MPPT and blade pitch angle controllers effectively achieved their targets by achieving maximum wind power extraction below nominal speed and limiting the power above the nominal speed. This fact is also confirmed in Figures 21 and 22 which show the variation of the tip speed ratio $\mu$ and blade pitch angle $\beta$; both are switched from their normal values when the wind speed goes above the nominal.

The generator performance was also evaluated using the four control algorithms. The results are presented in a comparative manner. Figure 23 shows the generator active and reactive powers, from which it is confirmed that the designed PVC exhibits the least ripples content in comparison with the others. In addition, Figure 23 confirms the validity of the control systems in achieving proper tracking for the wind power regime, as the active power follows the wind variation profile, while the reactive power is maintained at zero. Figure 24 shows a zoomed view for the power variation to illustrate the detailed power dynamics under different controllers. Figure 25 illustrates the generator torque profiles for the four controllers, from which the superiority of the designed PVC algorithm is also confirmed. Figure 26 illustrates the profiles of the $d-q$ components of the generator stator current. A zoomed view for the $d-q$ current components is shown in Figure 27 to illustrate the deviation from the reference currents under different control systems. In this figure, the PVC control ensures the least current oscillation. In addition, the $d$-axis component is maintained at zero while the $q$-axis current follows the variation in the power and torque.

The ripples statistics of the generator variables are summarized in Table 1, from which it is confirmed that the proposed PVC exhibits the lowest compared to the other predictive controllers.

Table 1. Generator variables ripples (deviation from reference signals) under grid connection mode.

\begin{tabular}{ccccc}
\hline & MP DPC & MP DTC & MP CC & PVC \\
\hline Generator active power ripples & $\pm 189.5 \mathrm{~W}$ & $\pm 128.8 \mathrm{~W}$ & $\pm 78.6 \mathrm{~W}$ & $\pm 38.8 \mathrm{~W}$ \\
Generator reactive power ripples & $\pm 141.4 \mathrm{Var}$ & $\pm 122.6 \mathrm{Var}$ & $\pm 76.2 \mathrm{Var}$ & $\pm 29.6 \mathrm{Var}$ \\
Generator torque ripples & $\pm 2.23 \mathrm{Nm}$ & $\pm 1.38 \mathrm{Nm}$ & $\pm 0.71 \mathrm{Nm}$ & $\pm 0.39 \mathrm{Nm}$ \\
D-axis stator current ripples & $\pm 0.66 \mathrm{~A}$ & $\pm 0.39 \mathrm{~A}$ & $\pm 0.19 \mathrm{~A}$ & $\pm 0.096 \mathrm{~A}$ \\
Q-axis stator current ripples & $\pm 1.21 \mathrm{~A}$ & $\pm 0.88 \mathrm{~A}$ & $\pm 0.41 \mathrm{~A}$ & $\pm 0.22 \mathrm{~A}$ \\
\hline
\end{tabular}

The generator currents are also illustrated for the four control algorithms as shown in Figures 28-31, which represent the generated currents under MP DPC, MP DTC, MP CC and proposed PVC control, respectively. From these figures, it can be confirmed that the designed PVC algorithm presents the least current harmonics compared with the others, which validates the effectiveness of the PVC. This was also investigated by applying FFT analysis for the generated currents as is presented later. 


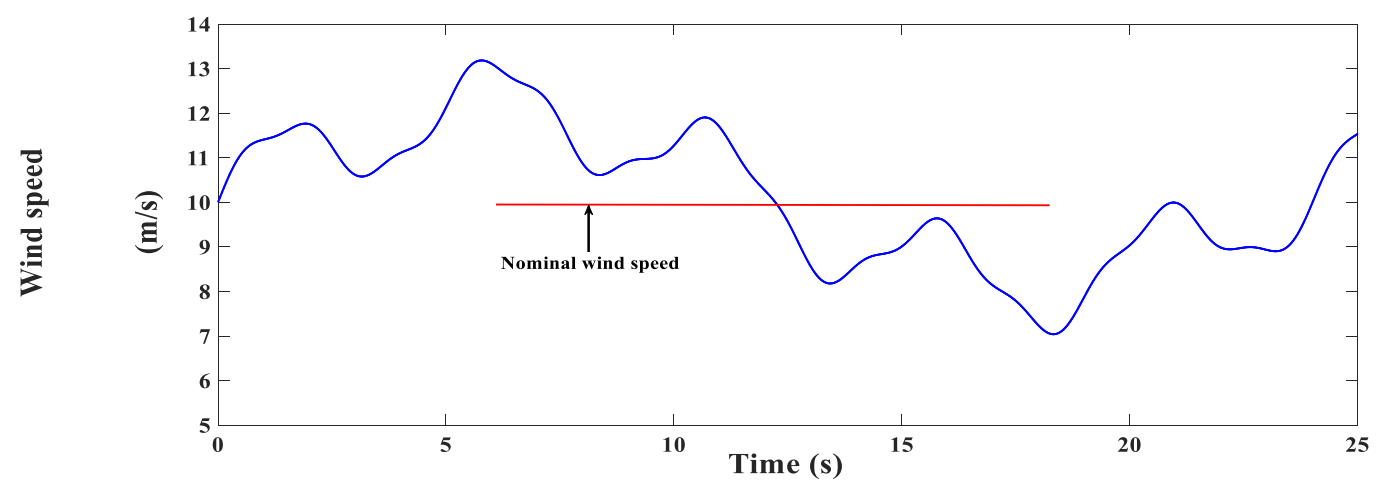

Figure 18. Wind speed profile.

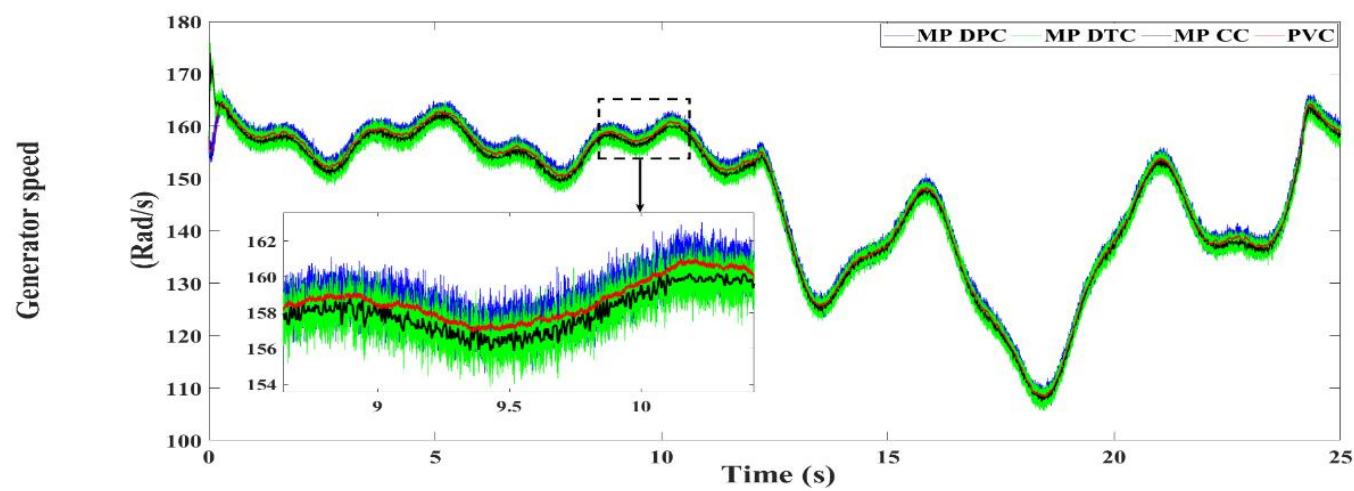

Figure 19. Generator speed for the grid connection regime.

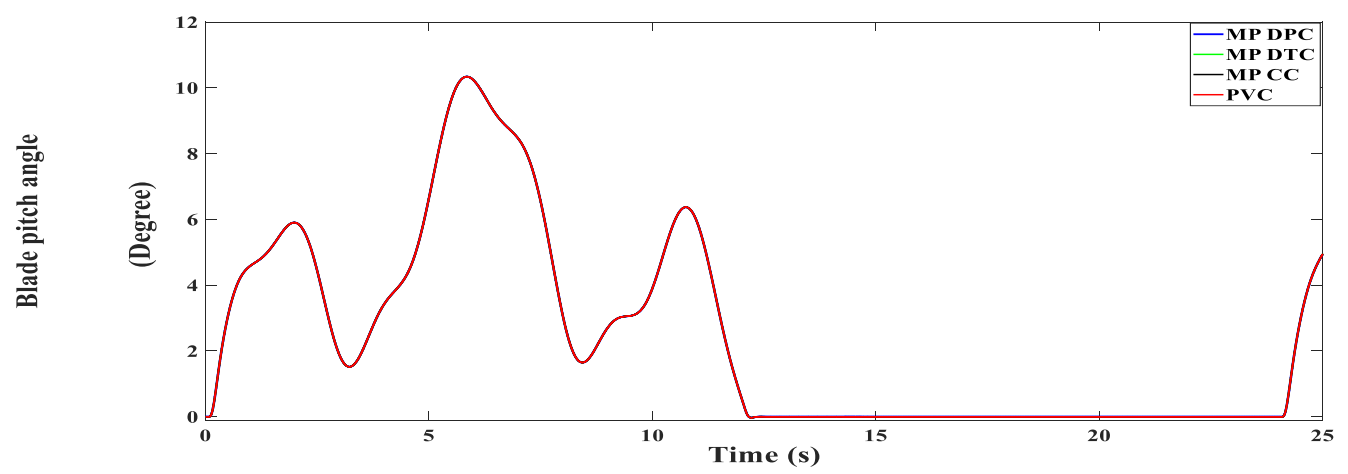

Figure 20. Turbine power coefficient for the grid connection regime.

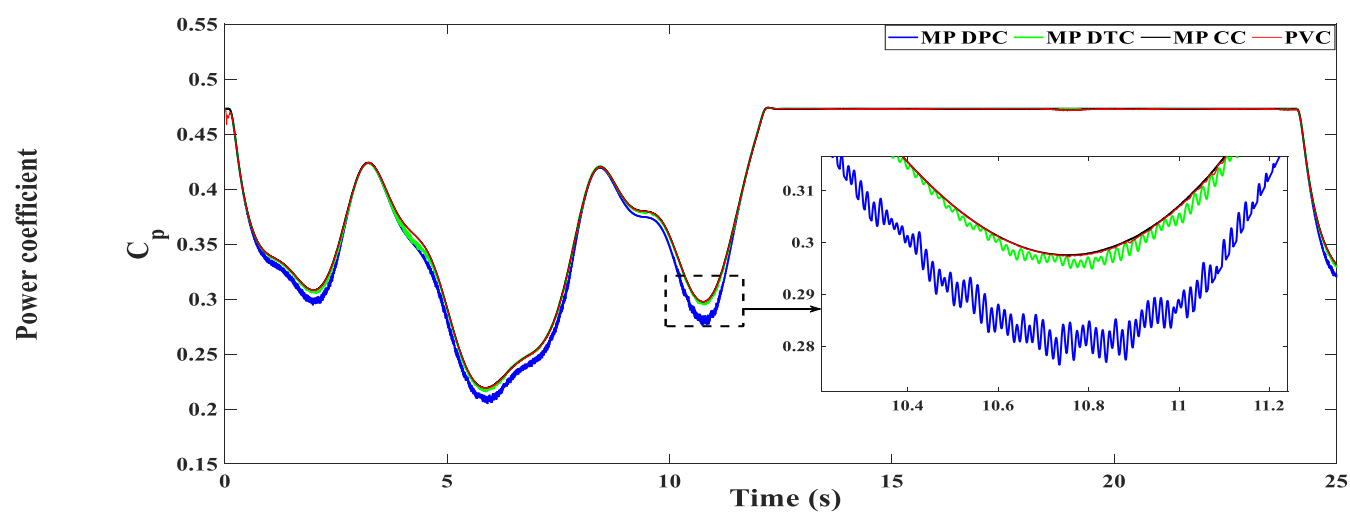

Figure 21. Tip speed ratio for the grid connection regime. 


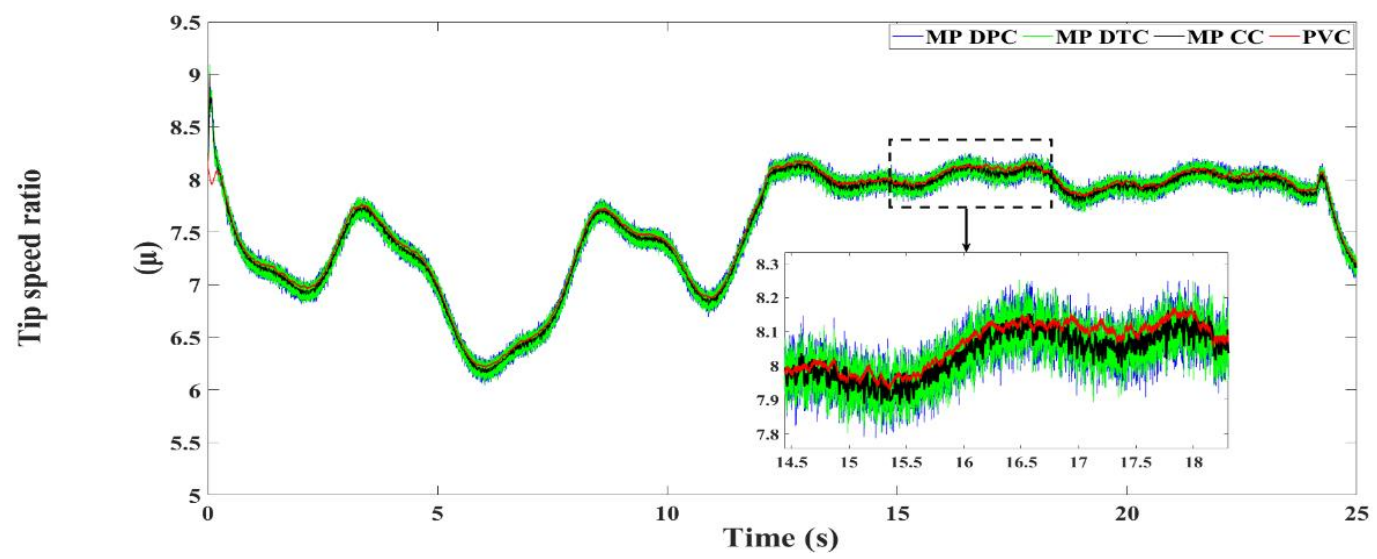

Figure 22. Blade pitch angle for the grid connection regime.

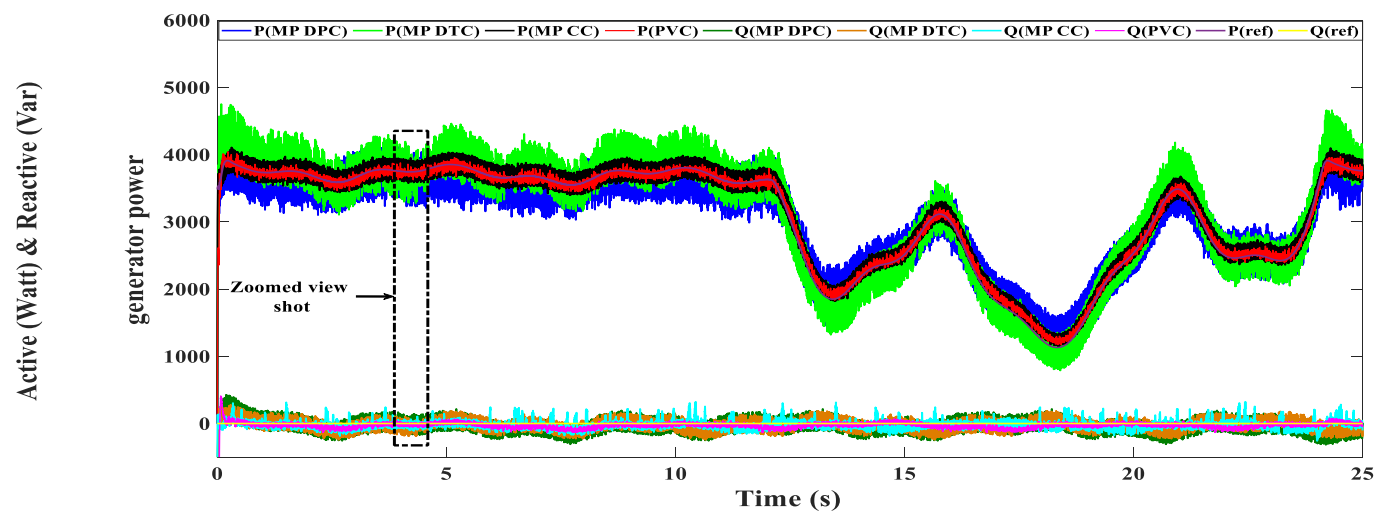

Figure 23. PMSG active and reactive powers for the grid connection regime.

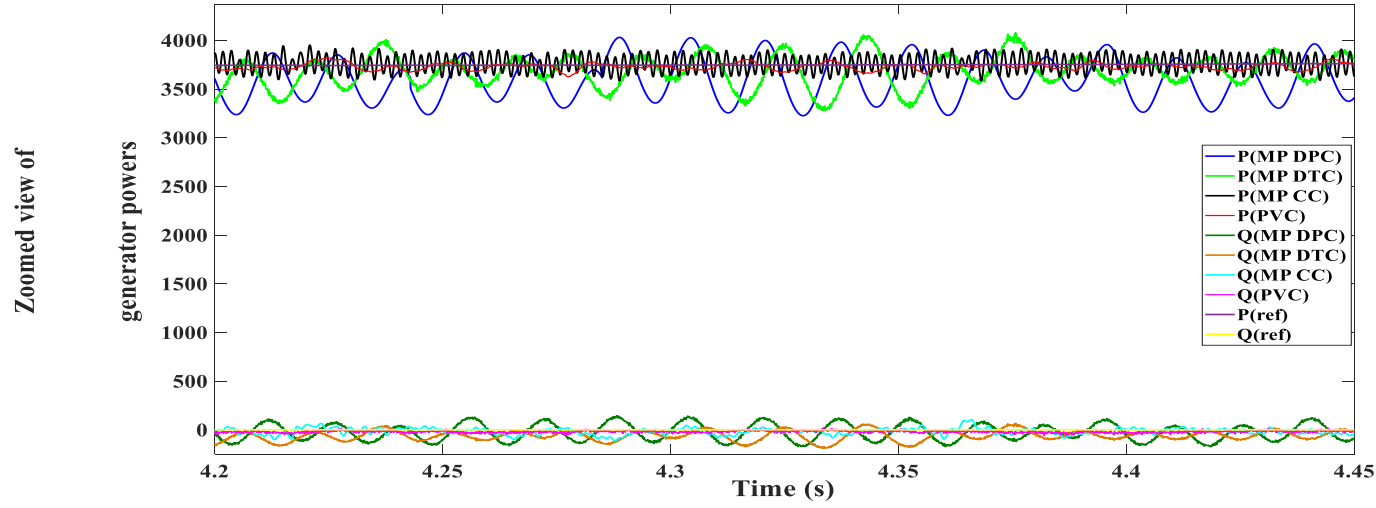

Figure 24. Zoomed view of active and reactive generator powers.

The grid side quantities were also measured. Figure 32 shows the active and reactive powers at the grid side. From this figure it is confirmed that the PVC provides optimal dynamics by limiting ripples. A zoomed view of the grid power variation is presented in Figure 33 to illustrate power dynamics. Figure 34 shows the $d-q$ components of the grid current, in which the $d$-axis is held to zero following the reactive power, which is maintained at zero to achieve unity pf operation. On the other hand, the $q$-current component follows the active power variation. A detailed view for the current components is shown in Figure 35. Finally, Figure 36 illustrates the DC link voltage profiles in which the PVC maintains the voltage at its reference $(400 \mathrm{~V})$ with minimum oscillations compared with the other techniques. All of these findings were also shown by the recorded grid variables ripples, as presented in Table 2. 


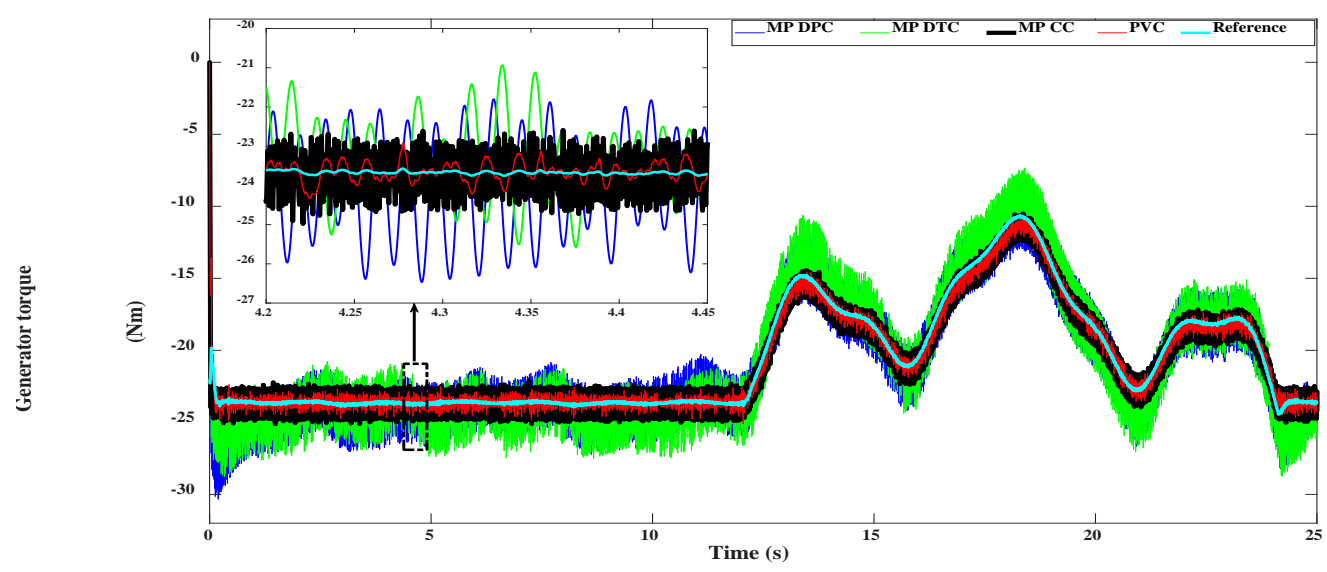

Figure 25. PMSG torque for the grid connection regime.

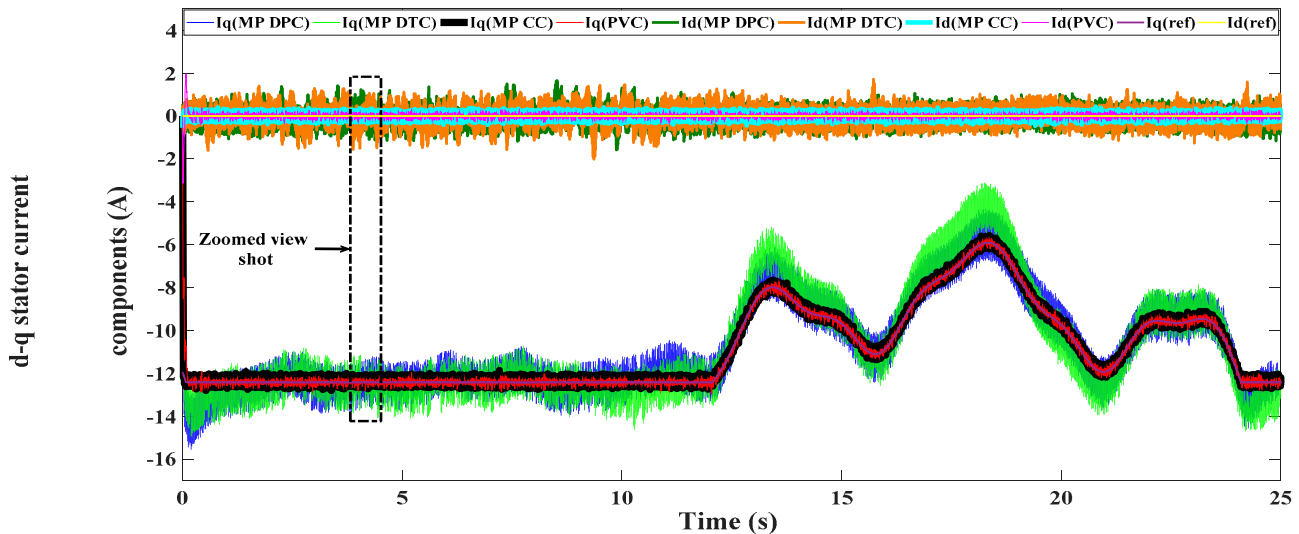

Figure 26. $d-q$ stator current components for the grid connection regime.

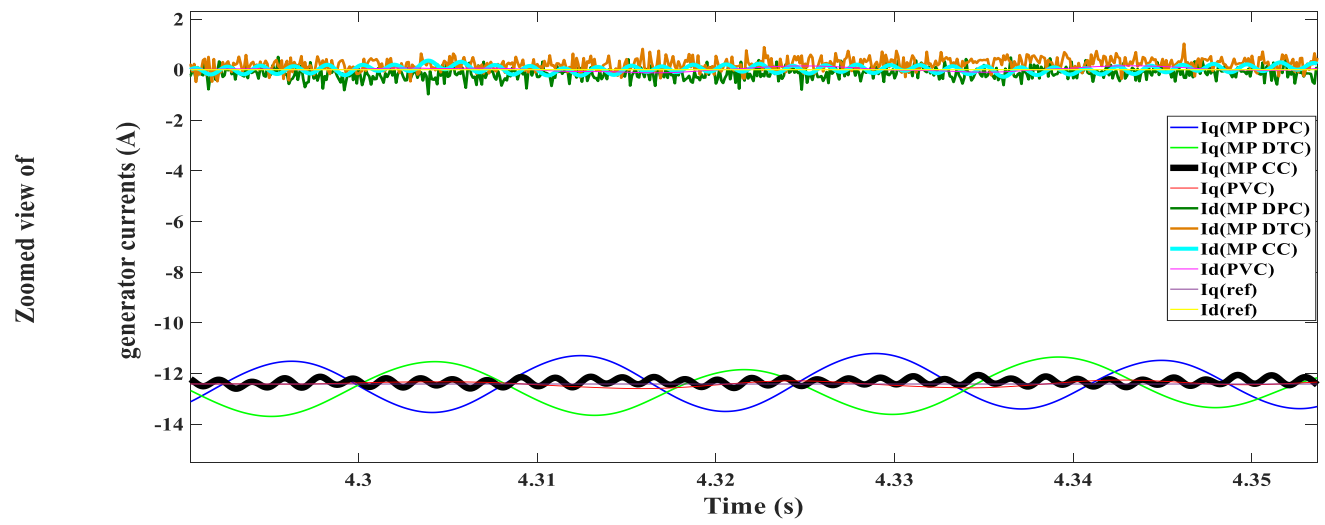

Figure 27. Zoomed view of $d-q$ stator current components.

Table 2. Grid variables ripples (deviation from reference signals).

\begin{tabular}{ccccc}
\hline & MP DPC & MP DTC & MP CC & PVC \\
\hline Grid active power ripples & $\pm 298.7 \mathrm{~W}$ & $\pm 223.3 \mathrm{~W}$ & $\pm 145.8 \mathrm{~W}$ & $\pm 103.6 \mathrm{~W}$ \\
Grid reactive power ripples & $\pm 138.6 \mathrm{Var}$ & $\pm 106.2 \mathrm{Var}$ & $\pm 81.7 \mathrm{Var}$ & $\pm 46.8 \mathrm{Var}$ \\
D-axis grid current ripples & $\pm 0.51 \mathrm{~A}$ & $\pm 0.38 \mathrm{~A}$ & $\pm 0.22 \mathrm{~A}$ & $\pm 0.16 \mathrm{~A}$ \\
Q-axis grid current ripples & $\pm 1.54 \mathrm{~A}$ & $\pm 1.16 \mathrm{~A}$ & $\pm 0.63 \mathrm{~A}$ & $\pm 0.24 \mathrm{~A}$ \\
DC link voltage ripples & $\pm 2.6 \mathrm{~V}$ & $\pm 1.8 \mathrm{~V}$ & $\pm 0.8 \mathrm{~V}$ & $\pm 0.3 \mathrm{~V}$ \\
\hline
\end{tabular}




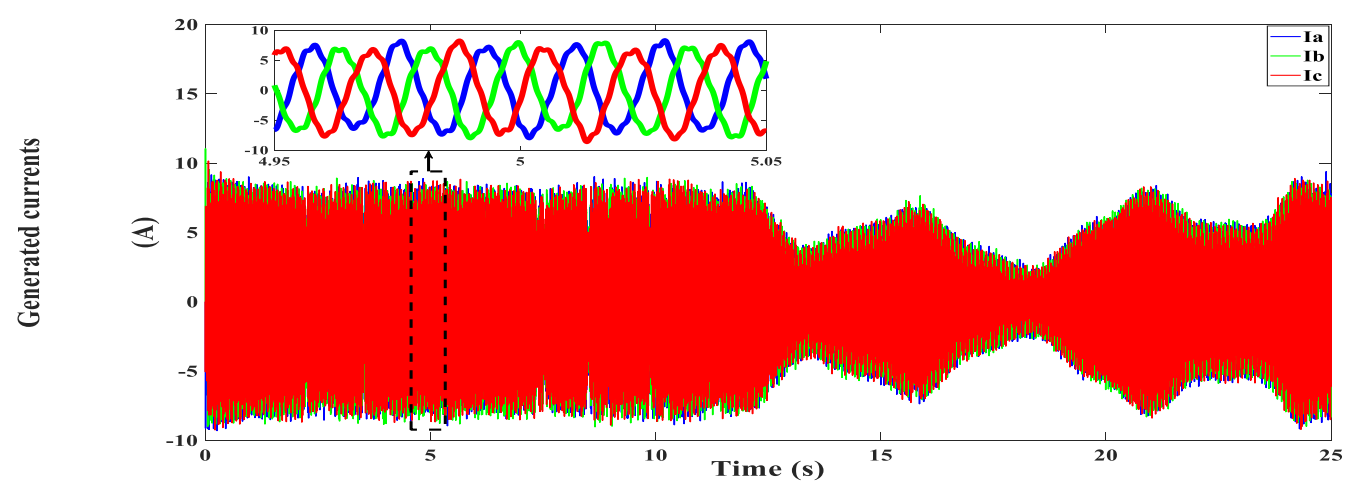

Figure 28. Generator currents under MP DPC for the connection regime.

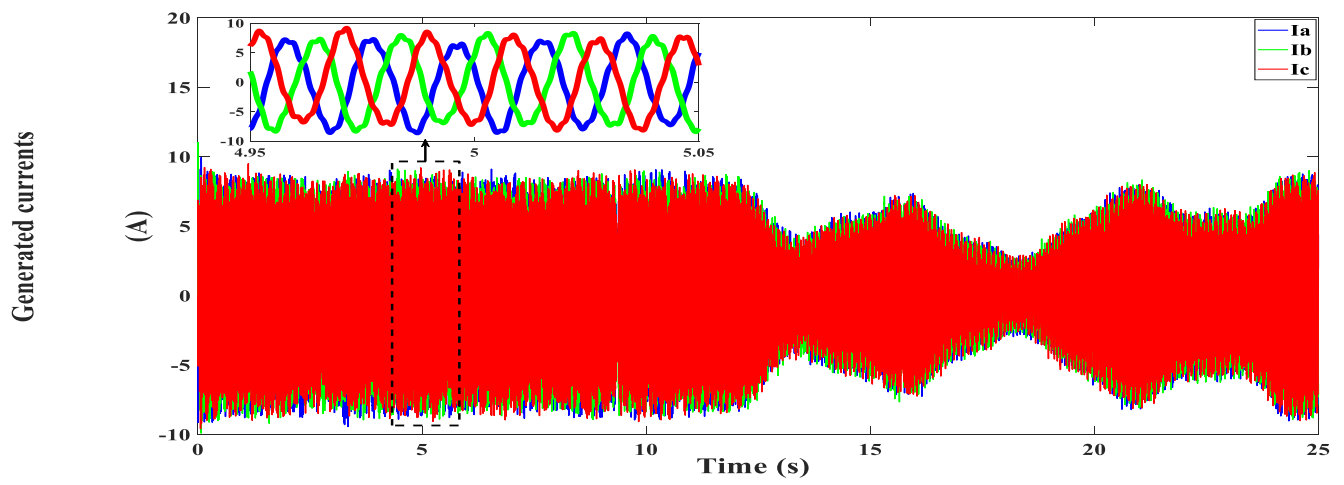

Figure 29. Generator currents under MP DTC for the grid connection regime.

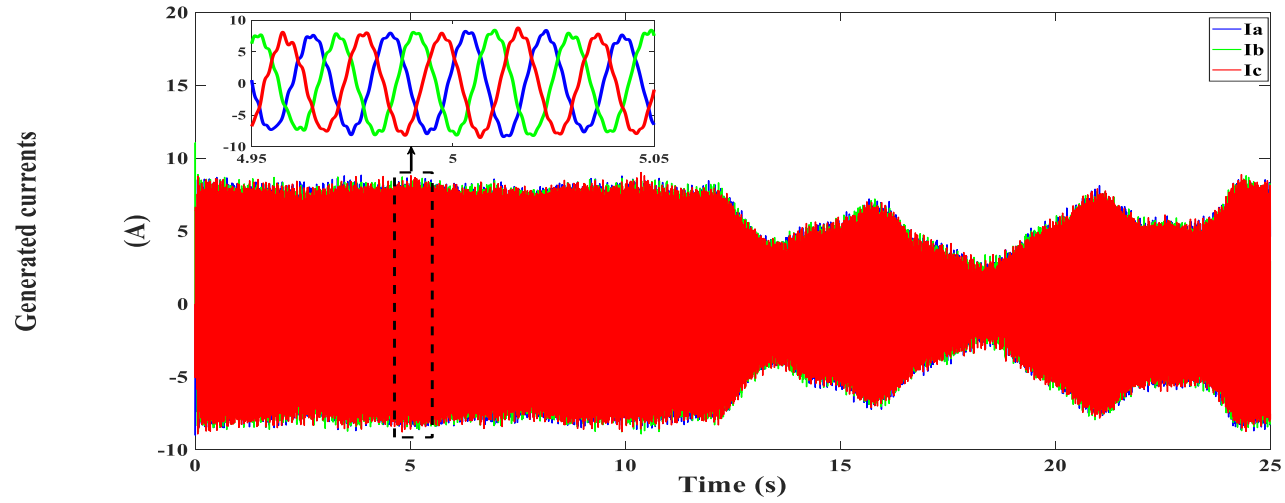

Figure 30. Generator currents under MP CC for the grid connection regime.

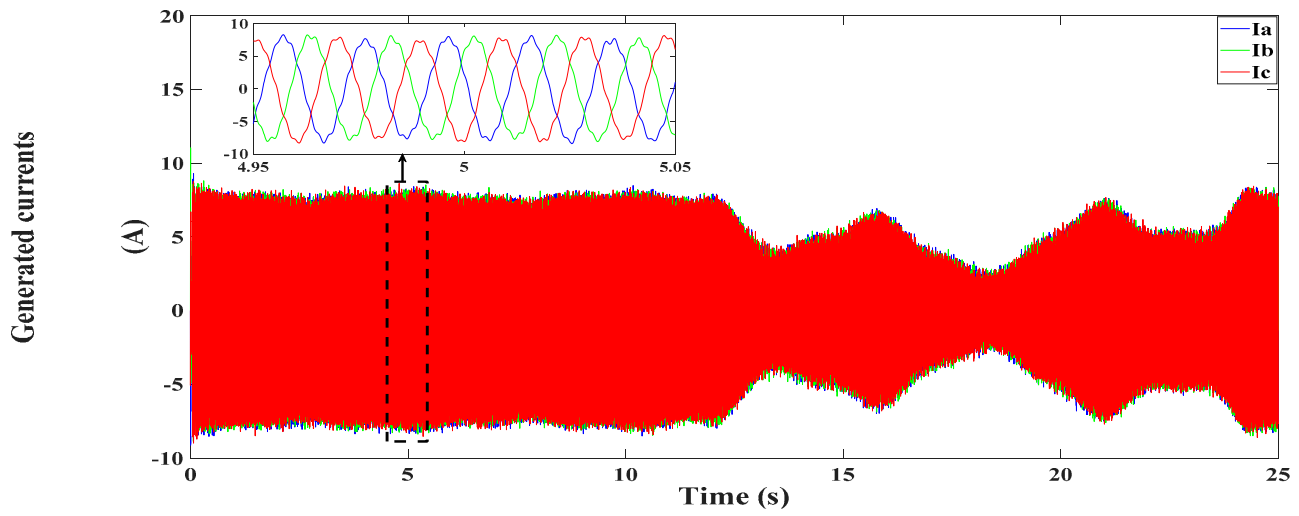

Figure 31. Generator currents under PVC for the grid connection regime. 


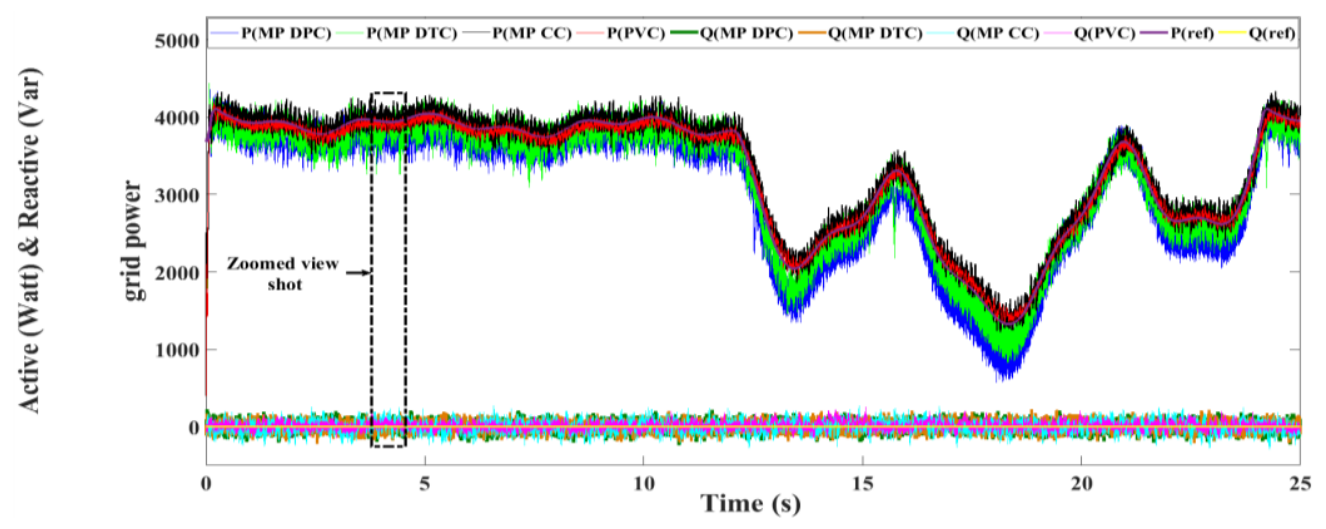

Figure 32. Grid powers.

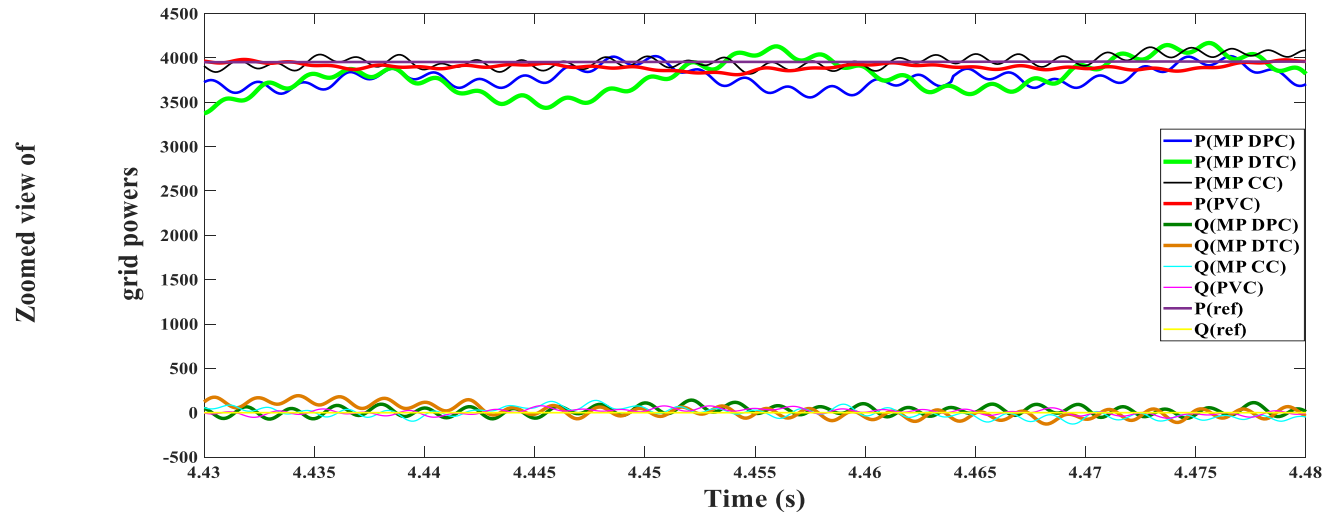

Figure 33. Zoomed view of grid powers.

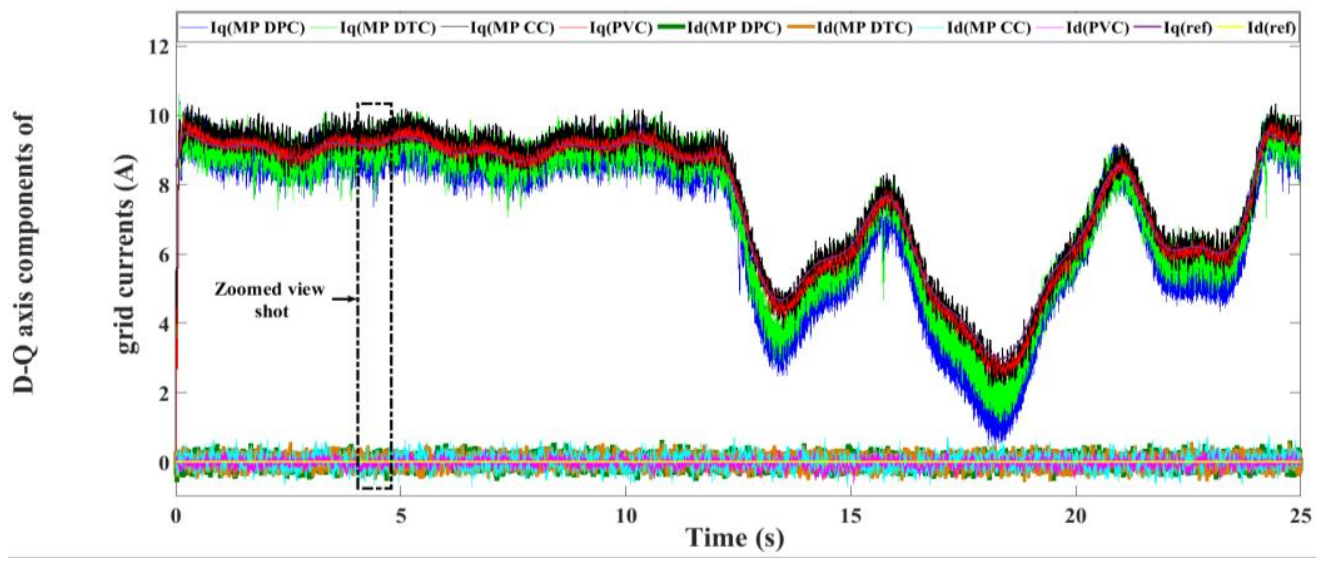

Figure 34. $d-q$ components of grid currents.

The comparison made between the four controllers in terms of the number of commutations and the results is shown in Table 3, which shows that the PVC has the least number of commutations and contributes effectively to reducing the computation burden that is considered one of the main challenges of predictive control schemes.

As stated earlier, FFT analysis was used to analyse the generated current ripples with the four predictive controllers. Figures 37-40 illustrate the three phase stator currents and their relevant current spectra for the four controllers, respectively. Checking the spectrum analysis figures, it is confirmed that the proposed PVC provides the lowest THD percentage. The THD analysis is also presented statistically in Table 4. 


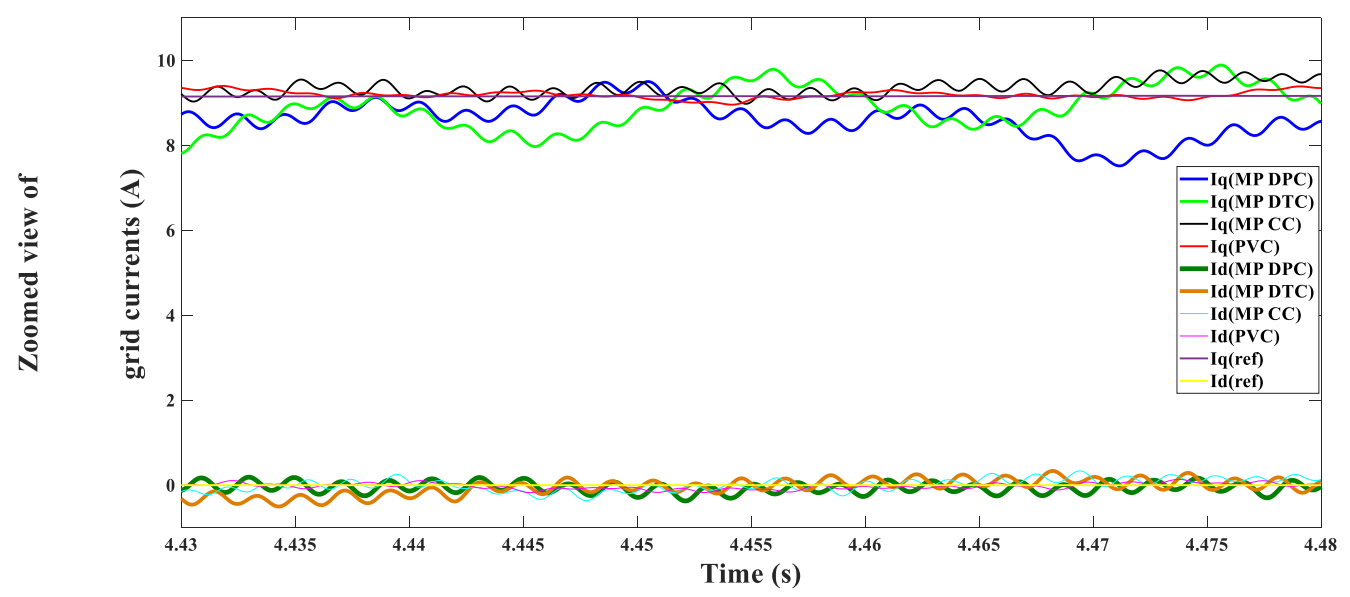

Figure 35. Zoomed view of $d-q$ components of grid currents.

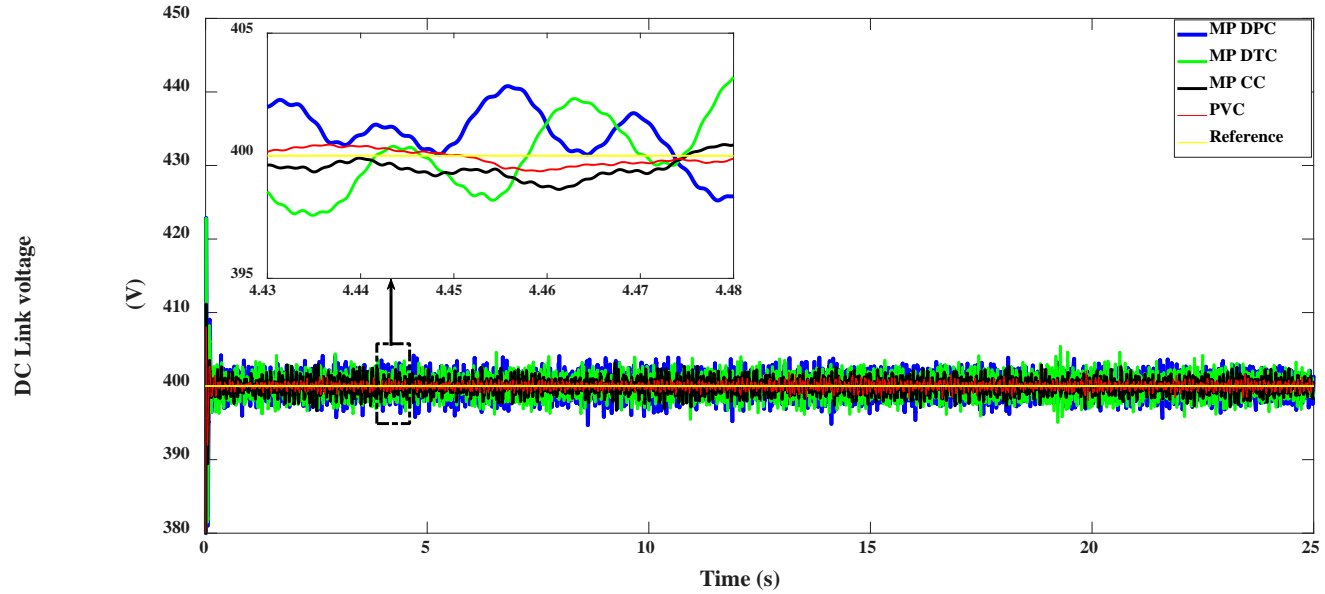

Figure 36. DC link voltage for the grid connection regime.

Table 3. Number of commutations for the four controllers.

\begin{tabular}{cc}
\hline Technique & Number of Commutations \\
\hline MP DPC & 31430 \\
MP DTC & 30130 \\
MP CC & 65340 \\
PVC & 8394 \\
\hline
\end{tabular}

The FFT spectrum analysis for the generated currents are presented in numerical form in Table 4. The statistics confirm the effectiveness of the proposed PVC in achieving lower THD in generated current signals in comparison with the other techniques.

Table 4. FFT analysis of generated currents for the four predictive controllers for the grid connection case.

\begin{tabular}{ccccc}
\hline Current Phase & MP DPC & MP DTC & MP CC & Proposed PVC \\
\hline \multirow{2}{*}{ Phase 'a' } & Fundamental (6.31943 A) & Fundamental (7.04328 A) & Fundamental (7.65033 A) & Fundamental (7.5305 A) \\
& THD (10.56\%) & THD (5.12\%) & THD (3.26\%) & THD (1.87\%) \\
Phase ' $b$ ' & Fundamental (6.31223 A) & Fundamental (7.21395 A) & Fundamental (7.5826 A) & Fundamental (7.5062 A) \\
& THD (11.26\%) & THD (4.55\%) & THD (3.41\%) & THD (1.88\%) \\
Phase 'c' & Fundamental (5.91479 A) & Fundamental (7.03298 A) & Fundamental (7.6745 A) & Fundamental (7.6875 A) \\
& THD (17.97\%) & THD (6.04\%) & THD (2.44\%) & THD (1.34\%) \\
\hline
\end{tabular}



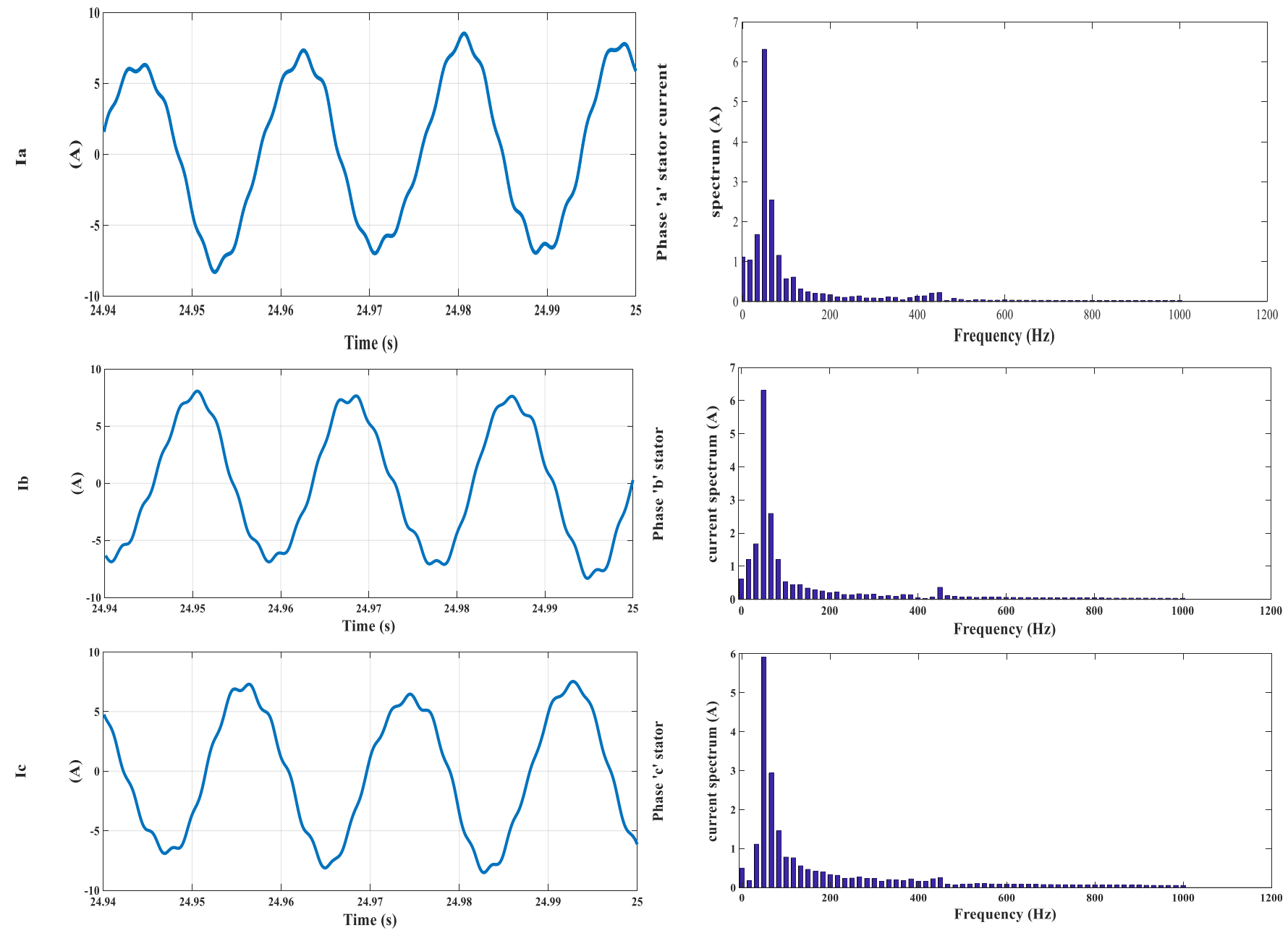

Figure 37. Generated currents and their relevant spectrum analysis using the MP DPC approach.
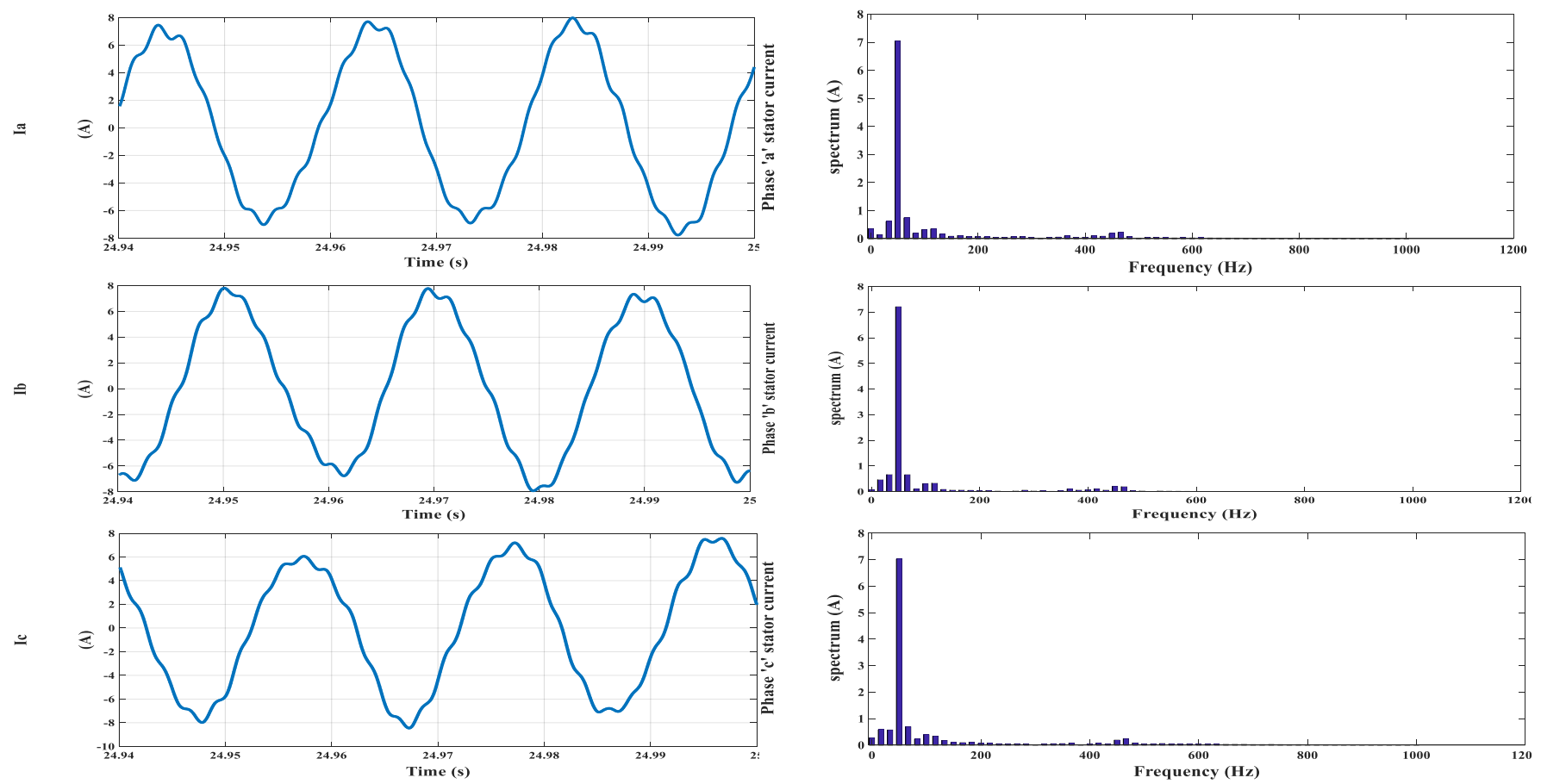

Figure 38. Generated currents and their relevant spectrum analysis using the MP DTC approach. 

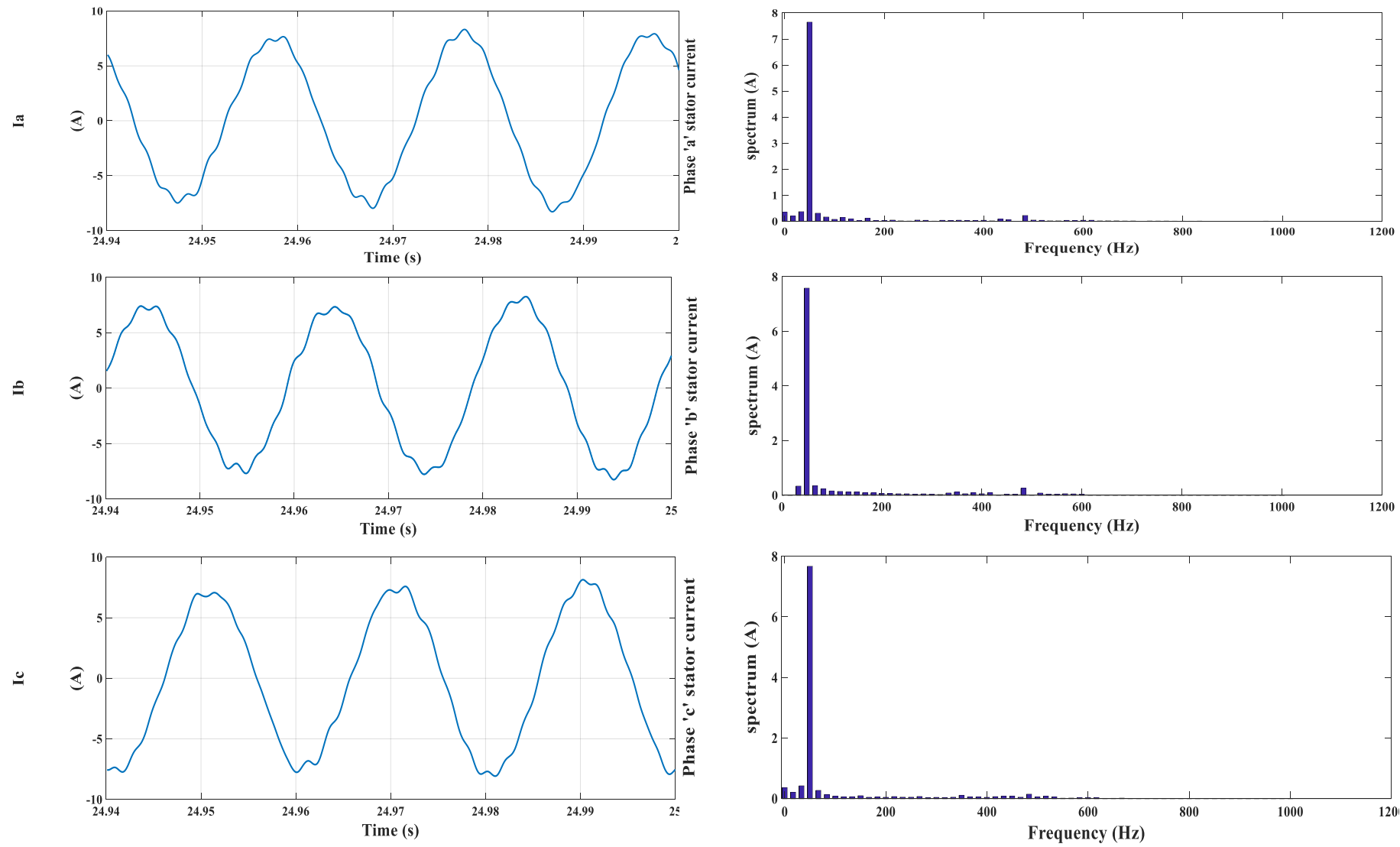

Figure 39. Generated currents and their relevant spectrum analysis using the MP CC approach.
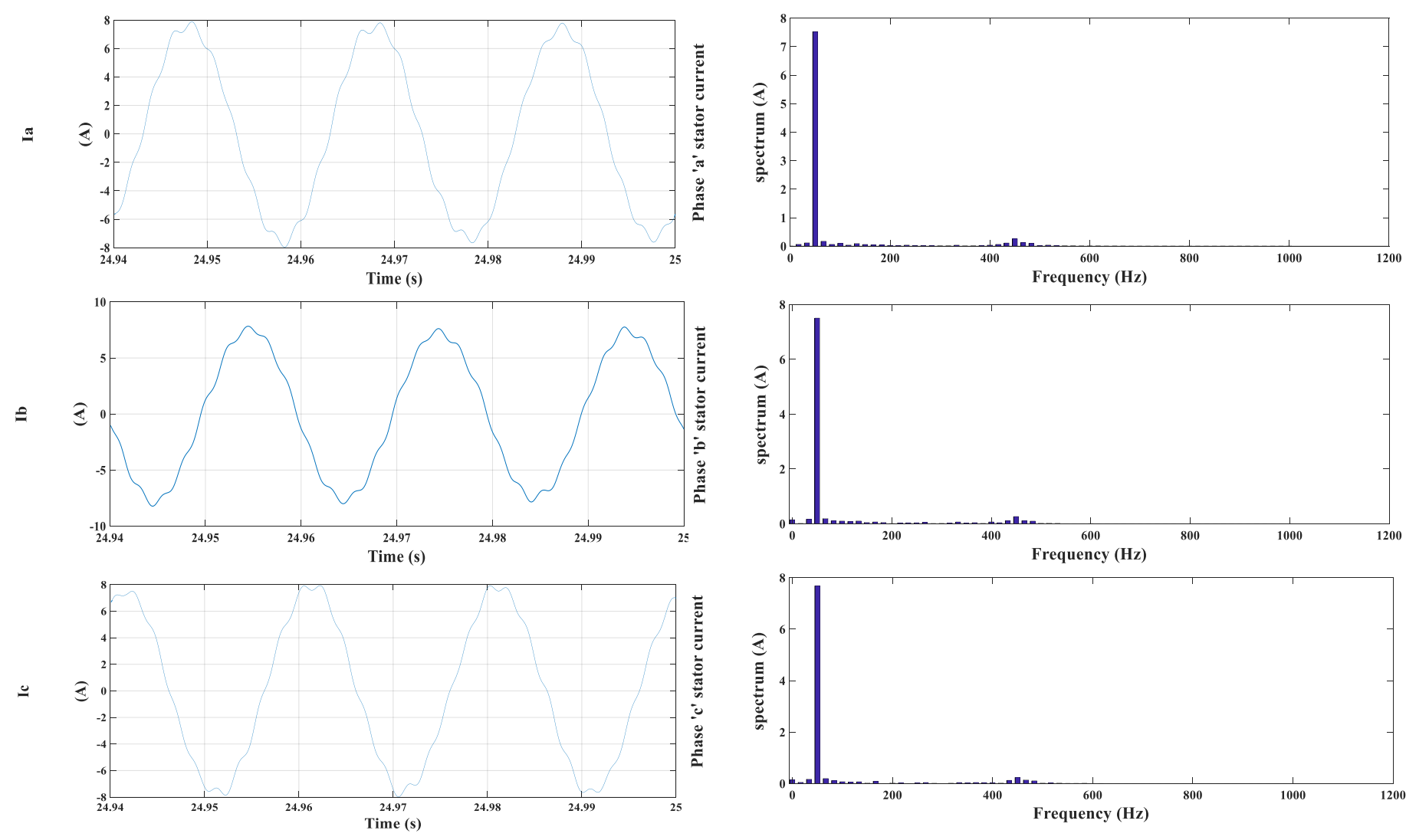

Figure 40. Generated currents and their relevant spectrum analysis using the proposed PVC approach. 


\subsection{Stand-Alone Operating Regime}

The dynamic performance of the four controllers was also tested under stand-alone operation in which the wind generation system was connected to an average DC isolated load and connected to a battery storage system. This test illustrated the effectiveness of the power handling/management system used to regulate the power flow between the SPMSG, DC link, load and battery system. The comparison was performed mainly for the PMSG generator quantities. In addition, the power flow and current flow between the different system units are also presented for the four controllers.

Figure 41 illustrates the wind speed profile, which is different from that used in Section 4.1 to test the generator dynamics. Figures 42 and 43 show the general and detailed sectional views of generator active and reactive power using the four controllers. From these figures, it is shown that the designed PVC provided minimum power oscillations compared with the other controllers. This is confirmed in Figure 44 that shows the generator torque, which tracks the change in active power, and tracks the wind speed variation. Figure 45 provides the $d-q$ components of the generator current using the four controllers. The $d$-axis current is kept effectively at zero following the dynamic of the reactive power, which is also maintained at zero, while the $q$-axis current follows the change in the torque and active power. The superiority of the PVC is present in this figure through achieving the minimum $d-q$ current deviations. The generator current profiles for the four controllers are shown, respectively, in Figures 46-49, respectively. In these figures, the PVC exhibits the minimum current harmonics.

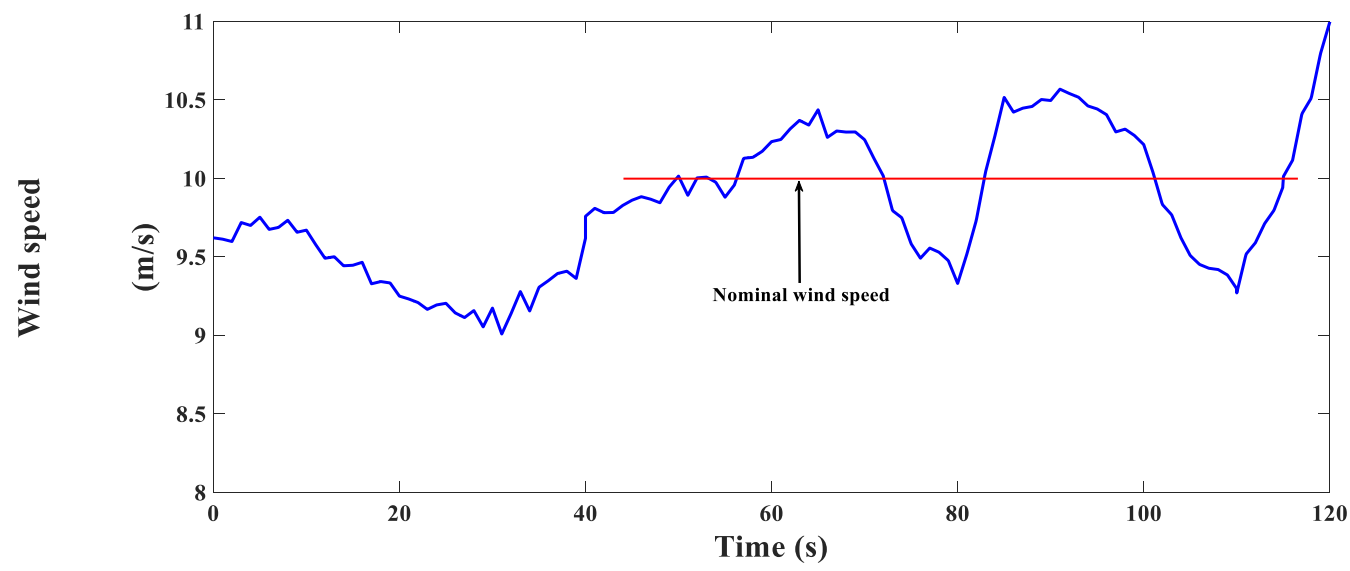

Figure 41. Wind speed profile for stand-alone operation.

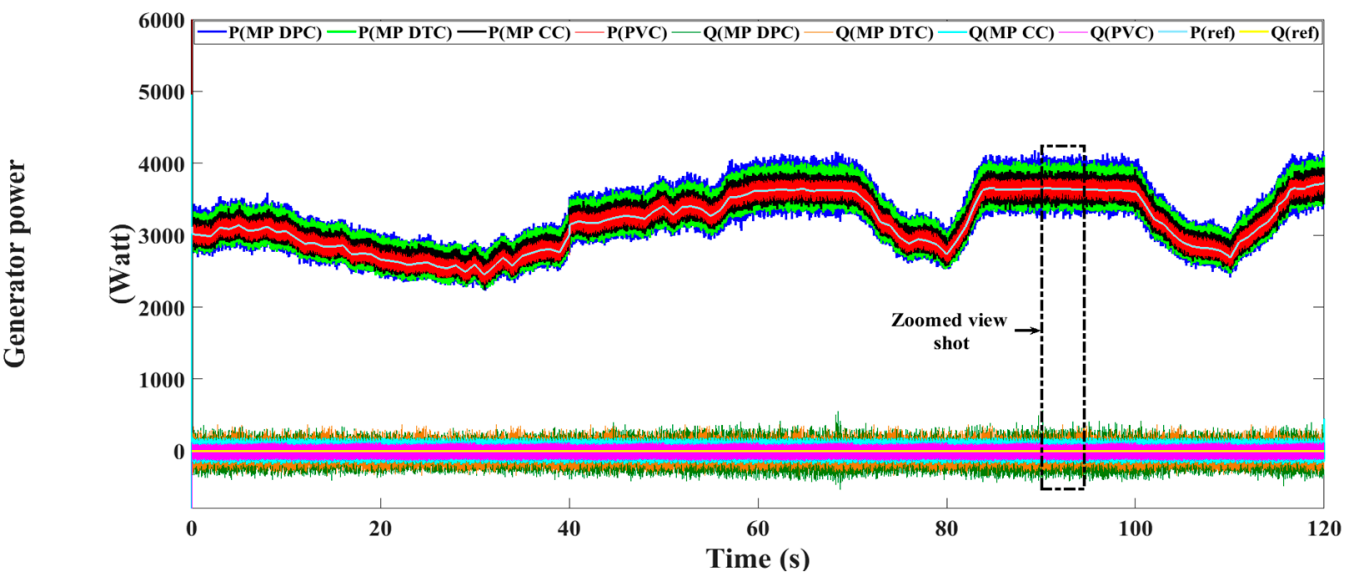

Figure 42. Active and reactive power of SPMSG for stand-alone operation. 


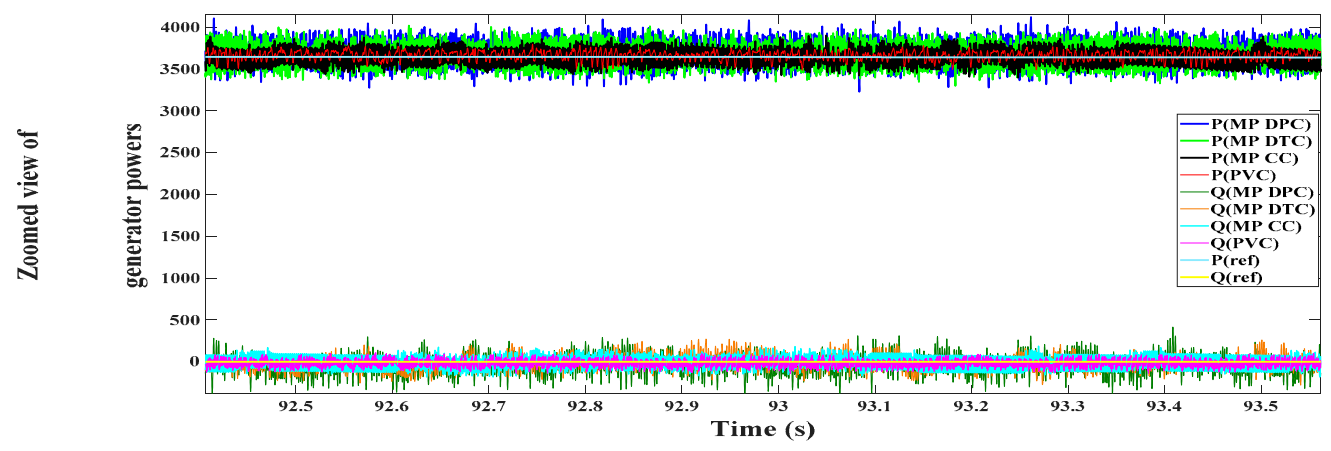

Figure 43. Detailed view of generator active and reactive powers.

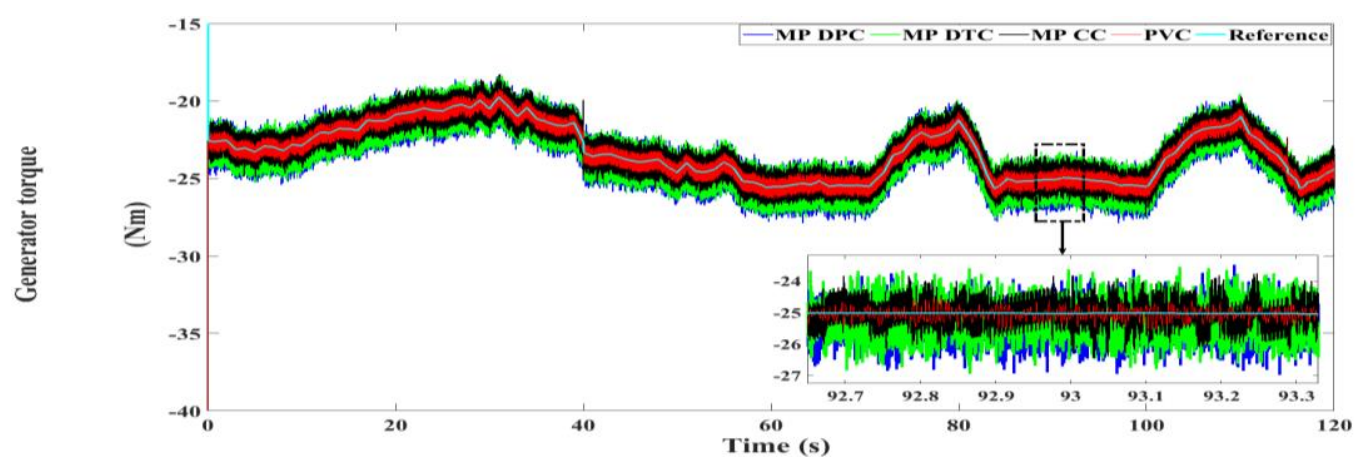

Figure 44. Generator torque for stand-alone operation.

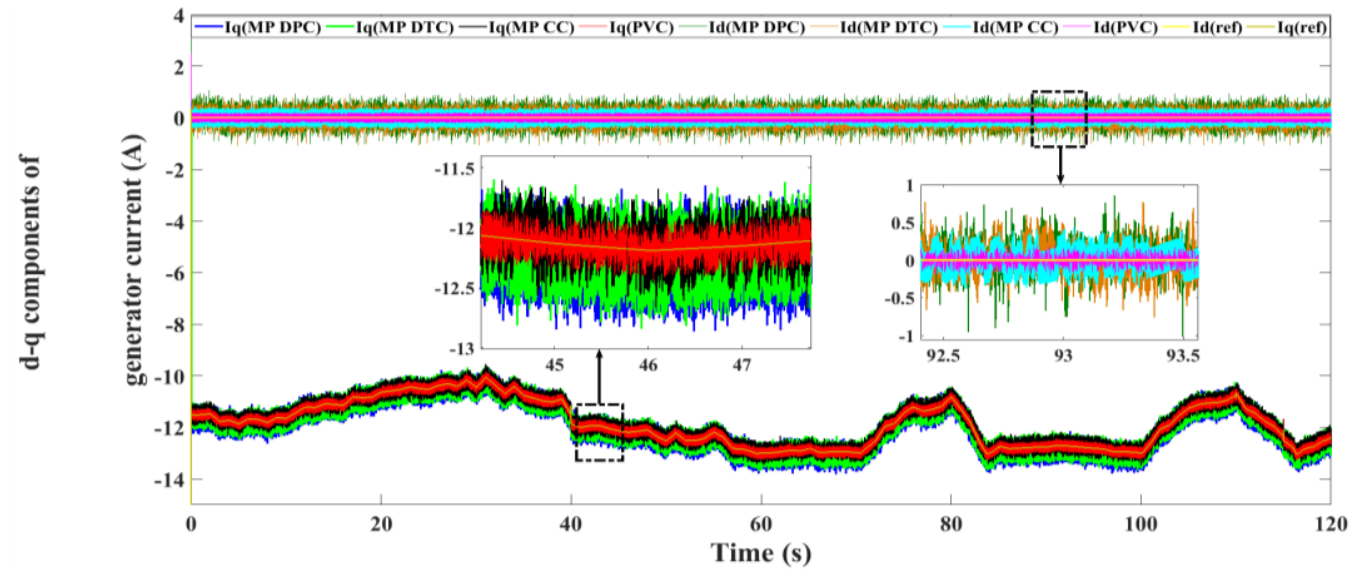

Figure 45. $d-q$ components of generator currents for stand-alone operation.

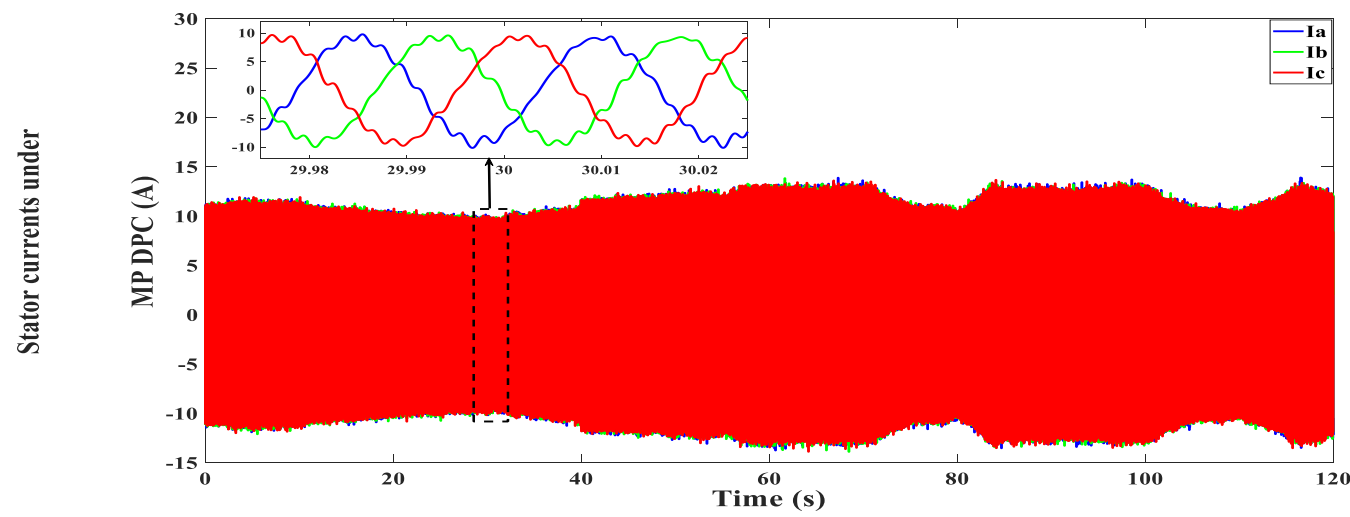

Figure 46. Generator currents under MP DPC for stand-alone operation. 


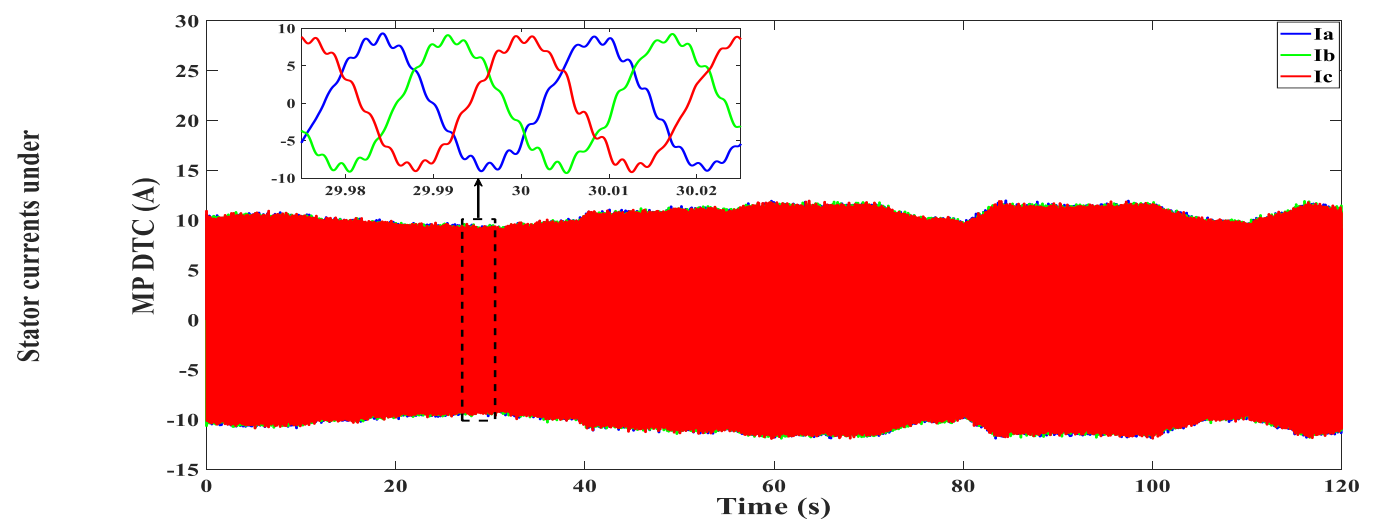

Figure 47. Generator currents under MP DTC for stand-alone operation.

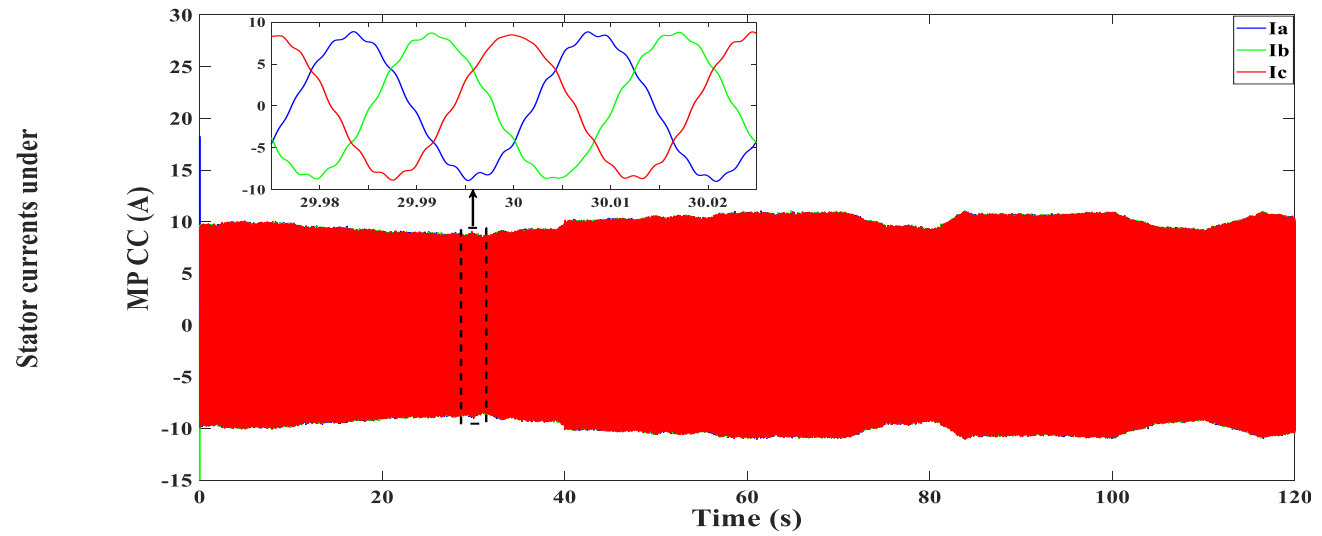

Figure 48. Generator currents under MP CC for stand-alone operation.

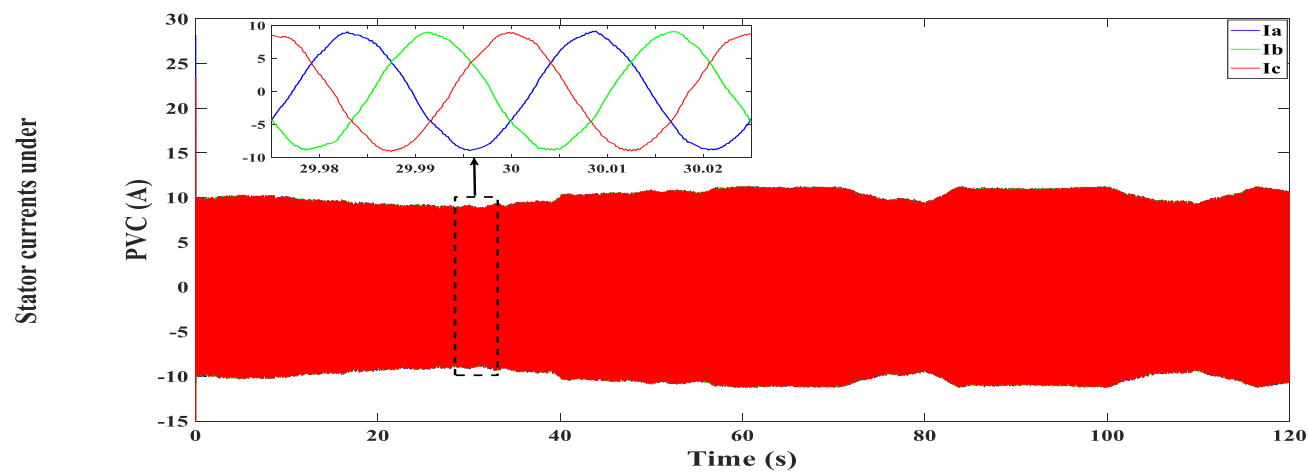

Figure 49. Generator currents under PVC for stand-alone operation.

To provide a detailed view of the generated current harmonics, FFT analysis was performed for the currents obtained using the four control techniques. The current spectra are shown, respectively, in Figures 50-53. From visual observation, it is clear that the PVC has the lowest current THD in comparison with the other three controllers. In addition, the THD analysis is presented numerically in Table 5. The THD statistics confirm the effectiveness of the proposed PVC in maintaining the lowest THD percentage.

The dynamics of the four controllers were also evaluated concerning power flow management between the generator, dc link, load and battery system. This is in addition to the illustration of battery charging/discharging states. 

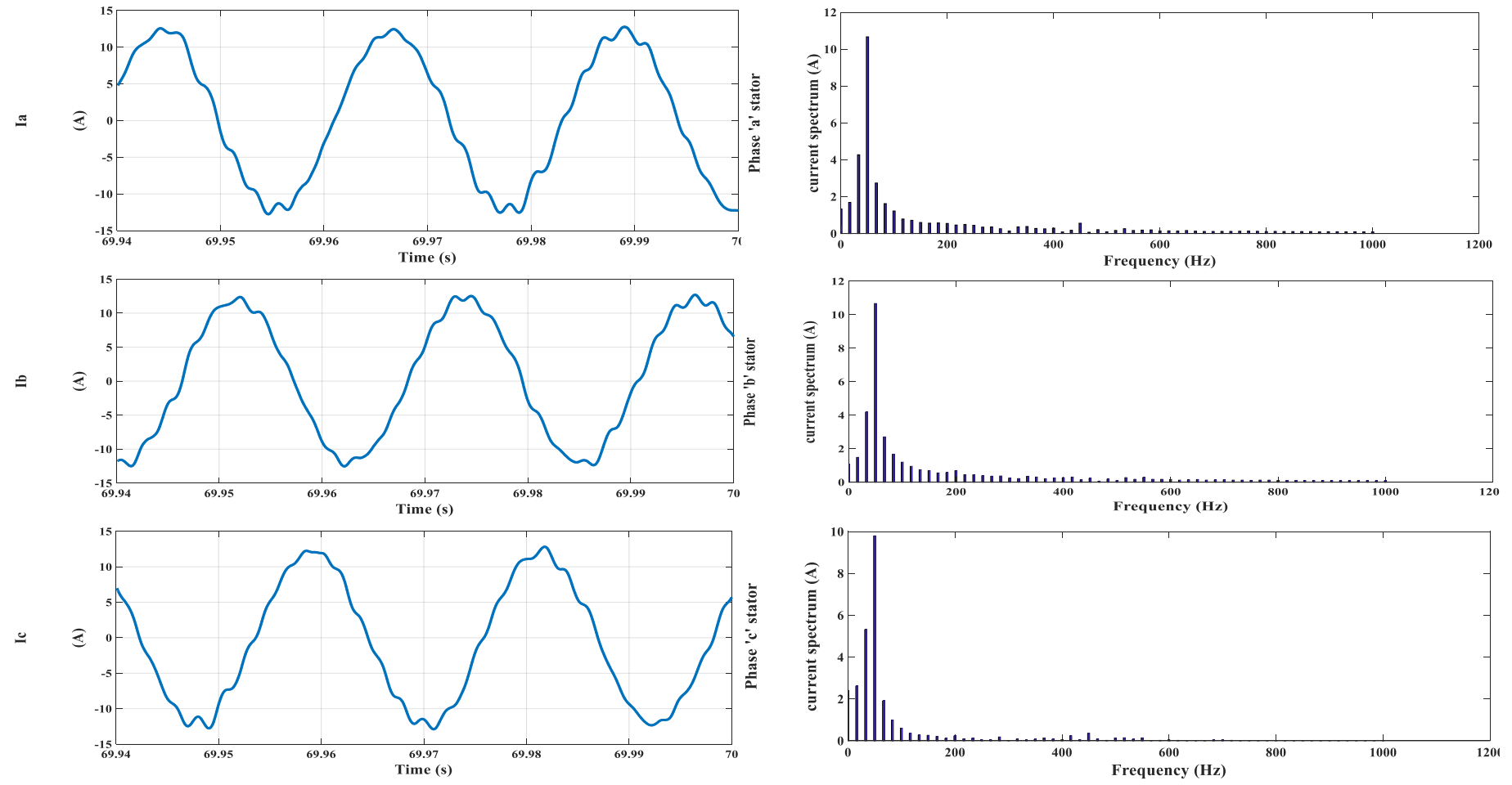

Figure 50. Generator currents and related FFT spectrum analysis using the MP DPC approach.

$\cong$
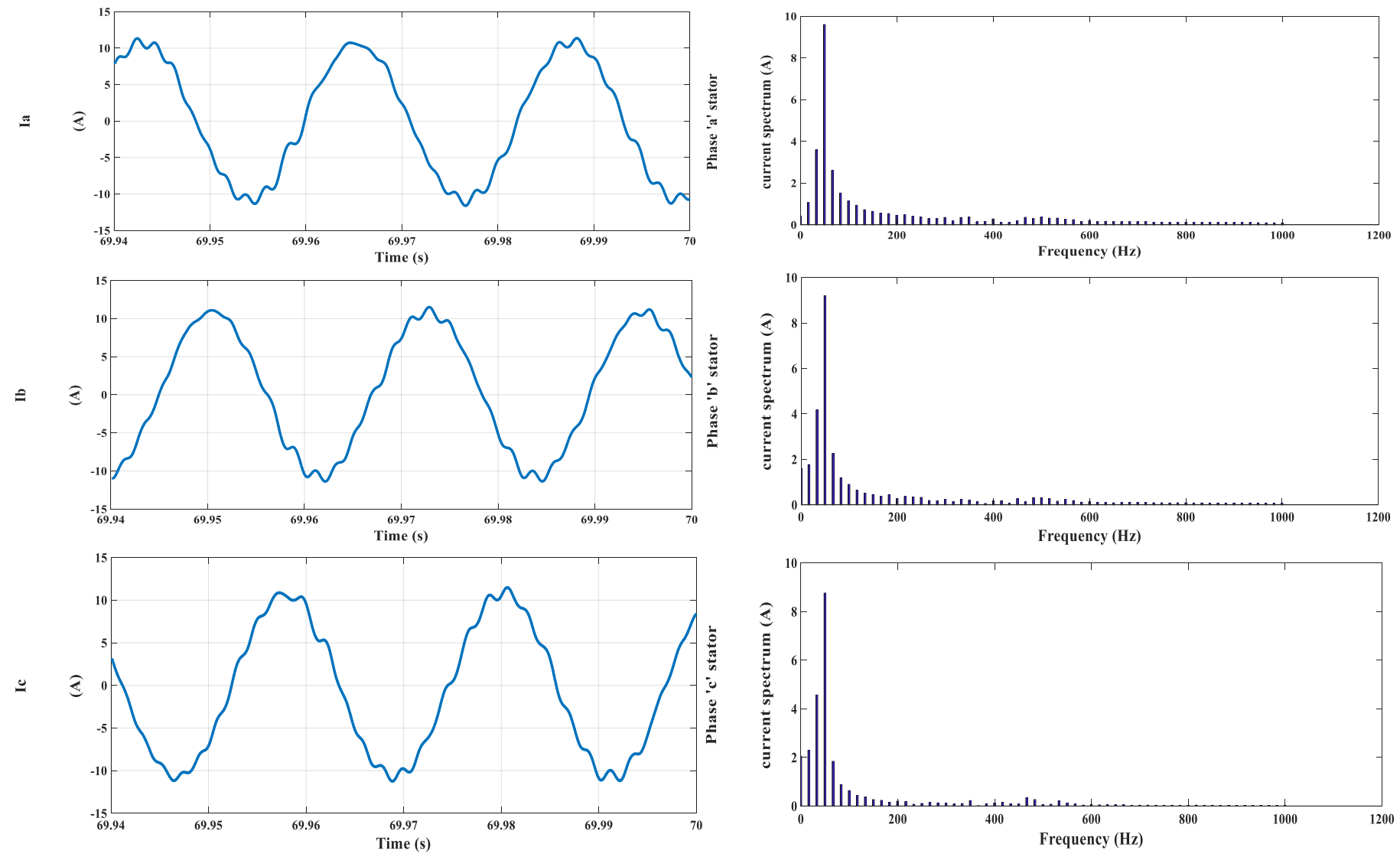

Figure 51. Generator currents and related FFT spectrum analysis using the MP DTC approach. 

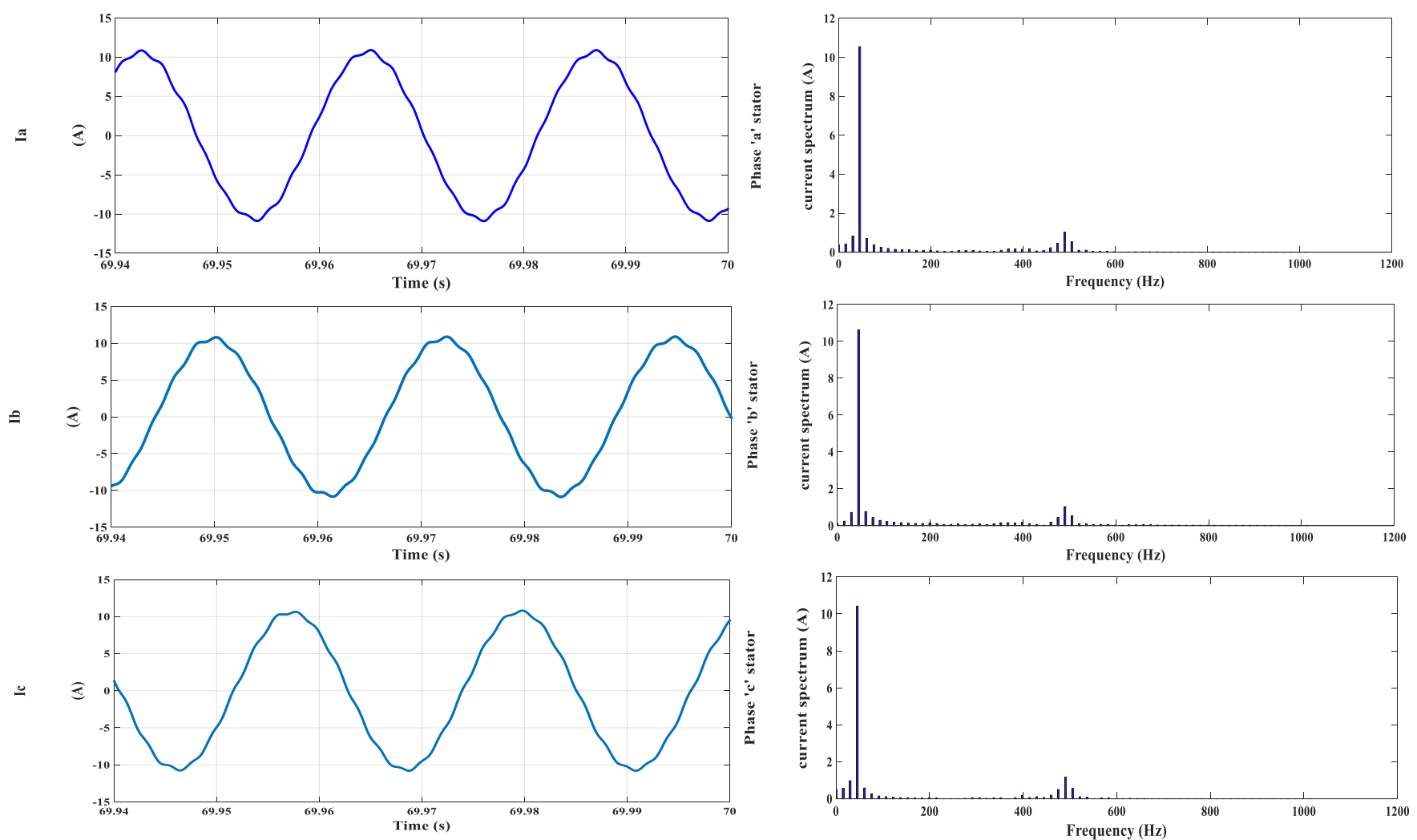

Figure 52. Generator currents and related FFT spectrum analysis using the MP CC approach.
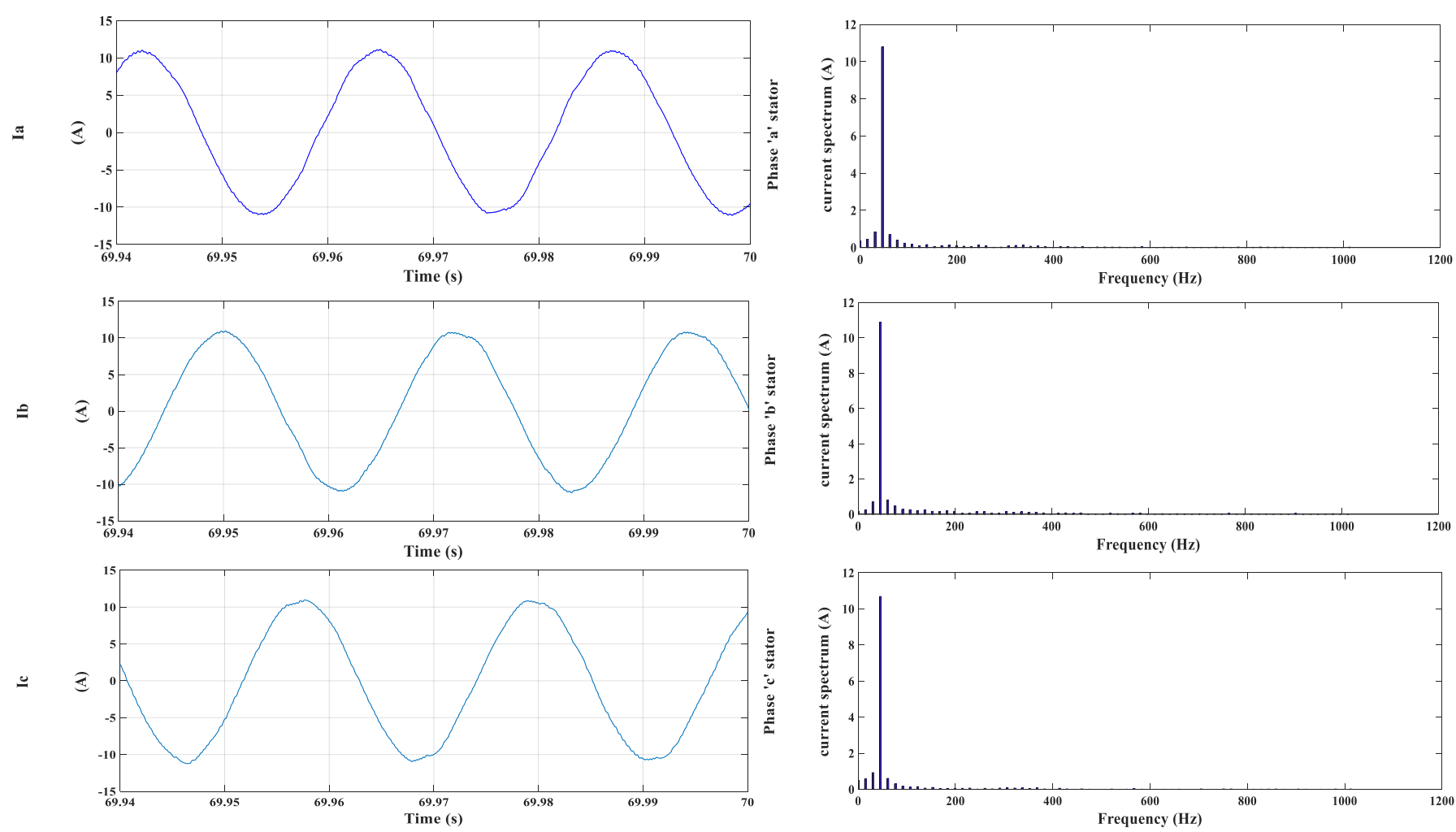

Figure 53. Generator currents and related FFT spectrum analysis using the proposed PVC approach. 
Table 5. FFT analysis of generated currents for the four predictive controllers for standalone operation.

\begin{tabular}{ccccc}
\hline Current Phase & MP DPC & MP DTC & MP CC & Proposed PVC \\
\hline \multirow{2}{*}{ Phase 'a' } & Fundamental (10.6698 A) & Fundamental (9.60881 A) & Fundamental (10.5553 A) & Fundamental (10.7981 A) \\
& THD (15.05\%) & THD (16.64\%) & THD (6.38\%) & THD (3.32\%) \\
Phase 'b' & Fundamental (10.6817 A) & Fundamental (9.20723 A) & Fundamental (10.6452 A) & Fundamental (10.9086 A) \\
& THD (16.04\%) & THD (12.64\%) & THD (6.30\%) & THD (4.07\%) \\
Phase 'c' & Fundamental (9.80714 A) & Fundamental (8.7651 A) & Fundamental (10.432 A) & Fundamental (10.6933 A) \\
& THD (12.51\%) & THD (9.21\%) & THD (5.67\%) & THD (2.39\%) \\
\hline
\end{tabular}

\subsubsection{Power Flow Using Model Predictive Direct Power Control}

Figures 54 and 55 illustrate the power flow and current flow for each system unit under the MP DPC. From these figures it is confirmed that the power management system has succeeded in making a power balance between the different units. However, the ripples in the generator power and current are obvious. Figure 56 illustrates the battery voltage, battery current and SOC of the battery.

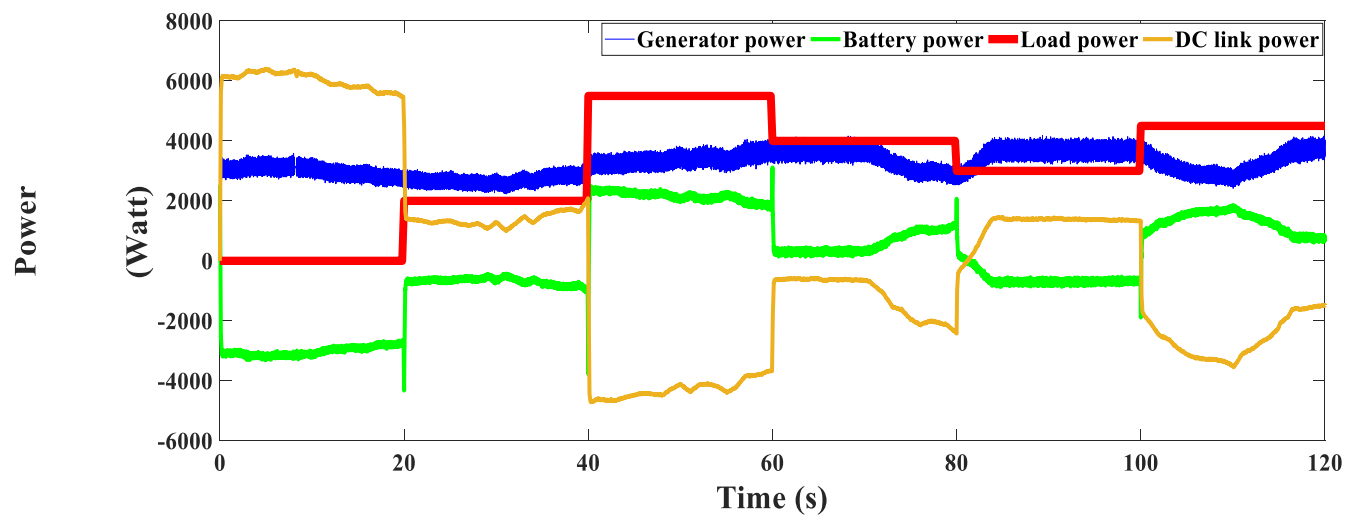

Figure 54. Power flow in different system units using MP DPC.

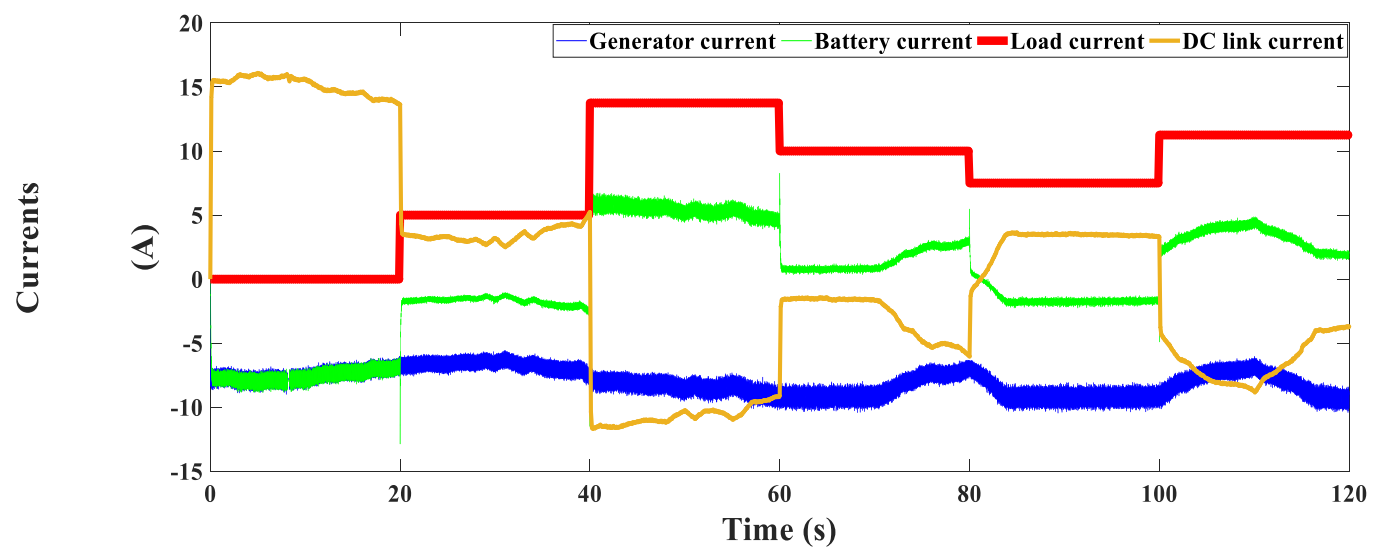

Figure 55. Currents flow in different system units using MP DPC.

\subsubsection{Power Flow Using Model Predictive Direct Torque Control}

The power and current flow under the MP DTC is illustrated in Figures 57 and 58 with similar observations concerning ripples of the generator power and current. Power management between each unit is confirmed and can be easily identified. Figure 59 shows the battery voltage, battery current and SOC under MP DTC control. 

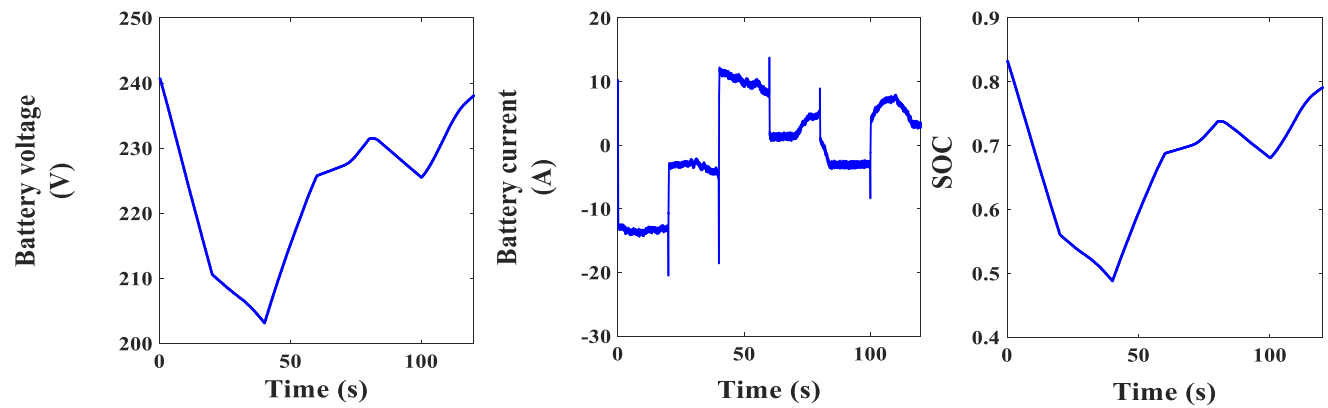

Figure 56. Battery voltage, battery current and SOC using MP DPC.

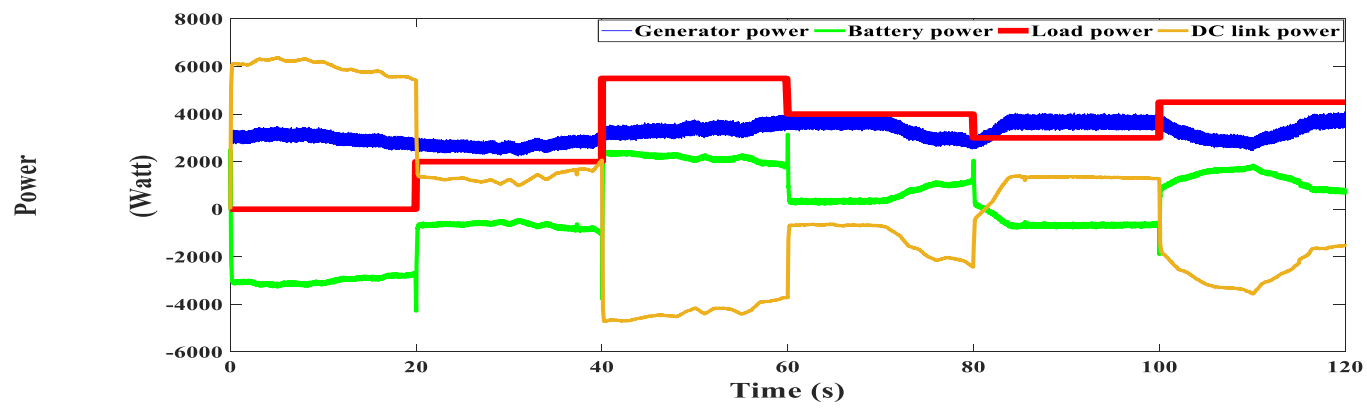

Figure 57. Powers flow in different system units under MP DTC control.

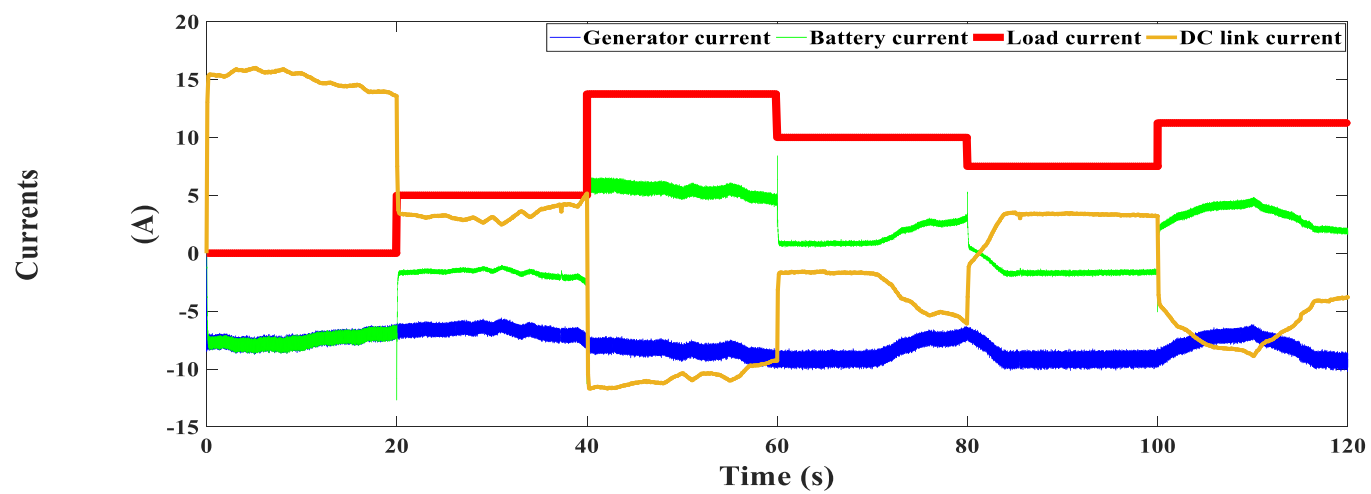

Figure 58. Currents flow in different system units under MP DTC control.
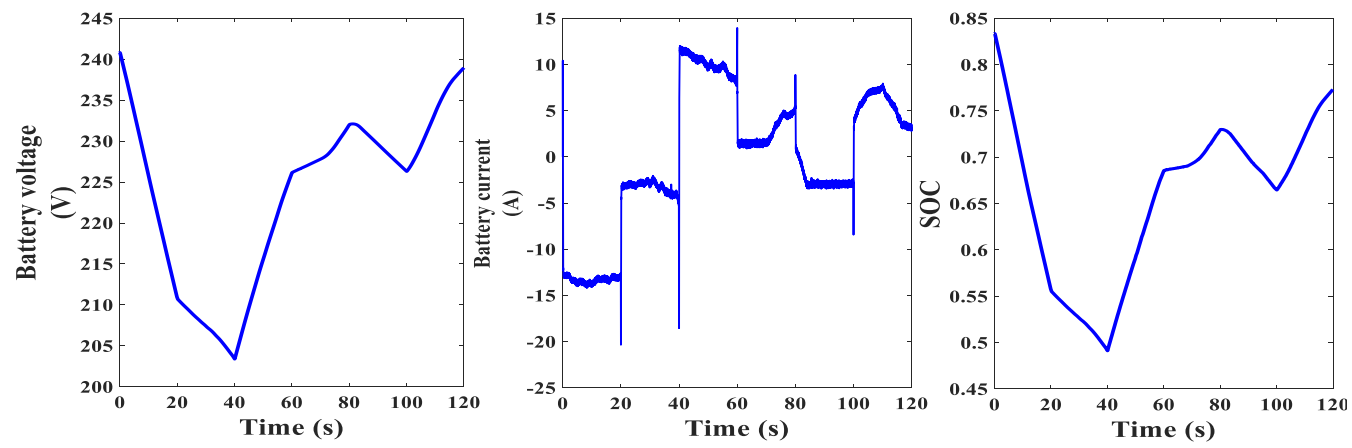

Figure 59. Battery voltage, battery current and SOC under MP DTC control.

\subsubsection{Power Flow Using Model Predictive Current Control}

The power and current flows in the system units were also investigated under MP CC as shown in Figures 60 and 61, respectively. The power and current were appropriately managed, although the generator power and current still exhibit ripples even though they 
are lower than their corresponding values under MP DPC and MP DTC. Figure 62 shows the battery voltage, battery current and SOC under MP CC control.

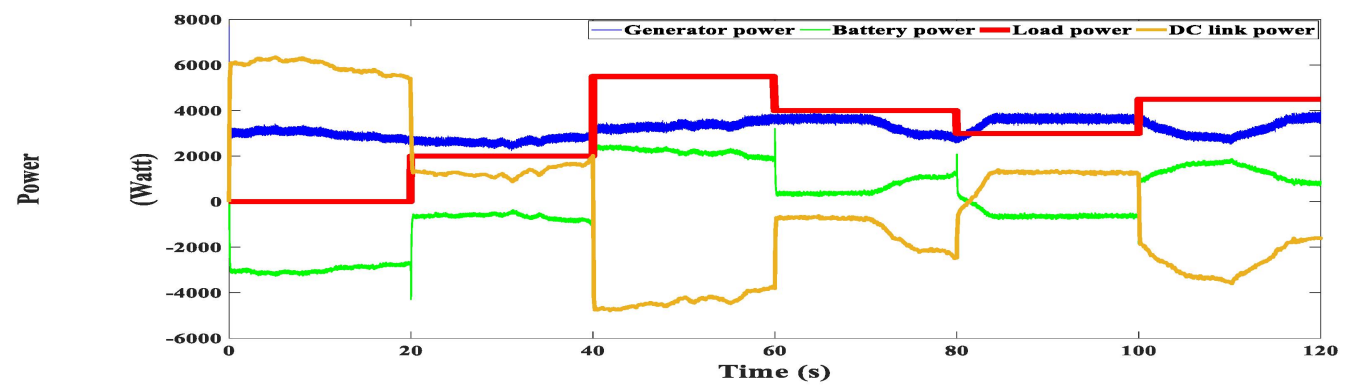

Figure 60. Power flow in different system units under MP CC control.

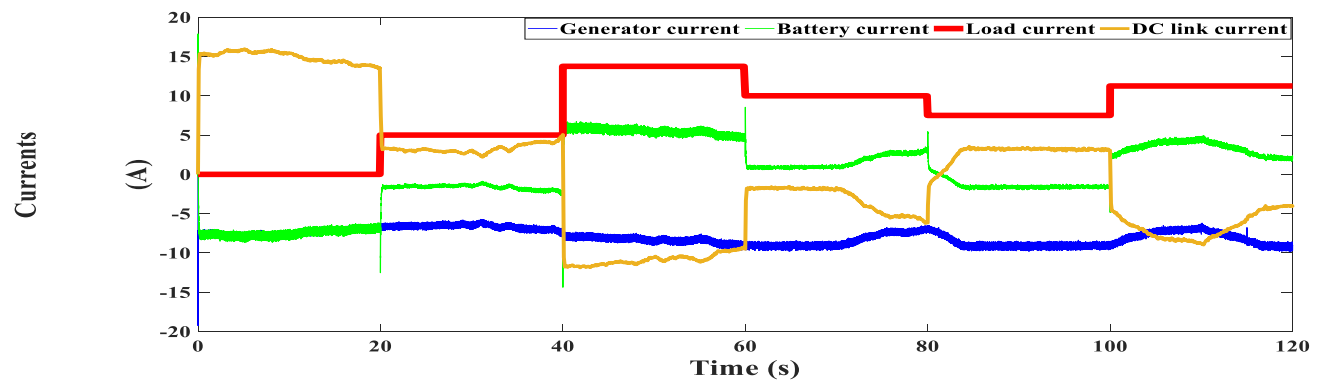

Figure 61. Current flow in different system units under MP CC control.
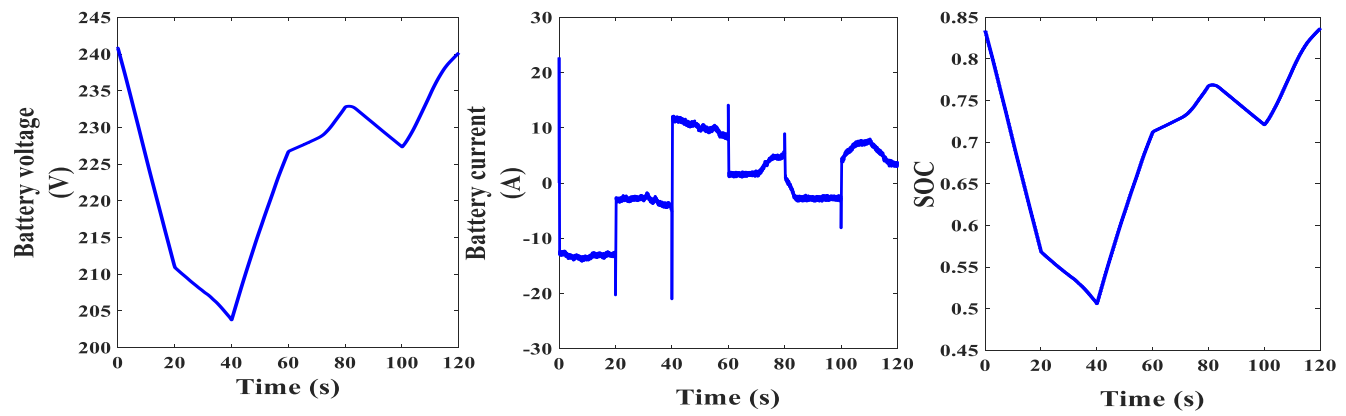

Figure 62. Battery voltage, battery current and SOC under MP CC control.

\subsubsection{Power Flow Using Proposed Predictive Voltage Control}

The power and current flows were also tested with the designed PVC. As shown in Figures 63 and 64, PVC exhibits much lower ripples in the generator power and current compared with the other controllers. At the same time, power management is effectively achieved. Lastly, Figure 65 illustrates the battery voltage, battery current and SOC of the battery under the PVC.

A comparison was also made between the four controllers in terms of the number of commutations; the results are shown in Table 6. PVC has the least number of commutations, which contributes effectively to reducing the computation burden.

Table 6. Number of commutations for the four controllers.

\begin{tabular}{cc}
\hline Technique & Number of Commutations \\
\hline MP DPC & 308300 \\
MP DTC & 299800 \\
MP CC & 321700 \\
PVC & 39710 \\
\hline
\end{tabular}




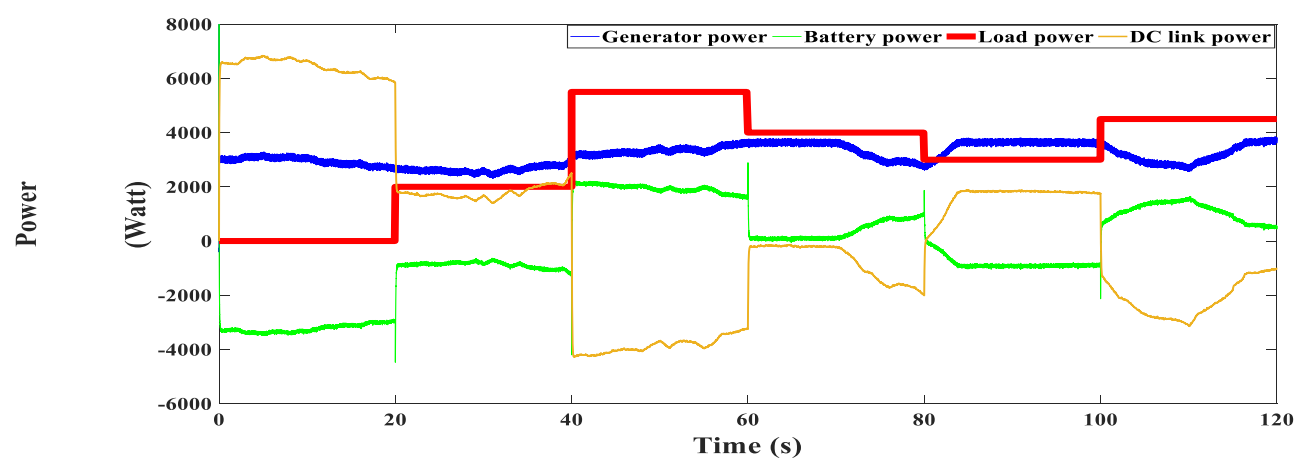

Figure 63. Power flow in different system units under PVC.

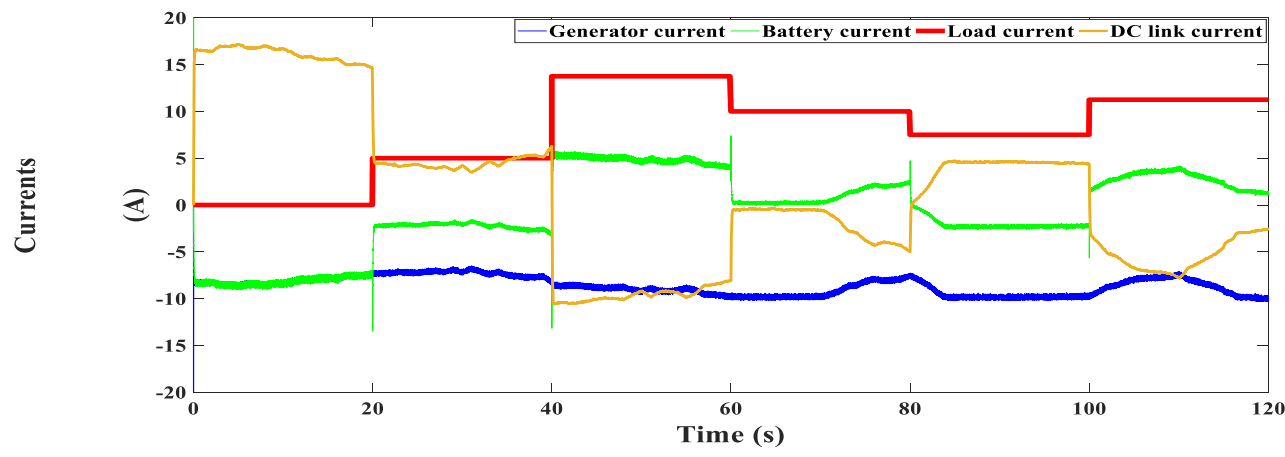

Figure 64. Current flow in different system units under PVC.
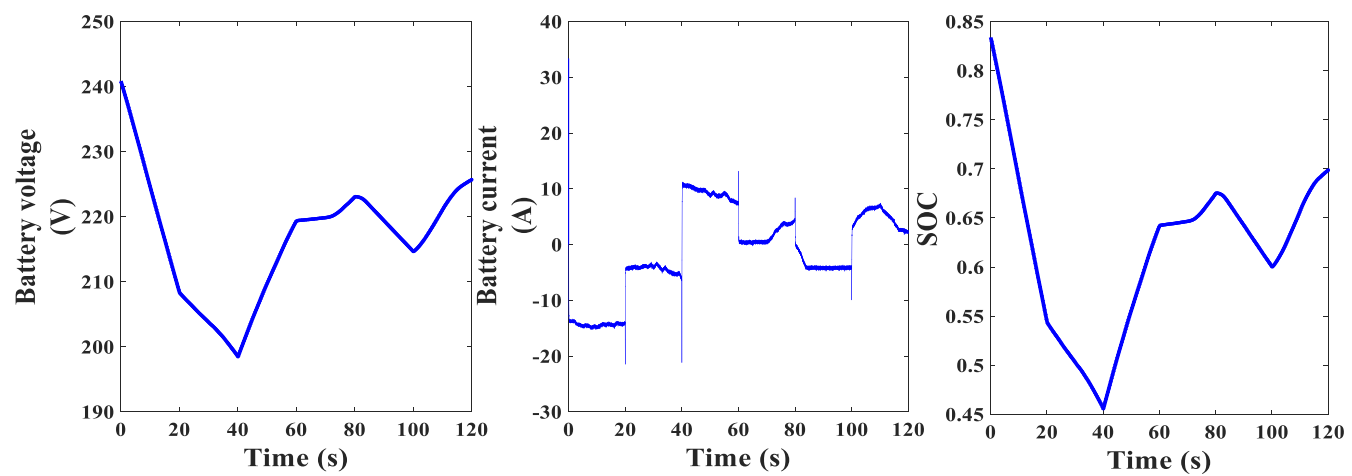

Figure 65. Battery voltage, battery current and SOC under PVC.

\section{Conclusions}

This research presented an effective predictive voltage control scheme to enhance the dynamic performance of a wind-driven permanent magnet synchronous generator operating in two modes of operation: grid connection and stand-alone operation. For the stand-alone operation, a battery management system was incorporated to enhance and manage the power delivery to the isolated loads. A complete wind turbine driving system was constructed and is described in detail. To clarify the validity of the proposed controller, the performance of the generator was evaluated using three classical predictive controllers: model predictive direct power control, model predictive direct torque control and model predictive current control. A detailed performance comparison was conducted between the four controllers in terms of variable ripples and THD currents. The results show that the proposed controller had the most effective dynamic performance in comparison with the other controllers, confirmed by its simple structure, low ripples, low computation burdens and low current harmonics. Furthermore, the effectiveness of the battery storage system was shown by smooth power exchange between the generator, battery and isolated loads. To summarize: 
- The study presented a novel predictive voltage control technique to improve the dynamic performance of a wind driven permanent magnet synchronous generator under two operating conditions.

- A wind turbine driving system was constructed and described in detail.

- A detailed design of a battery storage system is presented to manage power flow exchange between the different units of the wind generation system.

- The research involved comprehensive performance comparison between the proposed control scheme and three classical controllers to show the features of each control system and outline their advantages and shortcomings.

- The results revealed that the proposed predictive voltage controller had the most effective dynamic performance among the four used controllers. This was based on its simple structure, low ripples, low computation burdens, and low current harmonics.

Author Contributions: Conceptualization, M.A.M. and N.B.; methodology, M.A.M., N.B. and O.G.; software, M.A.M. and O.G.; validation, M.A.M., O.G. and N.B.; formal analysis, M.A.M., O.G. and N.B.; investigation, O.G., N.B. and M.A.M.; resources, M.A.M. and O.G.; data curation, M.A.M. and N.B; writing—original draft preparation, M.A.M. and O.G.; writing—review and editing, M.A.M. and N.B.; visualization, M.A.M. and N.B.; supervision, M.A.M. and N.B.; project administration, M.A.M. and N.B.; funding acquisition, M.A.M. All authors have read and agreed to the published version of the manuscript.

Funding: This research was funded by the Egyptian Mission Sector-Ministry of Higher Education of the Arab Republic of Egypt.

Institutional Review Board Statement: Not applicable.

Informed Consent Statement: Not applicable.

Data Availability Statement: The data presented in this study are available upon request from the corresponding author.

Acknowledgments: This work was made possible by a fellowship funded by the Egyptian Mission Sector at Ministry of Higher Education of the Arab Republic of Egypt.

Conflicts of Interest: The authors declare no conflict of interest.

\section{Abbreviations and Nomenclature}

SPMSG Surface permanent magnet synchronous generator

MPC Model predictive control

MP DPC Model predictive direct power control

MP DTC Model predictive direct torque control

MP CC Model predictive current control

PVC Predictive voltage control

MPPT Maximum power point tracking

DFIG Doubly fed induction generator

FOC Field oriented control

DTC Direct torque control

THD Total harmonics distortion

PWM Pulse width modulation

SVPWM Space vector pulse width modulation

FCS Finite control set

MSC Machine side converter

GSC Grid side converter

DC Direct current

LAB Lead acid battery

APS Autonomous power supply

DOD Depth of discharge

$\beta \quad$ Blade pitch angle

$\mu \quad$ Tip speed ratio 


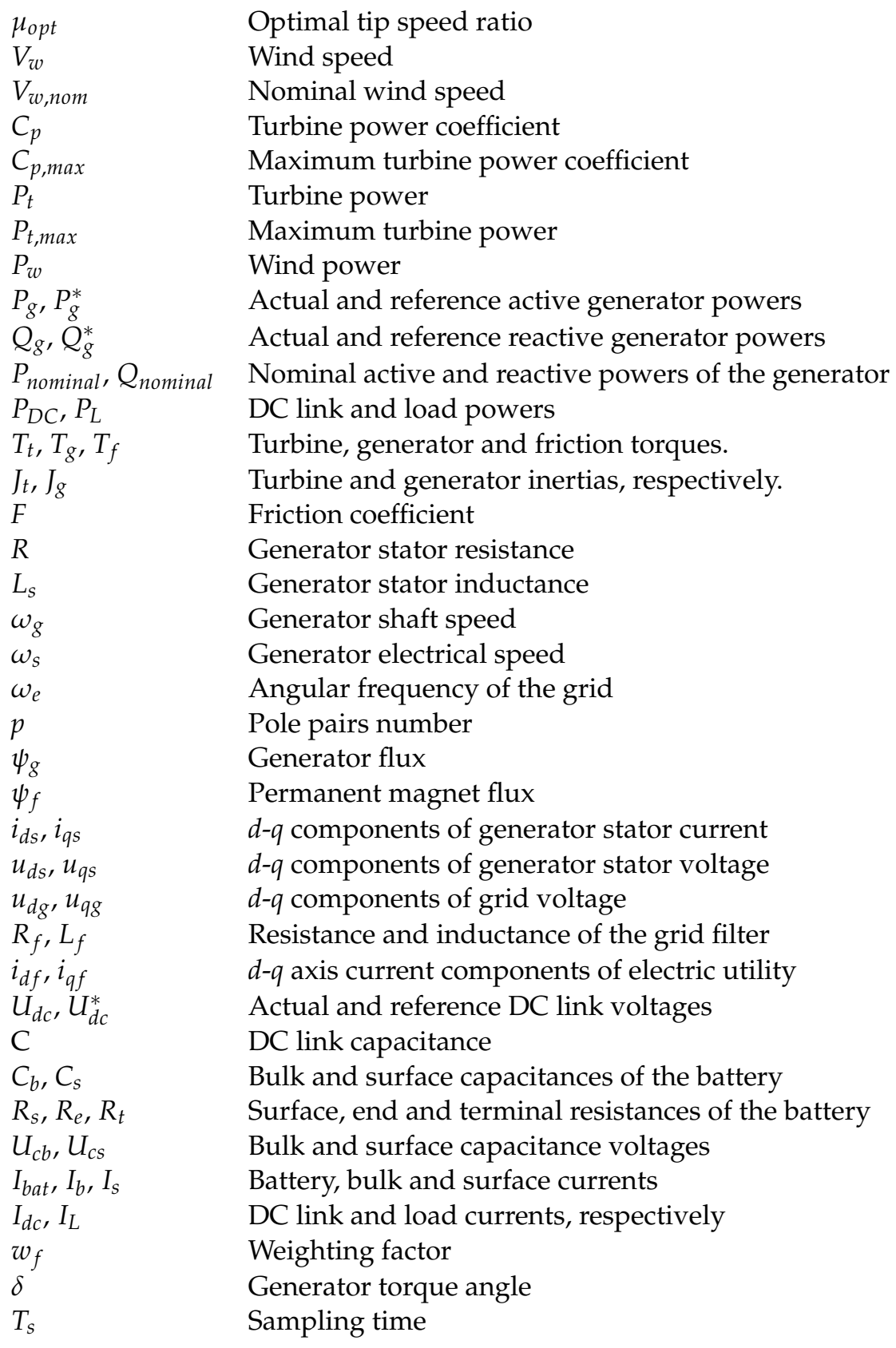

\section{Appendix A}

Table A1. Turbine and SPMSG parameters.

\begin{tabular}{cccc}
\hline Parameter & Value & Parameter & Value \\
\hline$r$ & $2 \mathrm{~m}$ & $p$ & 4 \\
$C_{\text {Pmax }}$ & 0.472 & $R$ & $0.82 \Omega$ \\
$\mu_{\text {opt }}$ & 8.1 & $L_{s}$ & $15.1 \mathrm{mH}$ \\
$P_{\text {nom }}$ & $3.9 \mathrm{KW}$ & $\psi_{f}$ & $0.5 \mathrm{Vs}$ \\
$V_{\text {w, nom }}$ & $10 \mathrm{~m} / \mathrm{s}$ & $R_{f}$ and $L_{f}$ & $0.1 \Omega$ and $3 \mathrm{mH}$ \\
$K$ & 3.83 & $C_{d c}$ & $2200 \mu \mathrm{F}$ \\
\hline
\end{tabular}


Table A2. Battery parameters and specifications.

\begin{tabular}{cccc}
\hline Parameter & Value & Parameter & Value \\
\hline$R_{t}$ & $2.75 \mathrm{~m} \Omega$ & $L_{b a t}$ & $30 \mathrm{mH}$ \\
$R_{e}$ & $3.75 \mathrm{~m} \Omega$ & Capacity & $50 \mathrm{Ah}$ \\
$R_{s}$ & $3.75 \mathrm{~m} \Omega$ & Rated voltage & $240 \mathrm{~V}$ \\
$C_{b}$ & $8.8373 \mathrm{~F}$ & DOD $(\%)$ & $60 \%$ \\
$C_{s}$ & $82.1 \mathrm{mF}$ & $\eta_{b a t} \%$ & $85 \%$ \\
\hline
\end{tabular}

\section{References}

1. Xie, X.; Zhang, Y.; Meng, K.; Dong, Z.Y.; Liu, J. Emergency control strategy for power systems with renewables considering a utility-scale energy storage transient. CSEE J. Power Energy Syst. 2021, 7, 986-995.

2. Gu, Y.; Huang, Y.; Wu, Q.; Li, C.; Zhao, H.; Zhan, Y. Isolation and Protection of the Motor-Generator Pair System for Fault Ride-Through of Renewable Energy Generation Systems. IEEE Access 2020, 8, 13251-13258. [CrossRef]

3. Telukunta, V.; Pradhan, J.; Agrawal, A.; Singh, M.; Srivani, S.G. Protection challenges under bulk penetration of renewable energy resources in power systems: A review. CSEE J. Power Energy Syst. 2017, 3, 365-379. [CrossRef]

4. Albatran, S.; Harasis, S.; Alomoush, I.M.; Alsmadi, Y.; Awawdeh, M. Realistic Optimal Power Flow of a Wind-Connected Power System With Enhanced Wind Speed Model. IEEE Access 2020, 8, 176973-176985. [CrossRef]

5. Kong, X.; Liu, X.; Ma, L.; Lee, K.Y. Hierarchical Distributed Model Predictive Control of Standalone Wind/Solar/Battery Power System. IEEE Trans. Syst. Man Cybern. Syst. 2019, 49, 1570-1581. [CrossRef]

6. Eltamaly, A.M.; Alotaibi, M.A. Novel Fuzzy-Swarm Optimization for Sizing of Hybrid Energy Systems Applying Smart Grid Concepts. IEEE Access 2021, 9, 93629-93650. [CrossRef]

7. Mossa, M.A.; Al-Sumaiti, A.S.; Do, T.D.; Diab, A.A.Z. Cost-Effective Predictive Flux Control for a Sensorless Doubly Fed Induction Generator. IEEE Access 2019, 7, 172606-172627. [CrossRef]

8. Abeynayake, G.; Van Acker, T.; Van Hertem, D.; Liang, J. Analytical Model for Availability Assessment of Large-Scale Offshore Wind Farms Including Their Collector System. IEEE Trans. Sustain. Energy 2021, 12, 1974-1983. [CrossRef]

9. Mossa, M.A.; Echeikh, H.; Iqbal, A. Enhanced control technique for a sensor-less wind driven doubly fed induction generator for energy conversion purpose. Energy Rep. 2021, 7, 5815-5833. [CrossRef]

10. Mossa, M.A.; Mohamed, Y.S. Novel Scheme for Improving the Performance of a Wind Driven Doubly Fed Induction Generator during Grid Fault. Wind. Eng. 2012, 36, 305-334. [CrossRef]

11. Jahangiri, M.; Shamsabadi, A.A. Designing a horizontal-axis wind turbine for South Khorasan province: A case study. Int. J. Precis. Eng. Manuf. 2017, 18, 1463-1473. [CrossRef]

12. Sedaghat, A.; Alkhatib, F.; Eilaghi, A.; Mehdizadeh, A.; Borvayeh, L.; Mostafaeipour, A.; Hassanzadeh, A.; Jahangiri, M. Optimization of capacity factors based on rated wind speeds of wind turbines. Energy Sources Part A Recovery Util. Environ. Eff. 2020, 43, 1-22. [CrossRef]

13. Islam, R.; Guo, Y.; Zhu, J. A review of offshore wind turbine nacelle: Technical challenges, and research and developmental trends. Renew. Sustain. Energy Rev. 2014, 33, 161-176. [CrossRef]

14. Vanco, W.E.; Silva, F.; Goncalves, F.A.S.; Bissochi, C.A. Evaluation of the Capacitor Bank Design for Self-Excitation in Induction Generators. IEEE Lat. Am. Trans. 2018, 16, 482-488. [CrossRef]

15. Teng, K.; Lu, Z.; Long, J.; Wang, Y.; Roskilly, A.P. Voltage Build-Up Analysis of Self-Excited Induction Generator With MultiTimescale Reduced-Order Model. IEEE Access 2019, 7, 48003-48012. [CrossRef]

16. Meng, F.; Sun, D.; Zhou, K.; Wu, J.; Zhao, F.; Sun, L. A Sub-Synchronous Oscillation Suppression Strategy for Doubly Fed Wind Power Generation System. IEEE Access 2021, 9, 83482-83498. [CrossRef]

17. Mossa, M.A.; Echeikh, H.; Diab, A.A.Z.; Quynh, N.V. Effective Direct Power Control for a Sensor-Less Doubly Fed Induction Generator with a Losses Minimization Criterion. Electronics 2020, 9, 1269. [CrossRef]

18. Mohamad, A.M.; Arani, M.F.M.; Mohamed, Y.A.R.I. In-vestigation of Impacts of Wind Source Dynamics and Stability Options in DC Power Systems With Wind Energy Conversion Systems. IEEE Access 2020, 8, 18270-18283. [CrossRef]

19. Prince, M.K.K.; Arif, M.T.; Gargoom, A.; Oo, A.M.T.; Haque, E. Modeling, Parameter Measurement, and Control of PMSG-based Grid-connected Wind Energy Conversion System. J. Mod. Power Syst. Clean Energy 2021, 9, 1054-1065. [CrossRef]

20. Islam, M.M.; Chowdhury, D. Advanced and comprehensive control methods in wind energy systems. In Emerging Power Converters For Renewable Energy And Electric Vehicles; Taylor \& Francis: Abingdon, UK, 2021; pp. 191-224.

21. He, L.; Li, Y.; Harley, R.G. Adaptive Multi-Mode Power Control of a Di-rect-Drive PM Wind Generation System in a Microgrid. IEEE J. Emerg. Sel. Top. Power Electron. 2013, 1, 217-225. [CrossRef]

22. Basak, R.; Bhuvaneswari, G.; Pillai, R.R. Low-Voltage Ride-Through of a Synchronous Generator-Based Variable Speed GridInterfaced Wind Energy Conversion System. IEEE Trans. Ind. Appl. 2019, 56, 752-762. [CrossRef]

23. Corradini, M.L.; Ippoliti, G.; Orlando, G. Robust Control of Variable-Speed Wind Turbines Based on an Aerodynamic Torque Observer. IEEE Trans. Control. Syst. Technol. 2013, 21, 1199-1206. [CrossRef]

24. Zhang, Z.; Zhao, Y.; Qiao, W.; Qu, L. A Discrete-Time Direct Torque Control for Direct-Drive PMSG-Based Wind Energy Conversion Systems. IEEE Trans. Ind. Appl. 2015, 51, 3504-3514. [CrossRef] 
25. Zhang, Z.; Zhao, Y.; Qiao, W.; Qu, L. A Space-Vector-Modulated Sensorless Direct-Torque Control for Direct-Drive PMSG Wind Turbines. IEEE Trans. Ind. Appl. 2014, 50, 2331-2341. [CrossRef]

26. Dos Santos Neto, P.J.; Pinto, A.C.; Ruppert Filho, E. A Proposal to Control Active and Reactive Power in Distributed Generation Systems Using Small Wind Turbines. IEEE Lat. Am. Trans. 2020, 18, 1699-1706. [CrossRef]

27. Torres, J.; Pena, R.; Tapia, J.; Riedemann, J.; Pesce, C. Direct power control of an axial flux permanent magnet synchronous machine. In Proceedings of the 2017 IEEE Southern Power Electronics Conference (SPEC), Puerto Varas, Chile, 4-7 December 2017; pp. 1-6.

28. Harrouz, A.; Benatiallah, A. Direct power control of a PMSG dedicated to standalone wind energy systems. In Proceedings of the 2013 Eighth International Conference and Exhibition on Ecological Vehicles and Renewable Energies (EVER), Monte Carlo, Monaco, 27-30 March 2013; IEEE: New York, NY, USA, 2013; pp. 1-5.

29. Mozayan, S.M.; Saad, M.; Vahedi, H.; Fortin-Blanchette, H.; Soltani, M. Sliding Mode Control of PMSG Wind Turbine Based on Enhanced Exponential Reaching Law. IEEE Trans. Ind. Electron. 2016, 63, 6148-6159. [CrossRef]

30. Yu, Y.; Mi, Z.; Guo, X.; Niu, X.; Zheng, X.; Sun, C. Control design and im-plementation of a spiral spring energy storage system connected to a grid via PMSG. CSEE J. Power Energy Syst. 2018, 4, 339-351. [CrossRef]

31. Muyeen, S.M.; Al-Durra, A. Modeling and Control Strategies of Fuzzy Logic Controlled Inverter System for Grid Interconnected Variable Speed Wind Generator. IEEE Syst. J. 2013, 7, 817-824. [CrossRef]

32. Bigarelli, L.; Di Benedetto, M.; Lidozzi, A.; Solero, L.; Odhano, S.A.; Zanchetta, P. PWM-Based Optimal Model Predictive Control for Variable Speed Generating Units. IEEE Trans. Ind. Appl. 2019, 56, 541-550. [CrossRef]

33. Wang, H.; Yang, J.; Chen, Z.; Ge, W.; Ma, Y.; Xing, Z.; Yang, L. Model Predictive Control of PMSG-Based Wind Turbines for Frequency Regulation in an Isolated Grid. IEEE Trans. Ind. Appl. 2018, 54, 3077-3089. [CrossRef]

34. Linder, A.; Kanchan, R.; Stolze, P.; Kennel, R. Model-Based Predictive Control of Electric Drives; Cuvillier Verlag: Gottingen, Germany, 2010.

35. Yaramasu, V.; Wu, B. Model Predictive Control of Wind Energy Conversion Systems; John Wiley \& Sons, Ltd.: New Jersey, NJ, USA, 2017.

36. Zhang, Z.; Li, Z.; Kazmierkowski, M.P.; Rodriguez, J.; Kennel, R. Robust Predictive Control of Three-Level NPC Back-to-Back Power Converter PMSG Wind Turbine Systems With Revised Predictions. IEEE Trans. Power Electron. 2018, 33, 9588-9598. [CrossRef]

37. Zhang, Z.; Fang, H.; Gao, F.; Rodriguez, J.; Kennel, R. Multiple-Vector Model Predictive Power Control for Grid-Tied Wind Turbine System With Enhanced Steady-State Control Performance. IEEE Trans. Ind. Electron. 2017, 64, 6287-6298. [CrossRef]

38. Jlassi, I.; Cardoso, A.J.M. Enhanced and Computationally Efficient Model Predictive Flux and Power Control of PMSG Drives for Wind Turbine Applications. IEEE Trans. Ind. Electron. 2021, 68, 6574-6583. [CrossRef]

39. Mahmoudi, H.; Aleenejad, M.; Moamaei, P.; Ahmadi, R. Fuzzy adjustment of weighting factor in model predictive control of permanent magnet synchronous machines using current membership functions. In Proceedings of the 2016 IEEE Power and Energy Conference, Urbana, IL, USA, 19-20 February 2016; pp. 1-5.

40. Guazzelli, P.R.U.; Pereira, W.C.D.A.; de Oliveira, C.M.R.; De Castro, A.G.; Aguiar, M. Weighting Factors Optimization of Predictive Torque Control of Induction Motor by Multiobjective Genetic Algorithm. IEEE Trans. Power Electron. 2019, 34, 6628-6638. [CrossRef]

41. Abdelrahem, M.; Hackl, C.M.; Zhang, Z.; Kennel, R. Robust Predictive Control for Direct-Driven Surface-Mounted PermanentMagnet Synchronous Generators Without Mechanical Sensors. IEEE Trans. Energy Convers. 2018, 33, 179-189. [CrossRef]

42. Rodriguez, J.; Cortes, P. Predictive Control of Power Converters and Electrical Drives, 1st ed.; Wiley: New York, NY, USA, 2012.

43. Landsmann, P.; Kennel, R.K. Saliency-based sensorless predictive torque control with reduced torque ripple. IEEE Trans. Power Electron. 2012, 27, 4311-4320. [CrossRef]

44. Zhang, Y.; Xie, W.; Li, Z.; Zhang, Y. Model predictive direct power control of a PWM rectifier with duty cycle optimization. IEEE Trans. Power Electron. 2013, 28, 5343-5351. [CrossRef]

45. Fang, H.; Zhang, Z.; Feng, X.; Kennel, R. Ripple-reduced MPDPC for active front end power converters with extended switching vectors and time-optimized control. IET Power Electron. 2016, 9, 1914-1923. [CrossRef]

46. Zhang, Z.; Fang, H.; Kennel, R. Novel ripple reduced Direct Model Predictive Control of three-level NPC active front end with reduced computational effort. In Proceedings of the 2015 IEEE International Symposium on Predictive Control of Electrical Drives and Power Electronics (PRECEDE), Valparaiso, Chile, 5-6 October 2015; pp. 32-37.

47. Mossa, M.A.; Do, T.D.; Al-Sumaiti, A.; Quynh, N.V.; Diab, A.A.Z. Effective Model Predictive Voltage Control for a Sensorless Doubly Fed Induction Generator. IEEE Can. J. Electr. Comput. Eng. 2021, 44, 50-64. [CrossRef]

48. Zhou, D.; Tu, P.; Tang, Y. Multi-vector model predictive power control of three-phase rectifiers with reduced power ripples under nonideal grid condi-tions. IEEE Trans. Ind. Electron. 2018, 65, 6850-6859. [CrossRef]

49. Zarei, M.E.; Ramirez, D.; Veganzones, C.; Rodriguez, J. Predictive Direct Control of SPMS Generators Applied to the Machine Side Converter of an OWC Power Plant. IEEE Trans. Power Electron. 2020, 35, 6719-6731. [CrossRef]

50. Zarei, M.E.; Nicolas, C.V.; Arribas, J.R. Improved Predictive Direct Power Control of Doubly Fed Induction Generator During Unbalanced Grid Voltage Based on Four Vectors. IEEE J. Emerg. Sel. Top. Power Electron. 2016, 5, 695-707. [CrossRef]

51. Xie, W.; Wang, X.; Wang, F.; Xu, W.; Kennel, R.M.; Gerling, D.; Lorenz, R.D. Finite-Control-Set Model Predictive Torque Control With a Deadbeat Solution for PMSM Drives. IEEE Trans. Ind. Electron. 2015, 62, 5402-5410. [CrossRef] 
52. Zhang, J.Z.; Sun, T.; Wang, F.; Rodriguez, J.; Kennel, R. A computationally efficient quasi-centralized DMPC for Back-to-Back converter PMSG wind tur-bine systems without DC-Link tracking errors. IEEE Trans. Ind. Electron. 2016, 63, 6160-6171. [CrossRef]

53. Lin, C.-K.; Liu, T.-H.; Yu, J.-T.; Fu, L.-C.; Hsiao, C.-F. Model-Free Predictive Current Control for Interior Permanent-Magnet Synchronous Motor Drives Based on Current Difference Detection Technique. IEEE Trans. Ind. Electron. 2014, 61, 667-681. [CrossRef]

54. Geng, H.; Liu, L.; Li, R. Synchronization and Reactive Current Support of PMSG-Based Wind Farm During Severe Grid Fault. IEEE Trans. Sustain. Energy 2018, 9, 1596-1604. [CrossRef]

55. Shinoda, K.; Guillaud, X.; Bacha, S.; Benchaib, A.; Francois, B. Modelling of a VSCbased multi-terminal HVDC network for dynamic stability analysis. COMPEL Int. J. Comput. Math. Electr. Electron. Eng. 2017, 36, 240-257. [CrossRef]

56. Abdelkafi, A.; Masmoudi, A.; Krichen, L. Assisted power management of a stand-alone renewable multi-source system. Energy 2018, 145, 195-205. [CrossRef]

57. Shuai, Z.; Fang, J.; Ning, F.; Shen, Z.J. Hierarchical structure and bus voltage control of DC microgrid. Renew. Sustain. Energy Rev. 2018, 82, 3670-3682. [CrossRef]

58. Vasebi, A.; Bathaee, S.; Partovibakhsh, M. Predicting state of charge of lead-acid batteries for hybrid electric vehicles by extended Kalman filter. Energy Convers. Manag. 2008, 49, 75-82. [CrossRef]

59. Jallouli, R.; Krichen, L. Sizing, techno-economic and generation management analysis of a stand alone photovoltaic power unit including storage devices. Energy 2012, 40, 196-209. [CrossRef] 